\title{
24. SOUND VELOCITY-DENSITY PARAMETERS OF SEDIMENT AND ROCK FROM DSDP DRILL SITES 315-318 ON THE LINE ISLANDS CHAIN, MANIHIKI PLATEAU, AND TUAMOTU RIDGE IN THE PACIFIC OCEAN
}

\author{
Robert E. Boyce, Scripps Institution of Oceanography, La Jolla, California
}

\begin{abstract}
Compressional sound velocity, wet-bulk density, water content, porosity, and acoustic impedance and anisotropy were determined for Quaternary through Cretaceous sediment and rock recovered from 0 to 1000 meters below the sea floor at Deep Sea Drilling Project Sites 315-318 on the Line Islands chain, Manihiki Plateau, and Tuamotu Ridge in the western Pacific Ocean. Regional correlations of these properties versus depth below sea floor are good for the Line Islands chain, the Manihiki Plateau, and the Tuamotu Ridge. Measurements were made under laboratory conditions, and comparison of laboratory interval velocities to those from the seismic reflection and drill depth records shows some discrepancies, suggesting that temperature-pressure corrections of up to $+15 \%$ might be needed. In order to properly determine the in situ corrections needed will require future research of the porosity and velocity rebound characteristics, when in situ pressures are released, for a variety of sedimentary types with a wide variation in porosity and cementation. Velocities through Pleistocene through Oligocene chalk are typically 0 to $3 \%$ greater horizontally than vertically, while Eocene and older sedimentary rocks typically have $5 \%$ to $15 \%$ anisotropy. Velocity versus its corresponding impedance is an approximately linear relationship for a given mineral makeup, with an impedance error of $\pm 0.5 \times 10^{5} \mathrm{~g} /\left(\mathrm{cm}^{2} \mathrm{sec}\right)$. Velocity versus porosity relationships are best enclosed by the Wyllie et al. (1956) equation and the Wood (1941) equation, while the Nafe and Drake (1957) equation requires values of $n$ from 4 through 9 in order to fit all the data.
\end{abstract}

\section{INTRODUCTION}

Compressional sound velocity, wet-bulk density, wetwater content, porosity, and acoustic impedance were determined on sediments and rocks of Quaternary through Cretaceous age, which were recovered from 0 to 1000 meters below the sea floor from Deep Sea Drilling Project Sites 315-318. These sites are on the Line Islands chain (315 and 316), Manihiki Plateau (317), and the Tuamotu Ridge (318) in the Pacific Ocean (Figure 1, Table 1).

These parameters are briefly defined here as follows. Sound velocity is the velocity of the compressional wave at $400 \mathrm{kHz}$ through the sample, in units of $\mathrm{km} / \mathrm{sec}$. Wetbulk density is the ratio of "weight of the wet-saturated sample" to its "volume," expressed as g/cc. Wet-water content is the ratio of the "weight of sea water in the sample" to the "weight of the wet saturated sample," and is expressed as a percentage. Porosity is the ratio of the "pore volume in a sample" to the "volume of the wet saturated sample," and is also expressed as a percentage. Acoustic impedance is defined as the product of the velocity and wet-bulk density, and is expressed as ( $\mathrm{g}$. $\left.10^{5}\right) /\left(\mathrm{cm}^{2} \mathrm{sec}\right)$. All of the equations, derivations, and techniques are discussed in detail in Boyce (this volume).

Sound velocity parameters are important in interpreting seismic geophysical investigations. The wet-bulk density, wet-water content, and porosity determinations are important inasmuch as they are the framework for calculating other physical properties such as heat conductivity (Ratcliff, 1960; Bullard et al., 1956; Parasonis, 1960), sound velocity (Wood, 1941; Bullen, 1947; Wyllie, et al., 1956; Birch, 1960, 1961; Nafe and Drake, 1963; Christensen, 1965; Hamilton, 1971a), electrical resistivity (Archie, 1942, Winsauer et al., 1952; Boyce, 1968), sediment consolidation (Hamilton, 1959, 1964; Richards and Hamilton, 1967), and sedimentation rates, volumes, and masses. In addition, density is used in gravity survey models (Worzel and Harrison, 1963).

The purpose of this paper will be to summarize the physical properties measured on Leg 33 in terms of (1) regional correlations, (2) interrelationships, (3) and seismic profile interpretations. These data are listed in the site reports of this volume. The detailed methods used to determine these parameters are discussed in detail by Boyce (this volume). The sediment classification used is discussed in the Explanatory Notes (this volume). However, the methods are briefly discussed below.

In general, a compressional sound velocity sample, 2.5 to $5 \mathrm{~cm}$ thick, was cut and removed from a split core liner after waiting at least $4 \mathrm{hr}$ after the core was on deck to allow it to reach room temperature. The sample was carefully smoothed with a sharp knife or file. Velocities 


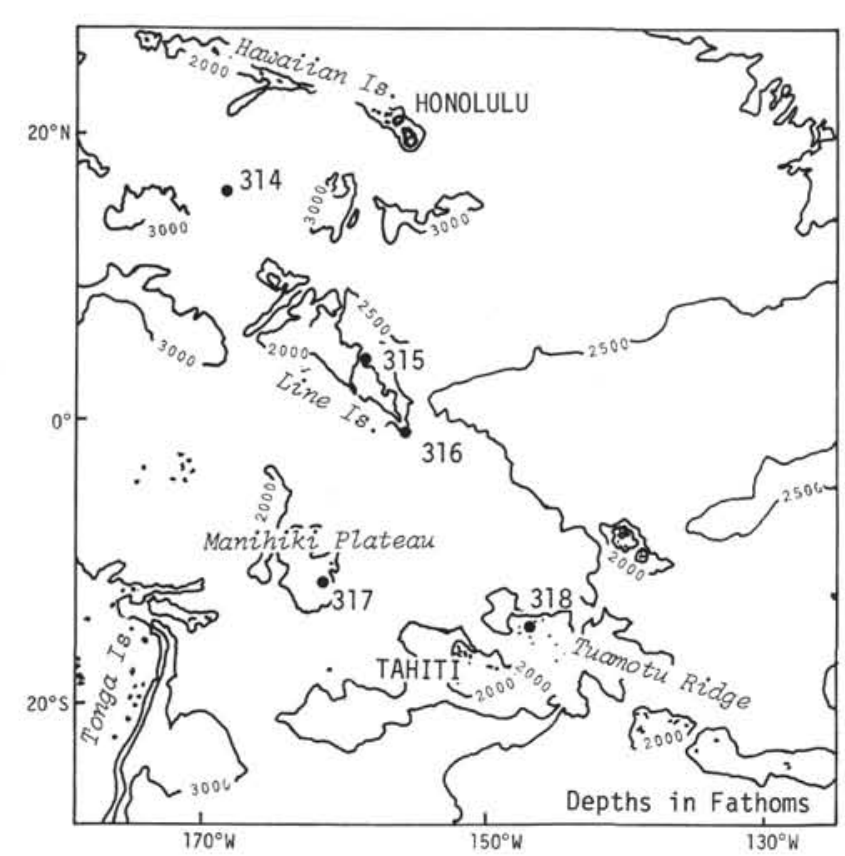

Figure 1. Leg 33 drill sites.

$( \pm 2 \%)$ were measured with the Hamilton frame velocimeter (Boyce, 1973a, b) perpendicular and parallel to bedding. Then, immediately afterward, wet-bulk density was measured within $\pm 2 \%$ or $3 \%$ using special twominute gamma ray counts with the Gamma Ray Attenuation Porosity Evaluator (GRAPE) (Evans, $1965)$ as modified by Boyce (this volume). These counts were measured through air, through the sample, and through different diameter aluminum (Alcoa 1100-F) and quartz for standards (Boyce, this volume). Then, a wet-water content sample was taken and was determined gravimetrically by weighing the wet sample and weighing the dry sample after drying $24 \mathrm{hr}$ at $110^{\circ} \mathrm{C}$. The weight of evaporated water was corrected for salt to give the weight of sea water (Boyce, this volume; Hamilton, 1971b). Precision here is $\pm 5 \%$. The porosity $( \pm 7 \%)$ is determined from the product of the wet-water content and wet-bulk density. The acoustic impedance is the product of the vertical velocity times the wet-bulk density.

\section{RESULTS}

The seismic profiles, the physical properties, and the stratigraphy are shown in Figures 2 through 5 for Sites 315 through 318, and are taken from Chapters 3-6 of this volume. These results will be discussed in three categories: (1) regional correlation; (2) interrelationships of the physical properties; and (3) seismic profile relationships.

\section{REGIONAL CORRELATION}

Regional correlations of the physical properties between the Line Islands chain (Sites 315 and 316), Manihiki Plateau (Site 317), and the Tuamotu Ridge (Site 318) can be seen in Figures 6 through 16 for the "drill rate and sedimentation rate," wet-water content, wet-bulk density, sound velocity and anisotropy, and acoustic impedance. These correlations are based on characteristic lithology which closely, but not precisely, agrees with the chronological boundaries: (1) the low density and velocity Pleistocene-Oligocene chalk, with chert in the Oligocene sections (there are probably soft oozes in the upper sections to the sea floor, but they are so drill-disturbed that it is not probable that any physical properties measured are quantitatively characteristic of in situ conditions, therefore the following discussions will not include quantitative reference to the possible oozes in the upper sections), (2) the EocenePaleocene chalk-limestone transition and chert, (3) the high density and velocity Maestrichtian limestone, (4) Campanian(?) transition to volcaniclastics, (5) the low density and velocity Campanian(?)-Santonian volcaniclastics, and (6) the high density and velocity basalts.

The characteristic physical property variations are caused by the lithologic changes with depth of low velocity chalk, high velocity limestone, low velocity volcaniclastics, and high velocity basalt, which are easily identified when looking at the physical property correlations. Therefore, Figures 6 through 16, which show the regional correlation of physical properties only, have the chronological boundaries drawn in, which are close to, but do not necessarily coincide with, the characteristic lithologic boundaries.

In general, the regional physical properties correlations are good for all the above-mentioned parameters from the Line Islands chain to the Manihiki

TABLE 1

Drill Site Locations and Coring Statistics

\begin{tabular}{|c|c|c|c|c|c|c|c|c|c|}
\hline Hole & $\begin{array}{l}\text { Dates } \\
\text { (GMT } \\
1973 \text { ) }\end{array}$ & Latitude & Longitude & $\begin{array}{c}\text { Water } \\
\text { Depth } \\
\text { (m) }\end{array}$ & $\begin{array}{l}\text { Penetration } \\
\text { (m) }\end{array}$ & $\begin{array}{l}\text { No. of } \\
\text { Cores }\end{array}$ & $\begin{array}{l}\text { Cored } \\
(\mathrm{m})\end{array}$ & $\begin{array}{l}\text { Recovered } \\
\text { (m) }\end{array}$ & $\begin{array}{c}\text { Recovery } \\
\text { (\%) }\end{array}$ \\
\hline 314 & Nov 6-8 & $15^{\circ} 54.76^{\prime} \mathrm{N}$ & $168^{\circ} 28.07^{\prime} \mathrm{W}$ & 5255 & 45.0 & 3 & 17.5 & 0.1 & 0.6 \\
\hline 315 & Nov 13 & $04^{\circ} 10.26^{\prime} \mathrm{N}$ & $158^{\circ} 31.54^{\prime} \mathrm{W}$ & 4164 & 85.0 & 4 & 37.5 & 17.2 & 45.9 \\
\hline $315 \mathrm{~A}$ & Nov $14-19$ & $04^{\circ} 10.26^{\prime} \mathrm{N}$ & $158^{\circ} 31.54^{\prime} \mathrm{W}$ & 4164 & 1034.5 & 34 & 323.0 & 130.5 & 40.4 \\
\hline 316 & Nov $22-27$ & $00^{\circ} 05.44^{\prime} \mathrm{N}$ & $157^{\circ} 07.71^{\prime} \mathrm{W}$ & 4464 & 837.0 & 30 & 285.0 & 102.8 & 36.1 \\
\hline 317 & Nov 30 & $11^{\circ} 00.09^{\prime} \mathrm{S}$ & $162^{\circ} 15.78^{\prime} \mathrm{W}$ & 2625 & 351.5 & 3 & 28.5 & 19.2 & 67.4 \\
\hline $317 \mathrm{~A}$ & Dec $1-4$ & $11^{\circ} 00.09^{\prime} \mathrm{S}$ & $162^{\circ} 15.78^{\prime} \mathrm{W}$ & 2622 & 934.5 & 34 & 313.5 & 163.3 & 52.1 \\
\hline 317B & Dec 5-7 & $11^{\circ} 00.09^{\prime} \mathrm{S}$ & $162^{\circ} 15.78^{\prime} \mathrm{W}$ & 2622 & 424.5 & 45 & 424.5 & 308.0 & 72.6 \\
\hline 381 & Dec 13-16 & $14^{\circ} 49.63^{\prime} \mathrm{S}$ & $146^{\circ} 51.51^{\prime} \mathrm{W}$ & 2659 & 745.0 & 32 & 398.5 & 147.1 & 49.3 \\
\hline Total & & & & & $4,466.0$ & 185 & $1,728.0$ & 888.1 & 51.4 \\
\hline
\end{tabular}



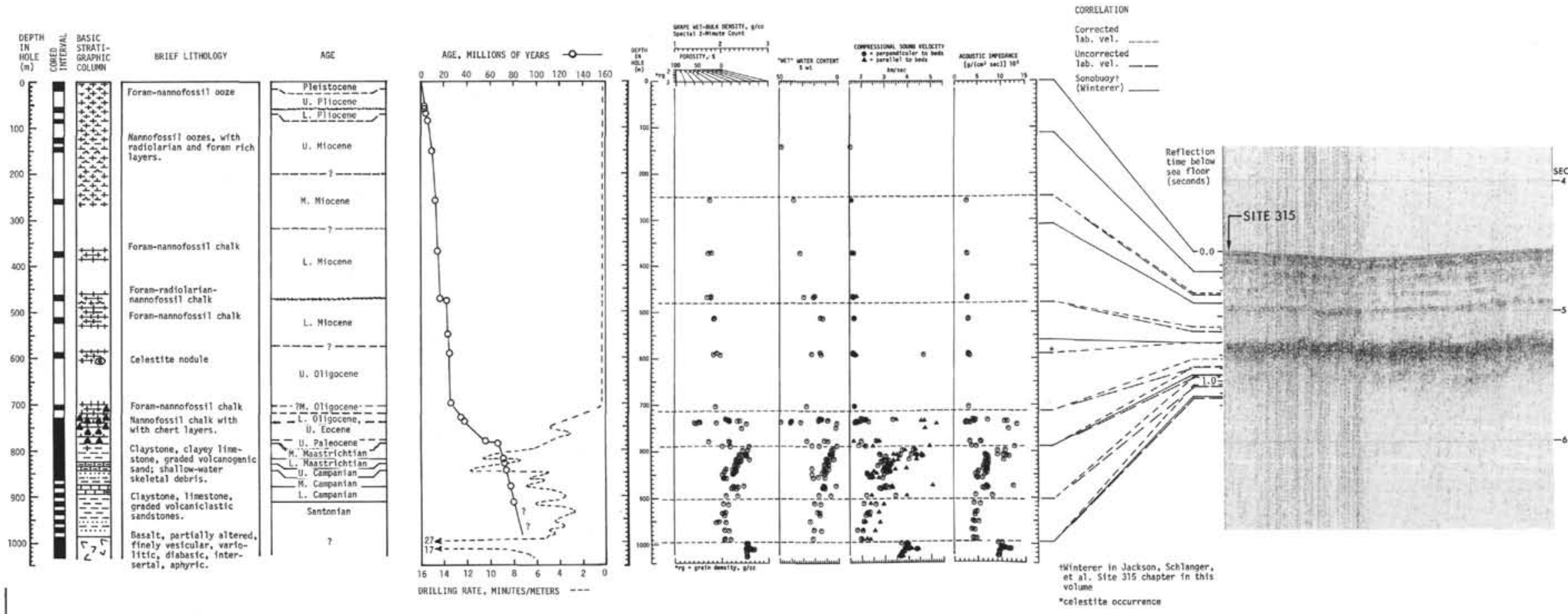

Figure 2. Site 315 stratigraphic and physical property data versus depth and the seismic profile approaching the site. 

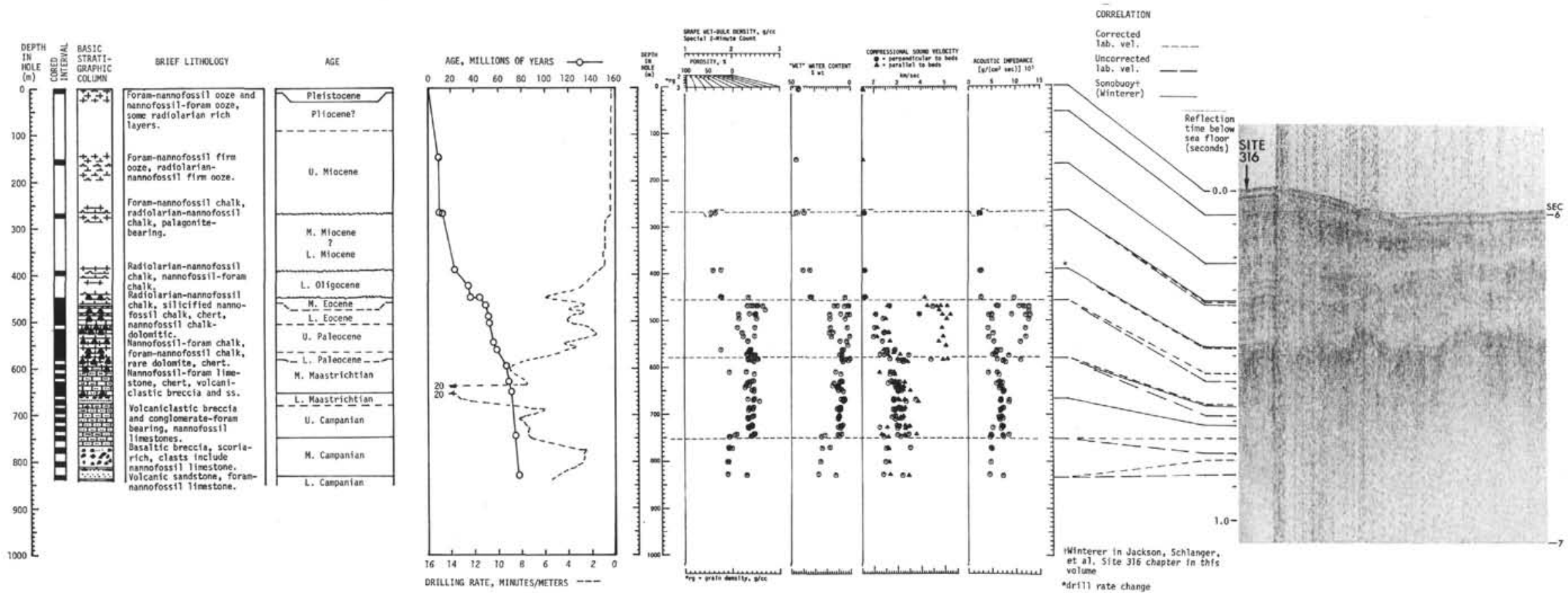

Figure 3. Site 315 stratigraphic and physical property data versus depth and the seismic profile approaching the site. 


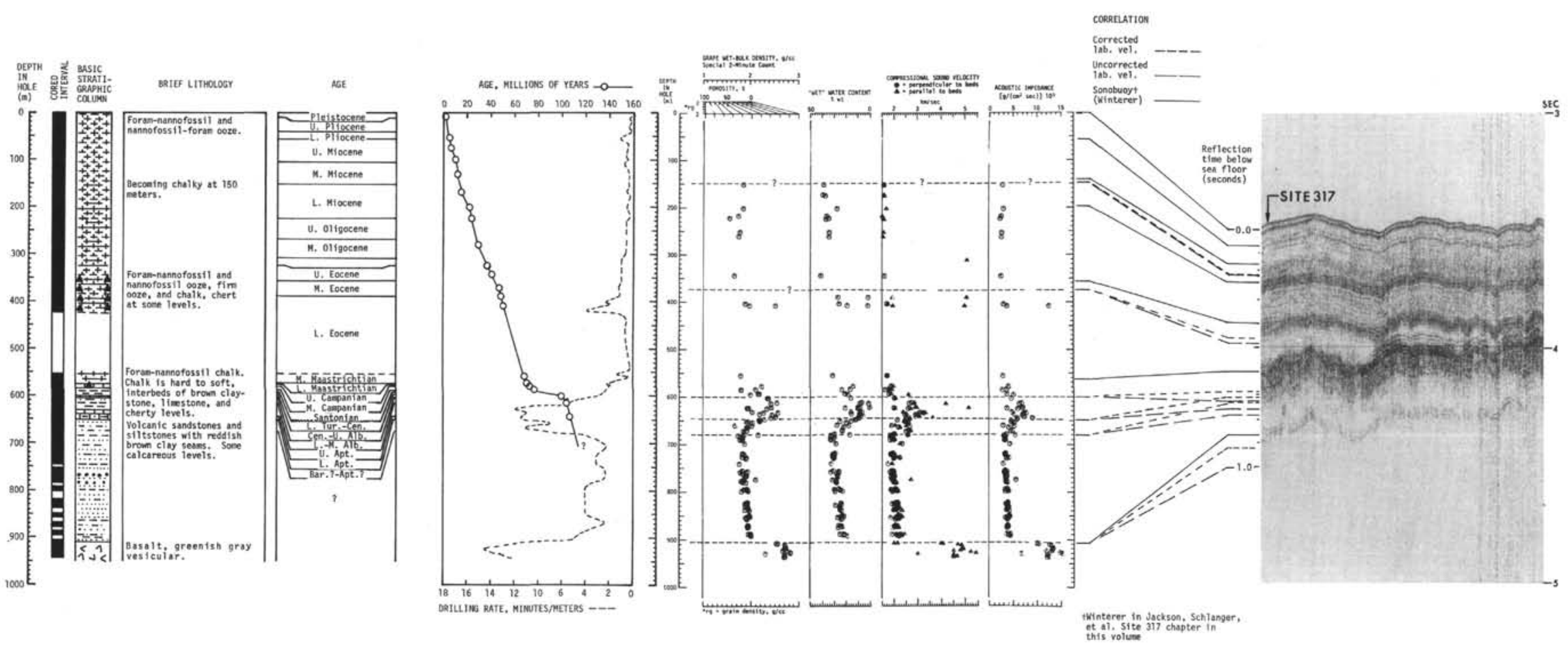

Figure 4. Site 317 stratigraphic and physical property data versus depth and the seismic profile approaching the site. 

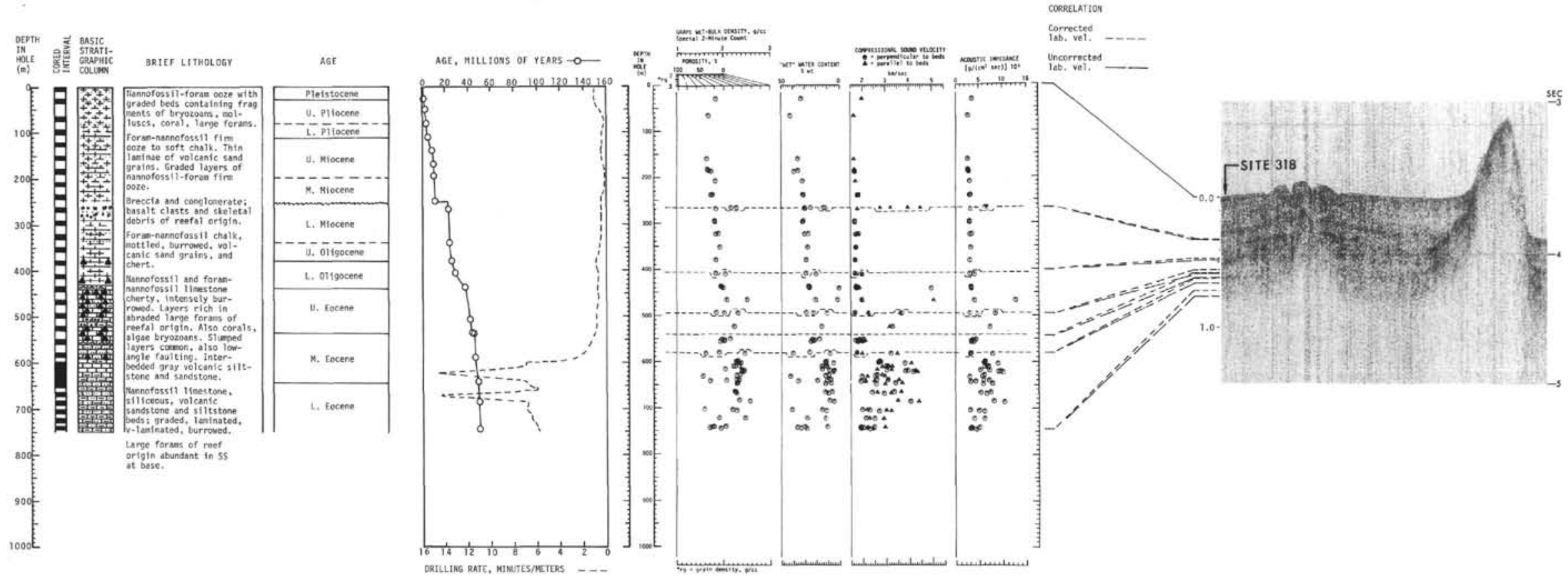

Figure 5. Site 318 stratigraphic and physical property data versus depth and the seismic profile approaching the site. 


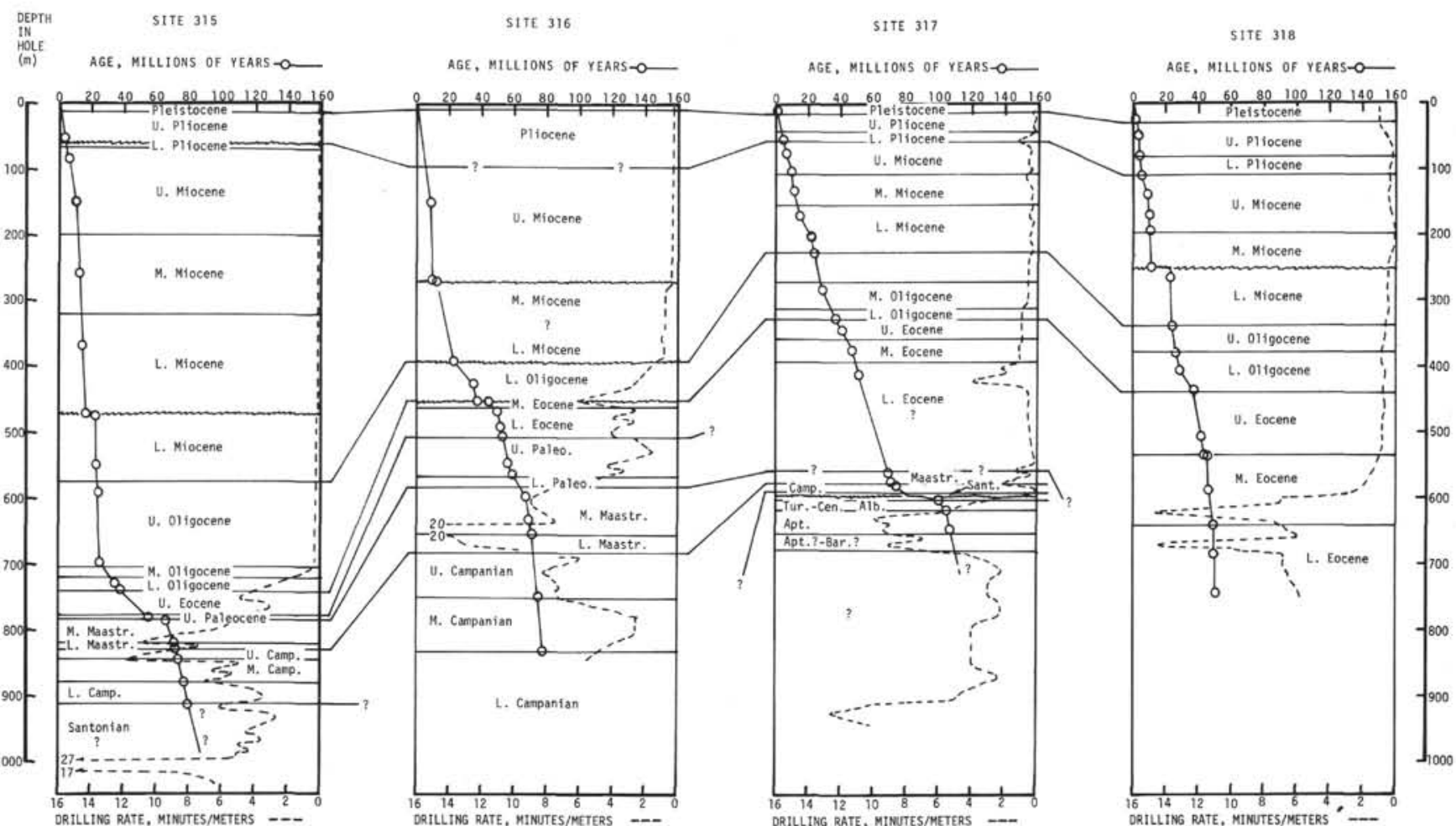

Figure 6. Regional correlation of the drilling rate and sedimentation rate. The solid correlation lines are the chronologic boundaries.

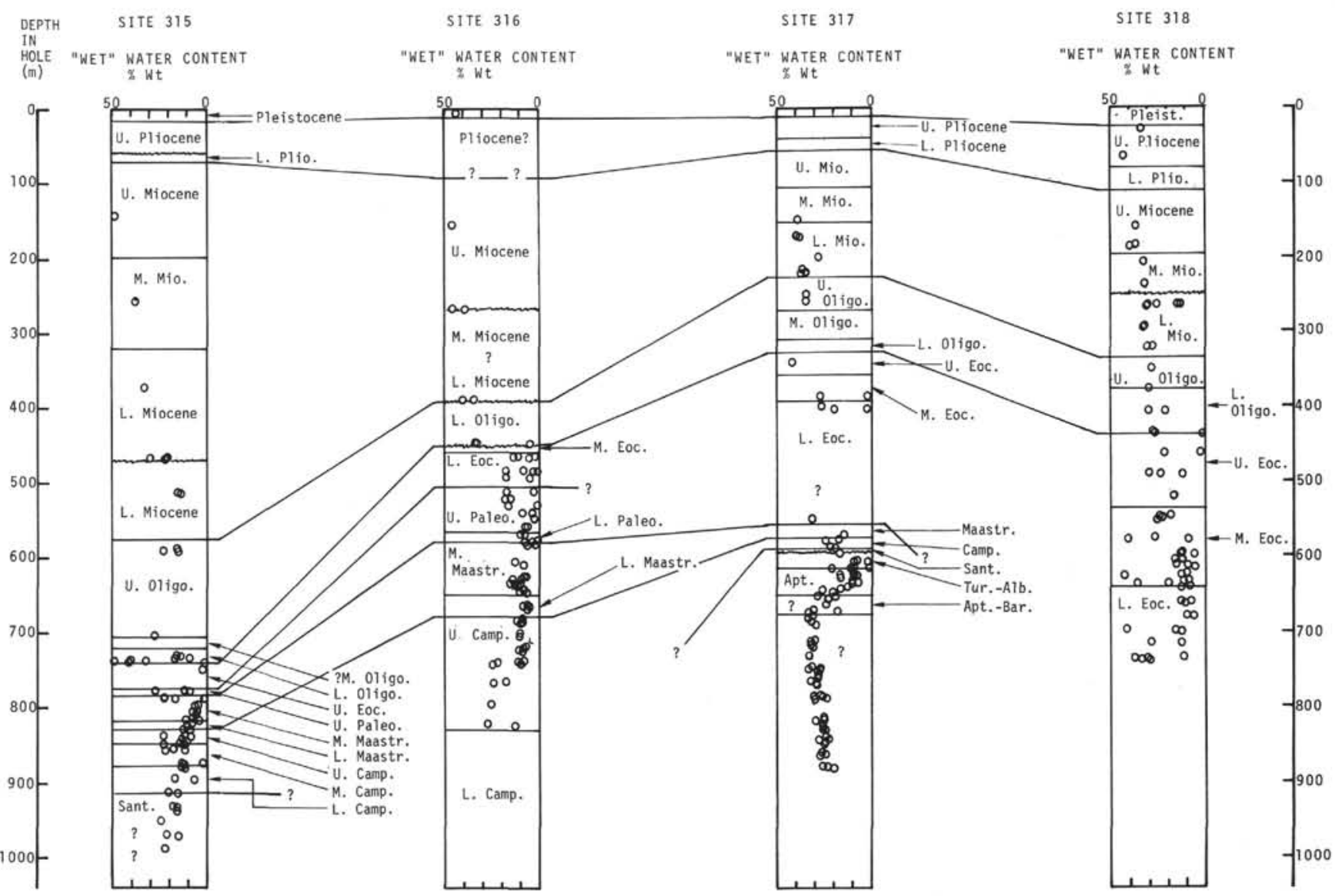

Figure 7. Regional correlation of wet-water content versus depth. The solid correlation lines are the chronologic boundaries. 


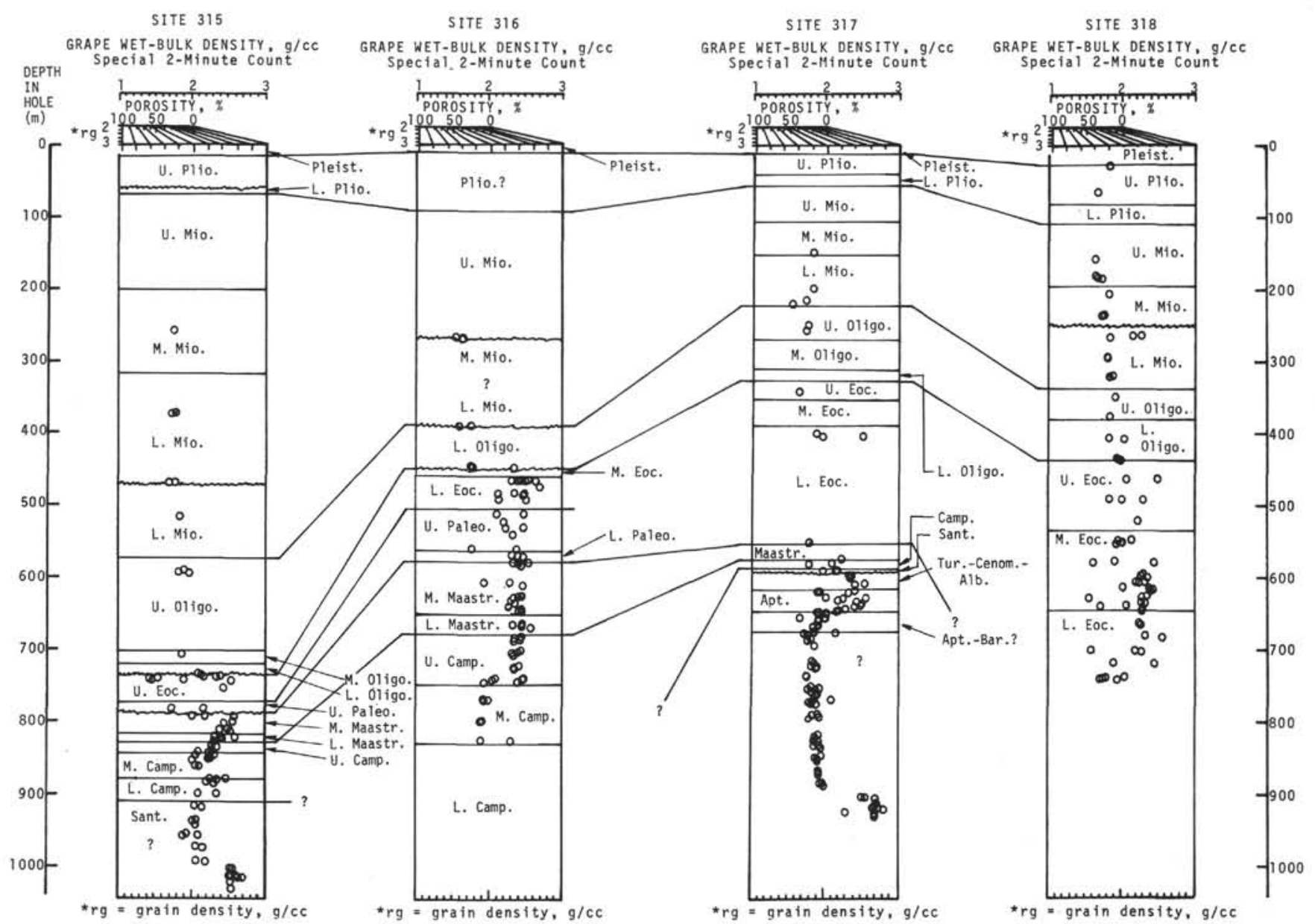

Figure 8. Regional correlation of wet-bulk density versus depth. The solid correlation lines are the chronologic boundaries.

Plateau and Tuamotu Ridge. The Tuamotu Ridge, however, was not drilled deep enough to recover the characteristic sequence of Cretaceous limestone, volcaniclastics, and basalt.

\section{Sedimentation Rates}

In general, there is a good correlation between the sedimentation rates or age versus depth and the other physical properties (Figures 2-5), which may in part be an artifact of sparse coring or sampling for undisturbed sediments. The data intervals were sparse in the Pleistocene through Oligocene sections, either because of coring intervals or coring disturbance; therefore, the Schlanger and Douglas (1974) theory, of various Cenozoic unconformities being the reflecting horizons in the seismic profiles, cannot be properly documented with the meager undisturbed physical property data over these particular geologic sections.

\section{Drill Rates}

Relative drill rates versus depth (compiled by Schlanger) appear to characterize particular chronologic and lithologic horizons in the more indurated parts of the geologic sections (Figures 2 through 4 and 6). Regional correlations are effective for Sites 315 through 317 , but 318 has an Eocene drill rate that appears to be anomalously high, but perhaps it is high because the hard units are thicker at Site 318 , as Site 318 has an expanded chronological section compared to Sites 315317. Of course, in the upper soft parts of the geologic section at all sites, the drill rates are not of a direct use, except to locate particularly thick and hard layers, if they exist.

\section{Wet-Water Content}

Wet-water content correlates very well from site to site, and also has a good correlation with the basic lithology of chalk, limestone, and volcaniclastics. In general, the wet-water content appears to decrease (from $50 \%$ to $20 \%$ or $30 \%$ ) with increasing depth (0 to $500 \mathrm{~m})$ in the Pleistocene-Miocene chalk. But in the Oligocene chalk, wet-water content tends to remain relatively constant with increasing depth, until cementation becomes a major factor in the Eocene-Paleocene chalks. The Eocene-Cretaceous limestones have water contents from 1 to $10 \%$. The limestone gradually changes with increasing depth to semilithified volcaniclastics and the wet-water content gradually increases until $20 \%$ to $30 \%$ is characteristic for the volcaniclastic sequence.

It is interesting to note that the volcaniclastic sequence was only semilithified, although below a highly cemented limestone layer. A question to be considered was whether the overlying limestone allowed the interstitial waters to migrate and subsequently allow the 


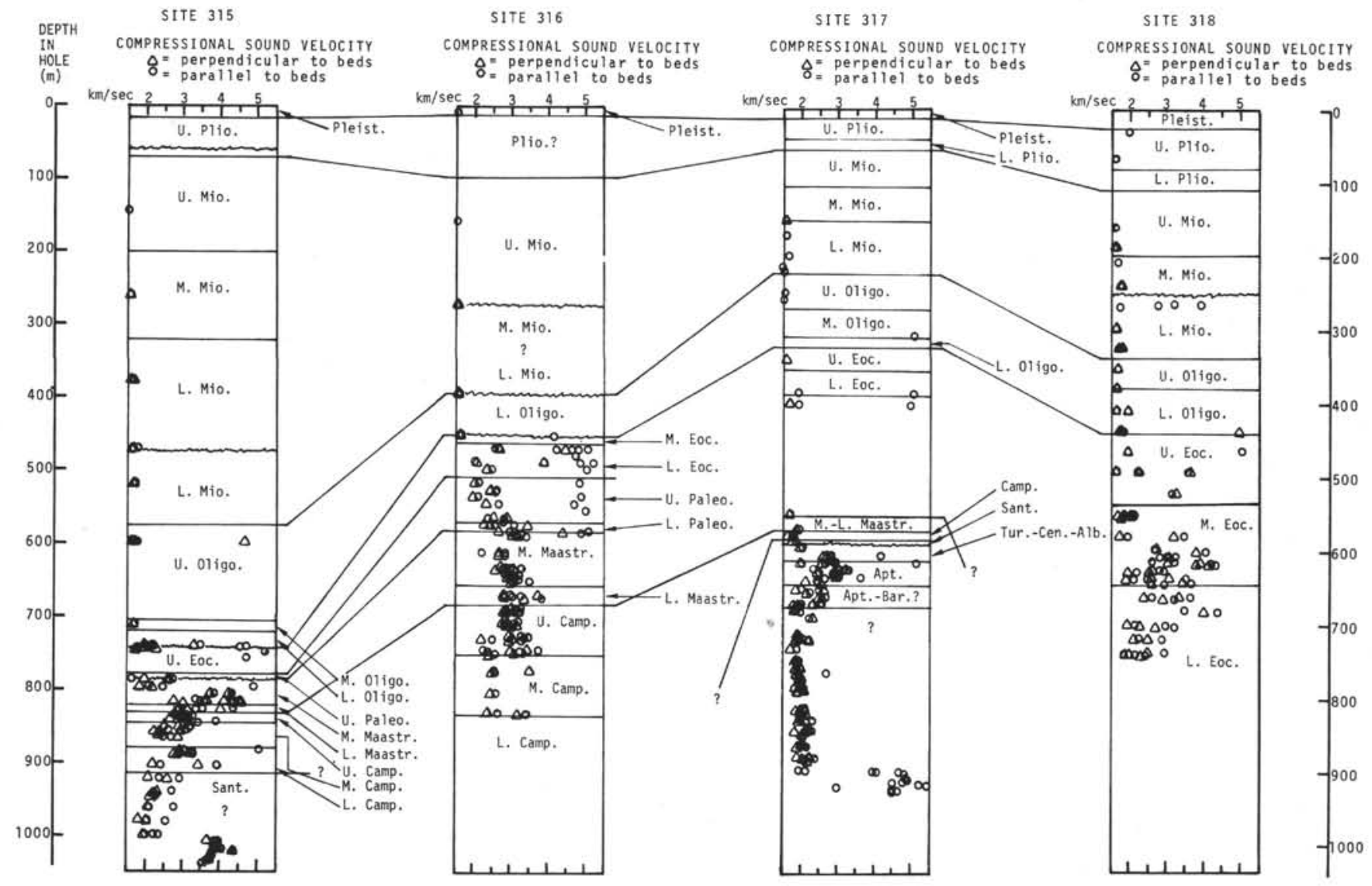

Figure 9. Regional correlation of sound velocity versus depth. The solid correlation lines are the chronologic boundaries.

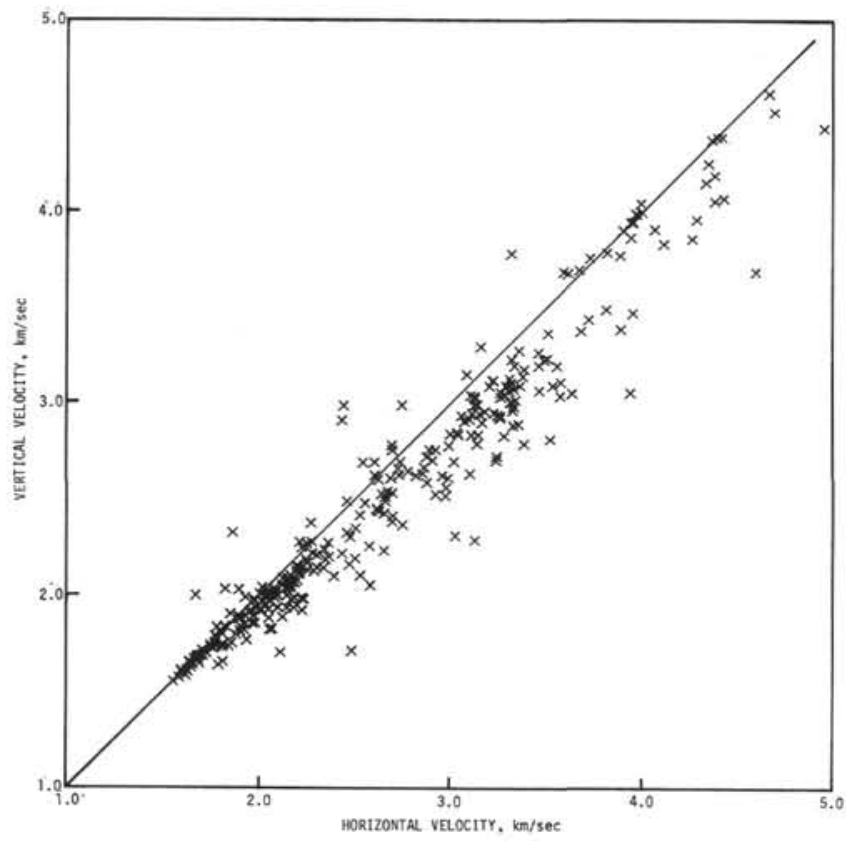

Figure 10. Horizontal velocity versus vertical velocity for all sites.

clastics to consolidate. However, the volcaniclastics do not appear underconsolidated compared to the Tertiary chalk or the consolidation curves in Hamilton (1959).

\section{Wet-Bulk Density}

Wet-bulk density is also a good regional correlation indicator for Sites 315 through 318. In general, the density is low $(1.6$ to $2.0 \mathrm{~g} / \mathrm{cc}$ ) for the Pliocene-Oligocene chalks, with a slightly irregular increase with increasing depth and age. The sampling is sparse for good undisturbed samples, and it is therefore possible to miss unusual layers. Within the Oligocene section at Site 315, a celestite layer(?) $(7 \mathrm{~cm}$ [?] thick) has a very high density of about $4 \mathrm{~g} / \mathrm{cc}$.

The Eocene-Paleocene chalk has a wide variation in density which irregularly increases with increasing depth as a result of increasing siliceous and calcareous cementation, in addition to abundant chert. The Maestrichtian and Campanian sections at Sites 315 and 316 and the Maestrichtian and Aptian-Barremian sections at Site 317 are limestones with densities around $2.5 \mathrm{~g} / \mathrm{cc}$. The limestone is transitional with increasing depth to a low density $(2.1 \mathrm{~g} / \mathrm{cc})$ volcaniclastic sequence, and also has many interbeds of relatively low density volcanic sandstones. Within the volcaniclastic sequence a sample of vein rock was recovered. It has a density of $2.2 \mathrm{~g} / \mathrm{cc}$ compared with the density of $1.9 \mathrm{~g} / \mathrm{cc}$ in the surrounding sediment.

The underlying basalts at Sites 315 and 317 had contrasting densities for the least vesicular samples, which were 2.5 and $2.7 \mathrm{~g} / \mathrm{cc}$, respectively. At Site 317 the basalt had clastic interbeds with densities near $2.3 \mathrm{~g} / \mathrm{cc}$. 
R. E. BOYCE

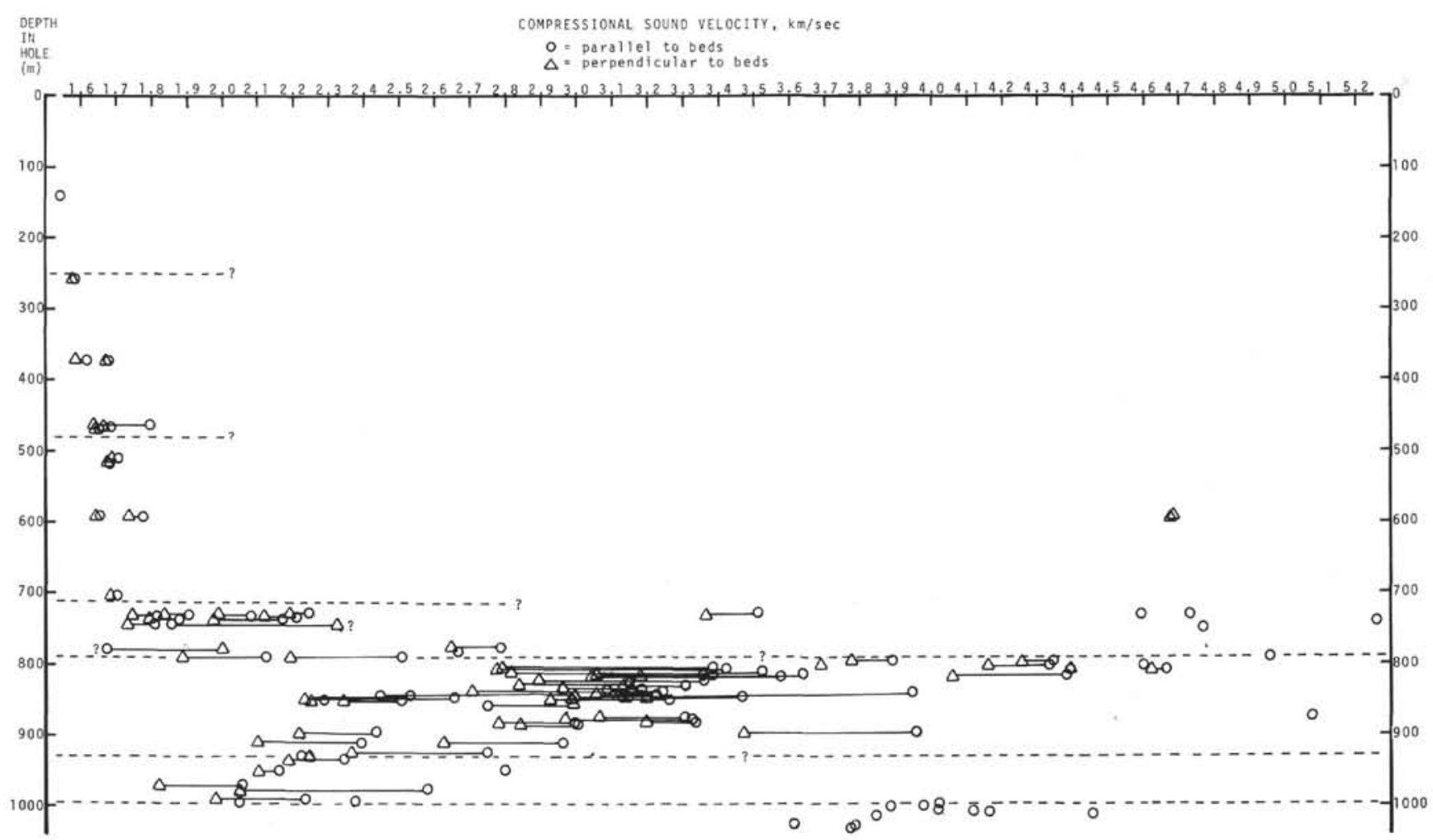

Figure 11. Sound velocity versus depth at Site 315, with an expanded velocity scale in order to observe the acoustic anisotropy of the vertical velocity to the horizontal velocity. The horizontal dashed lines are physical property boundaries used for seismic correlations.

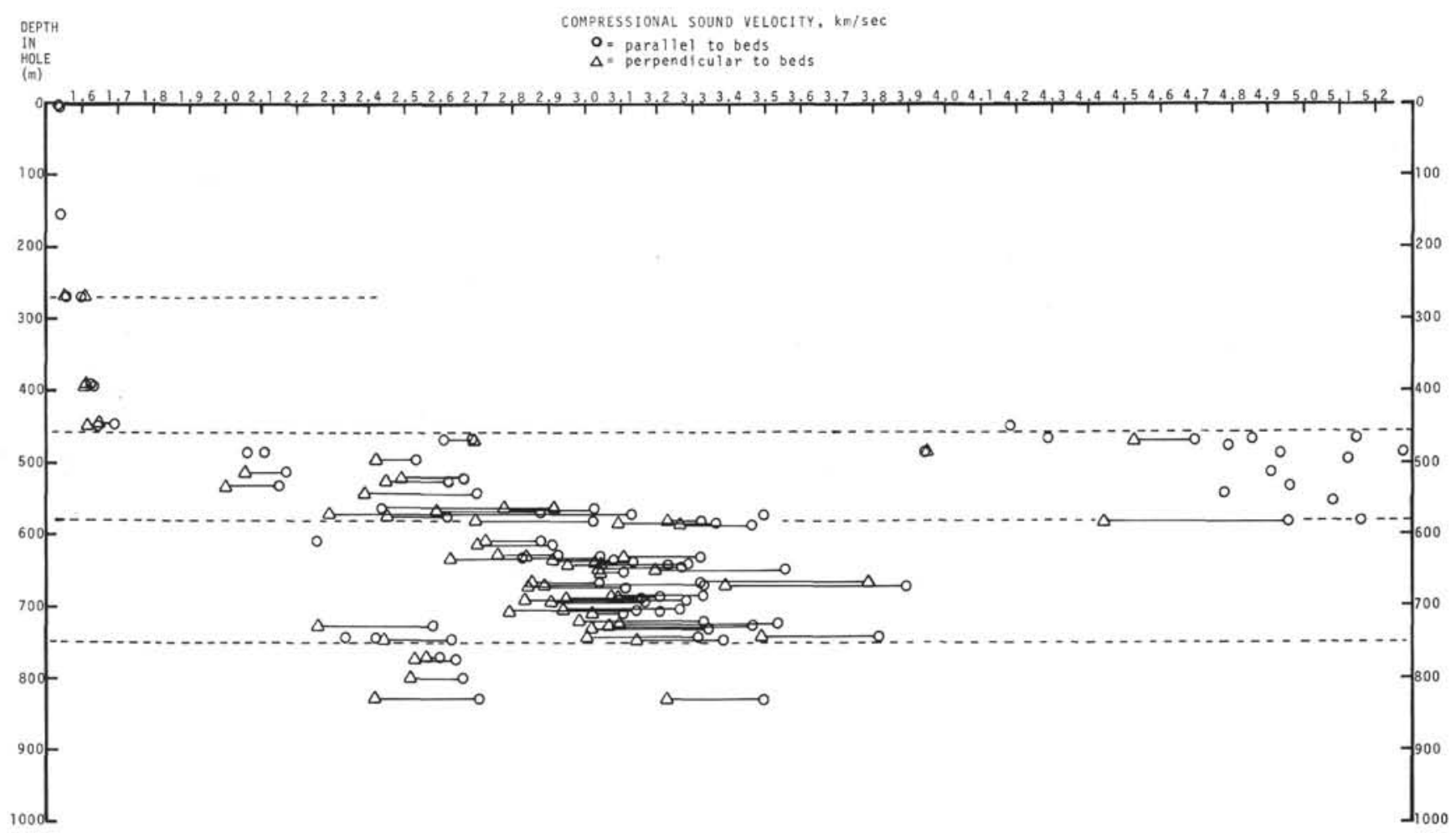

Figure 12. Sound velocity versus depth at Site 316, with an expanded velocity scale in order to observe the acoustic anisotropy of the vertical velocity to the horizontal velocity. The horizontal dashed lines are physical property boundaries used for seismic correlations. 


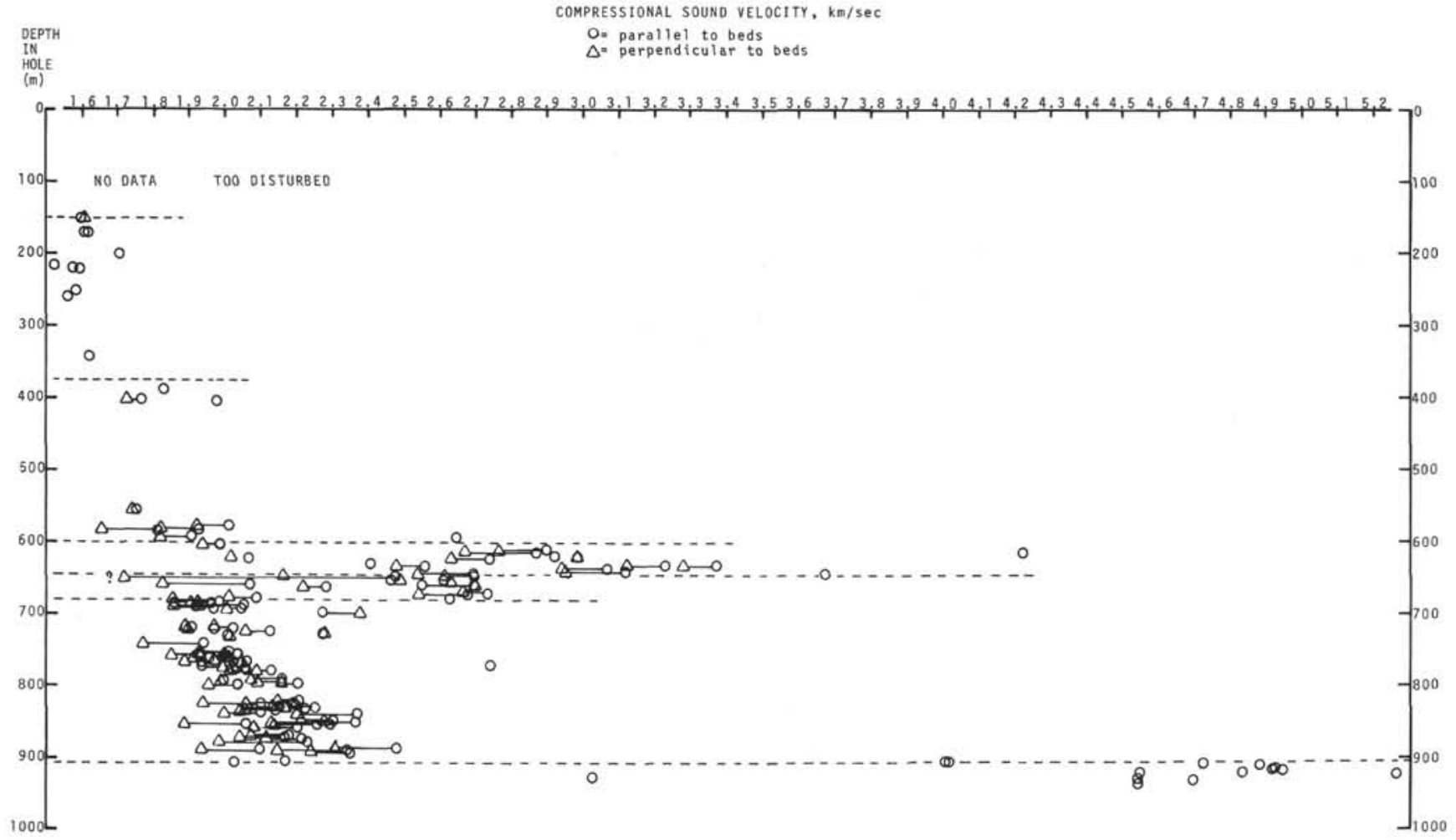

Figure 13. Sound velocity versus depth at Site 317 , with an expanded velocity scale in order to observe the acoustic anisotropy of the vertical velocity to the horizontal velocity. The horizontal dashed lines are physical property boundaries used for seismic correlations.

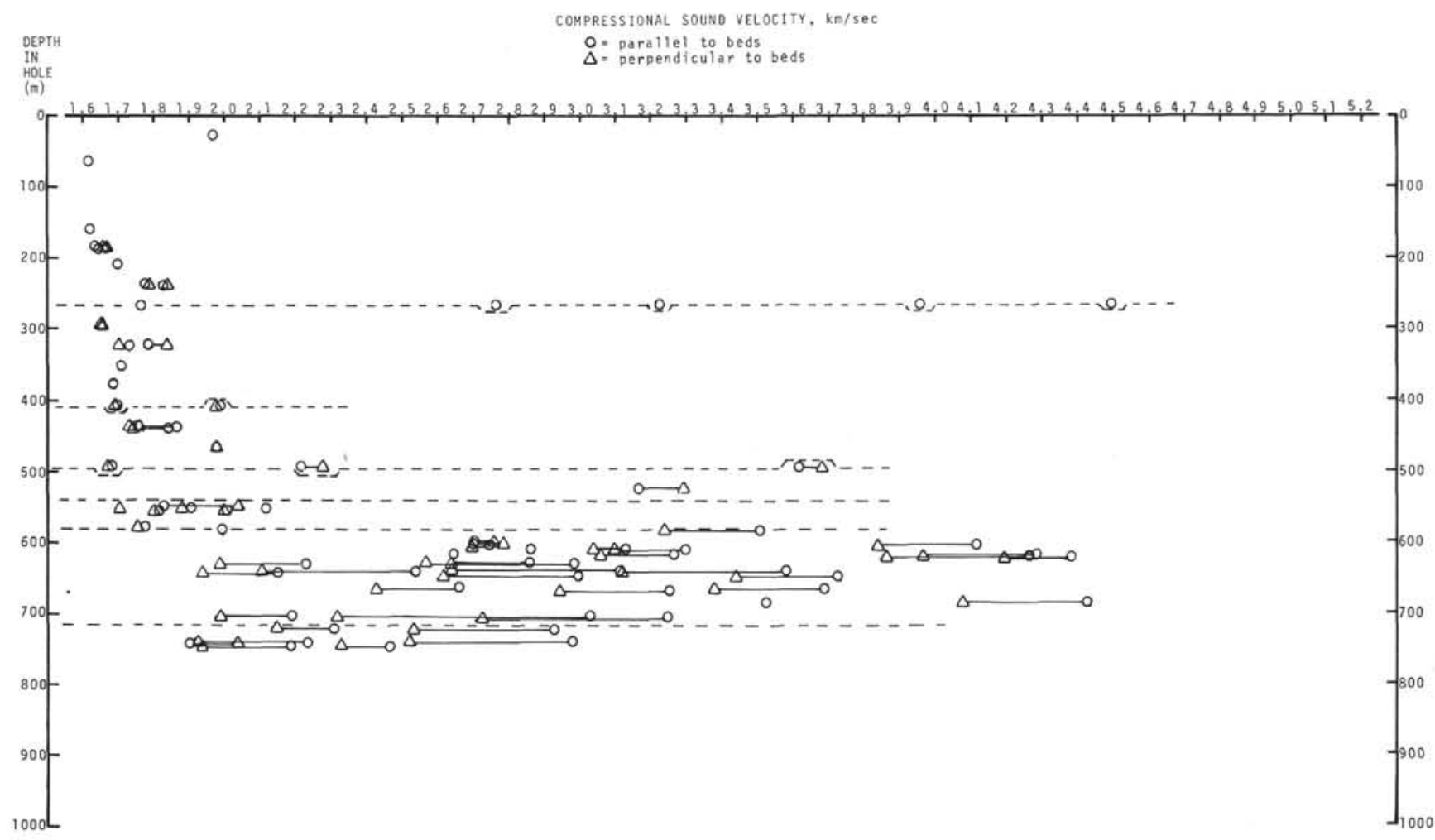

Figure 14. Sound velocity versus depth at Site 317 , with an expanded velocity scale in order to observe the acoustic anisotropy of the vertical velocity to the horizontal velocity. The horizontal dashed lines are the physical property boundaries used for seismic correlation. 


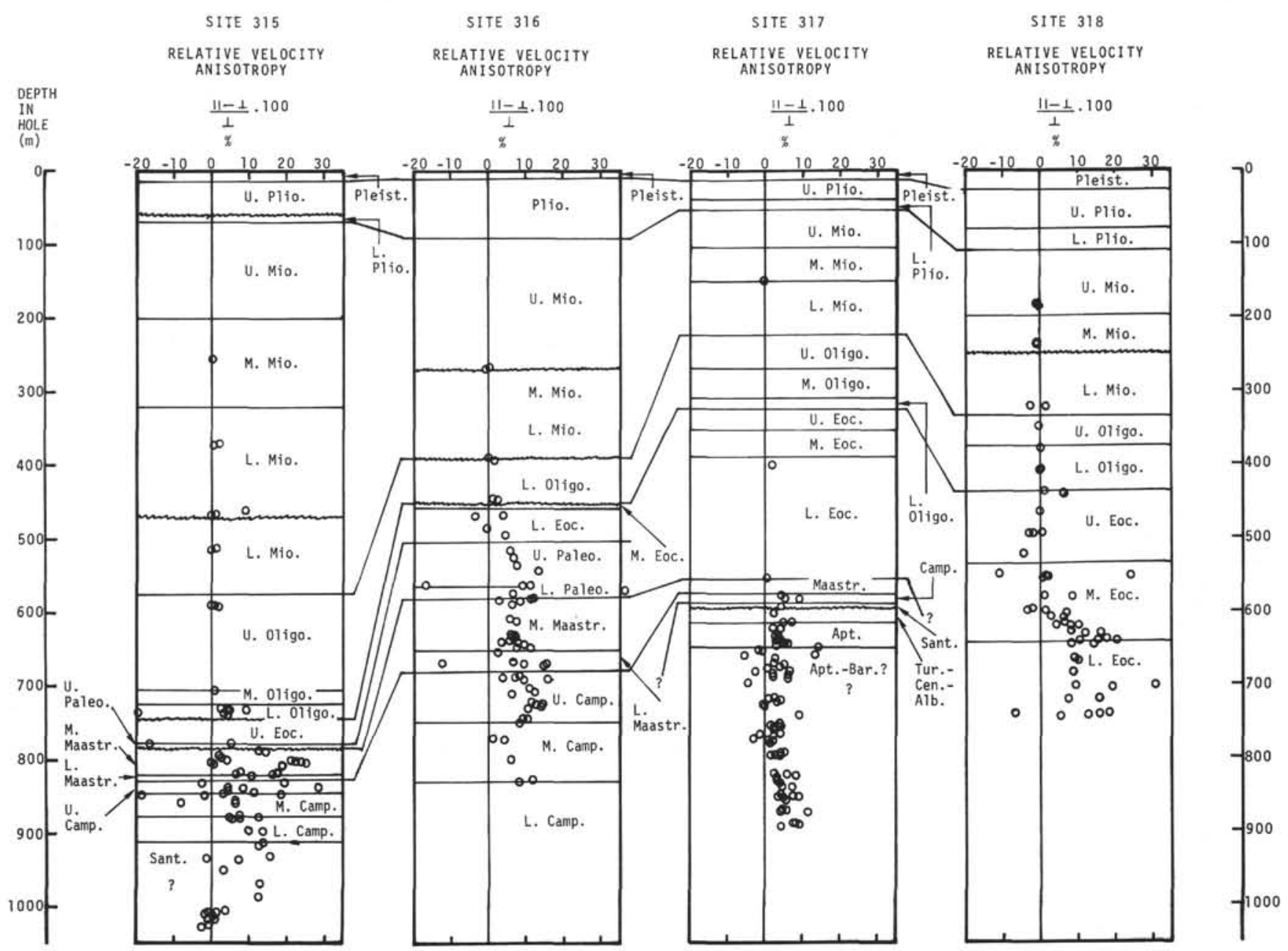

Figure 15. Regional correlation of the percentage velocity anisotropy versus depth. The solid correlation lines are the chronological boundaries.

\section{Sound Velocity}

Sound velocity varies with age and lithology and correlates regionally. Pliocene-Oligocene chalks have velocities (laboratory conditions) from 1.55 to 1.9 $\mathrm{km} / \mathrm{sec}$ which appear to increase irregularly and slightly with increasing depth and age, particularly within the Pliocene-Miocene chalks. The velocities in the Oligocene chalks appear to remain relatively constant with increasing depth, but high-velocity chert nodules are frequent. At Site 318 near the low-mid Miocene boundary there is a conglomerate unit with high velocity clasts. Also at Site 318 the Pliocene-Oligocene chalk velocities appear to be slightly faster and the sediments seem more cemented.

Eocene-Paleocene chalk becomes more cemented with calcareous and siliceous cement as these chalks change to limestone. High-velocity chert nodules are abundant, with velocities around $5 \mathrm{~km} / \mathrm{sec}$. In general, the chalk velocities have a wide range from 1.7 to $4 \mathrm{~km} / \mathrm{sec}$, and in addition are typically 0 to $15 \%$ greater horizontally than vertically (Figures 10 through 15).

The Maestrichtian-Campanian sections at Sites 315 and 316 and the Maestrichtian to Aptian-Barremian section at Site 317 are limestone with very high velocities of 2.7 to $3.5 \mathrm{~km} / \mathrm{sec}$ and with an anisotropy of 0 to $15 \%$.
Velocities decrease with age and depth as the limestones are transitional with low velocity volcaniclastics. These volcaniclastics have velocities of 1.8 to $2.2 \mathrm{~km} / \mathrm{sec}$ and also an anisotropy of 0 to $15 \%$.

The basalts have velocities of 3.5 to $4.5 \mathrm{~km} / \mathrm{sec}$ at Site 315 , and 4.7 to $5.5 \mathrm{~km} / \mathrm{sec}$ at Site 317 for the least vesicular samples. If they are anisotropic, then it is less than the $2 \%$ precision of the velocimeter.

In general, the anisotropy is very little ( 0 to $3 \%$ ) in the Pleistocene-Oligocene chalks, but typically the Eocene and older sedimentary rocks have anisotropies which are significant (0 to $15 \%)$.

Anisotropy (Figures 10 through 15) may be a good device to distinguish sedimentary rocks from basalt on a well-log basis, if a well-logging device were designed to measure velocity in both directions of very thin intervals.

Also refraction surveys should note the low velocity volcaniclastic sequence underlying the high velocity limestone sequence, so that it is not assumed that velocities of layers always increase with depth.

Impedance also correlates well regionally, but it has a similar variance as discussed for sound velocity and density, and therefore will not be discussed. The regional correlation can be seen in Figure 16. 
SITE 315

DEPT
IN
HOL
$(\mathrm{m})$

$\left[\mathrm{g} /\left(\mathrm{cm}^{2} \mathrm{sec}\right)\right] 10^{5}$
SITE 316

ACOUSTIC IMPEDANCE $\left[\mathrm{g} /\left(\mathrm{cm}^{2} \mathrm{sec}\right)\right] 10^{5}$
SITE 317

ACQUSTIC IMPEDANCE $\left[\mathrm{g} /\left(\mathrm{cm}^{2} \mathrm{sec}\right)\right] 10^{5}$
SITE 318

ACOUSTIC IMPEDANCE $\left[9 /\left(\mathrm{cm}^{2} \mathrm{sec}\right)\right] 10^{5}$
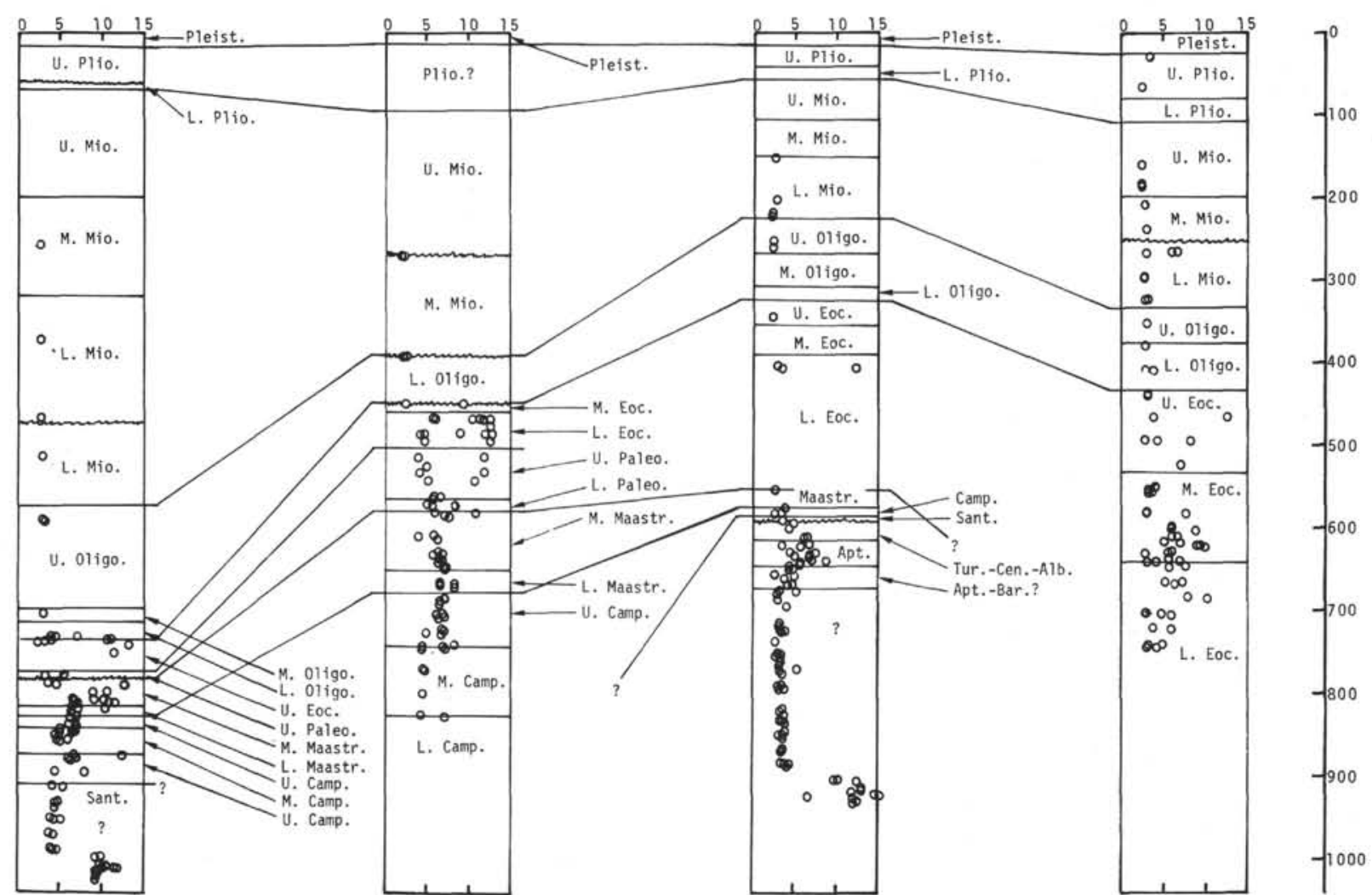

Figure 16. Regional correlation of the acoustic impedance versus depth. The solid correlation lines are the chronological boundaries.

\section{INTERRELATIONSHIPS OF PHYSICAL PROPERTIES}

There have been many studies of the interrelationships of physical properties. A primary relationship has been wet-bulk density and porosity versus sound velocity, as summarized by Nafe and Drake (1963). They point out that mainly the end-member relationships have been empirically reported, such as that for the soft sediments or hard rocks, and there is a lack of intermediate data, which will be provided here. In addition, the previous data will now have acoustic anisotropy systematically introduced as a factor. Previous theoretical inferences as to anisotropy in marine sediments have been discussed in Hamilton (1959) and measured in artificially compacted marine sediments by Laughton (1957). L. Kroenke, on DSDP Leg 30, also has good systematic anisotropy measurements, and anisotropy has also been spot-measured as reported in many previous DSDP Initial Report volumes. Other physical property interrelationships of sediments studied (Hamilton, 1970) are the bulk elasticity and impedance relative to porosity, wet-bulk density, and grain size. The igneous and metamorphic rocks have been studied by Birch $(1960,1961)$; Christensen (1965); Brace (1965); and others. Birch (1961) reported that hard rock velocity, when plotted versus density, is a linear relationship for rocks with similar mean atomic weights. Acoustic anisotropy in hard rocks is attributed to acoustic anisotropy in minerals, alignment of minerals, and cracks.

\section{Theoretical Equations}

A sound pulse is an acceleration of particles of a medium according to the elastic rebound of the propagating medium. Green (1962) states "since the propagation of the pulse is related to the acceleration of the particles of the medium, it seems reasonable that the velocity should depend on the magnitude of the particle acceleration." Force is the product of mass multiplied by acceleration; therefore, when calculating force, "it isn't practical to consider the mass of each individual particle of the medium and the force acting on it. Instead, it is more convenient to consider the acceleration of larger portions of the medium, such as one cubic centimeter. The mass of this volume of the medium will be numerically the same as the density, by definition." Therefore, since we are using mass per unit area, then we must use a force per unit area, such as the elasticity values, as follow: Compressional sound velocity in isotropic material has been defined (Wood, 1941; Birch, 1961; Hamilton, 1970) as

$$
\mathrm{V}=\left(\frac{L}{\rho_{b}}\right)^{1 / 2}=\left(\frac{k+\frac{4 \mu}{3}}{\rho_{b}}\right)^{1 / 2}
$$


where, $\mathrm{V}$ is the compressional velocity

$\rho_{\mathrm{b}}$ is the wet-bulk density in $\mathrm{g} / \mathrm{cc}$, where

$$
\rho_{b}=\rho_{w} \phi+(1-\phi) \rho_{g}
$$

$\phi$ is the fractional porosity of the sediment or rock and the subscripts $b, g$, and $w$, represent the wetbulk density, grain density, and water density, respectively.

$L$ is the bulk elasticity of the medium

$k$ is the incompressibility or bulk modulus, $1 / k=\beta$ compressibility modulus

$\mu$ is the shear (rigidity) modulus

Where samples are anisotropic, then $L, K$, and $\mu$ may have unique values for the corresponding vertical and horizontal directions. See Laughton (1957) for discussions of anisotropy.

The following relationships are shown as they will be presented later in various scatter diagrams:

Acoustic impedance (I) is defined as follows:

$$
\mathrm{I}=\mathrm{V}_{\rho}
$$

Since impedance is essentially the momentum (mass $\times$ velocity), as density $(\rho)$ is substituted for the mass, then

$$
\mathrm{V}_{1 \rho 1}=\mathrm{V}_{2 \rho_{2}}
$$

should be true for a given elasticity $(L)$. The subscripts 1 and 2 represent different mediums with corresponding velocities (V) and densities $(\rho)$. In addition:

$$
\begin{gathered}
\mathrm{V}^{2}=\frac{L}{\rho} \\
\mathrm{V}^{2} \rho=\mathrm{VI}=L \\
\mathrm{~V}=\frac{L}{\mathrm{~V} \rho}=\frac{L}{\mathrm{I}}
\end{gathered}
$$

Compressional velocity of sediments and rocks has been related to the sediment components by Wood (1941), Wyllie et al. (1956), and Nafe and Drake (1963), whose equations are listed in Table 2 . These will be presented later in comparison with the empirical scatter diagrams. The following empirical scatter diagrams will be presented in order to provide practical empirical relationships, for comparison with previous studies, and to help develop predictive relationships.

\section{Scatter-Diagram Relationships}

The first group of scatter diagrams is wet-bulk density versus porosity (Figures 17-21). The data are plotted for the individual sites and with all the site data lumped together. On these diagrams a line connecting the point of " $1.025 \mathrm{~g} / \mathrm{cc}$ density at $100 \%$ porosity" and that passes through a given datum point of "wet-bulk density versus porosity" and if extended until it intersects with the wetbulk density scale at $0 \%$ porosity, then that intersection (at $0 \%$ porosity) density value will be the approximate grain density of the sample. However, this grain density determination is subject to great error, especially at high porosity, but will allow identification of some sample data that have either wet-bulk density, or water content, or porosity values that appear to be too low or too high, by placing theoretical limits on the possible grain density values. For Leg 33 samples, the data which are less than the $2.4 \mathrm{~g} / \mathrm{cc}$ grain density are suspicious values (unless rich in radiolarians) and these samples have been listed in Table 3. These samples in all other scatter diagrams of water content or porosity will have a question mark (?) adjacent to them so that they can be identified, or will be deleted.

The relationship of wet-water content versus porosity will also allow a similar interpretation and unusual samples can be identified. These scatter diagrams are presented as individual site plots and with all the site data grouped in Figures 22-26.

Individual site plots and all site data plots for vertical sound velocity versus wet-water content are shown in Figures 27-31. The horizontal sound velocity versus wetwater content is shown in Figures 32-36. In Figures 31 and 36 the data are coded for the basic lithologic differences of clastics, carbonates, and chert. An average of the vertical and horizontal velocities are plotted versus wet-water content in Figure 37.

Horizontal and vertical sound velocity versus porosity are shown in Figures 38-41. The horizontal and vertical velocity versus porosity, respectively, for all sites are shown in Figures 42 and 43. Figures 38 through 41 are also coded for the clastics, carbonate, and chert. The plots compare well with the data summary in the Nafe and Drake (1963) scatter diagram of velocity versus porosity, and fill in some of the intermediate densityvelocity data points which were previously sparse. In addition, the wet-bulk density versus velocity relationship now has acoustic anisotropy related to it.

The average of the horizontal velocity and vertical velocity versus porosity is shown in Figure 44. Also in Figure 44 are the theoretical lines of the Wood (1941) Equation 7; the Wyllie et al. (1956) Equation 8; and the Nafe and Drake (1957) Equation 9 with $n$ of 4, 5, and 6 (see Table 2 for these equations). These equation lines were calculated assuming a theoretical mixture of calcite with a density of $2.72 \mathrm{~g} / \mathrm{cc}$ and a velocity of $6.45 \mathrm{~km} / \mathrm{sec}$, and sea water with a density of $1.025 \mathrm{~g} / \mathrm{cc}$ and a velocity of $1.53 \mathrm{~km} / \mathrm{sec}$. In general, the data fall between the Wood (1941) equation and the Wyllie et al. (1956) equation. The Nafe and Drake equation (with $n=4,5,6$ ) cuts across the data in the lower velocities (high porosity) and appears to be higher than the data at high velocity. Higher values of $n$ of 7,8 , or 9 may be necessary to fit the low porosity data. No single line of the Nafe and Drake equation fits the Leg 33 empirical data. However, the Wyllie and Wood equations seem to provide upper (?) and lower limits to the data, and possibly a good fit for the empirical data may be easily calculated by averaging the velocities of the Wood (1941) and Wyllie et al. (1956) equations.

Vertical and horizontal velocities are plotted versus wet-bulk density in Figures 45-48 and horizontal velocity versus density and vertical velocity versus density, respectively, are shown in Figures 49 and 50. Figures 45- 
TABLE 2

Theoretical Equations Relating Compressional Velocity of the Wet-Saturated Rock to the Velocities and Densities of the Fluid and Solid Grain End-Member Constituents

Wood (1941) equation applies to velocities through suspensions without rigidity:

$$
\mathrm{V}_{b}=\left(\frac{1}{\left(\left[\phi \beta_{w}+(1-\phi) \beta_{g}\right]\left[\phi \rho_{w}+(1-\phi) \rho_{g}\right]\right.}\right)^{1 / 2}
$$

where $\mathrm{V}=$ compressional velocity

$$
\begin{aligned}
\rho= & \text { density, } \beta=\text { compressibility, and subscripts } g, w \text {, and } b \text { rep } \\
& \text { resent the solid grains, interstitial water, and wet-bulk rock } \\
& \text { or sediment, respectively } \\
\phi= & \text { fractional porosity where } \rho_{b}=\phi \rho_{w}+(1-\phi) \rho_{g}
\end{aligned}
$$

Wyllie et al. (1956) equation applies in rocks with rigidity:

$$
\frac{1}{\mathrm{~V}_{b}}=\frac{\phi}{\mathrm{V}_{w}}+\frac{(1-\phi)}{\mathrm{V}_{g}}
$$

Nafe and Drake (1963) equation applies to rock with aring degrees of rigidity, which is controlled in the equation by the value of $n$ :

$$
\mathrm{V}_{b}^{2}=\phi \mathrm{V}_{w}^{2}\left[1+\left(\frac{\rho_{w}}{\rho_{b}}\right)(1-\phi)\right]+\frac{\rho_{g}}{\rho_{b}}(1-\phi)^{n} \mathrm{~V}_{g}{ }^{2}
$$

48 are coded for clastics, carbonate, chert, and basalt. For the Leg 33 data the velocity versus wet-bulk density have groupings or approximate alignments of cherts, volcaniclastics, carbonates, and basalts.

The average of the horizontal velocity and vertical velocity versus wet-bulk density is shown in Figure 51. Also in Figure 51 are equation lines of Wood (1941), Wyllie et al. (1956), and Nafe and Drake (1957) for $n=$ 4,5 , and 6 . These equations were reproduced on the density scatter diagrams because the density values measured are probably more accurate than the porosity values measured. These plots confirm the findings from Figure 44 of the average velocity versus porosity scatter diagram.

In general, in the velocity-density diagram the data points for chalks of Pliocene, Miocene, and Oligocene age tend to have an irregularly increasing velocitydensity relationship, which would be expected because of consolidation with depth below the sea floor. However, rocks older than Oligocene have a very wide scatter and can occur almost any place on the scatter diagram, which is related to varying degrees of cementation.

The impedance versus velocity relationships are shown in Figures 52-56. Note the approximately linear relationship within $\pm 0.5 \mathrm{~g} \times 10^{5} /\left(\mathrm{cm}^{2} \mathrm{sec}\right)$ for sediments and rocks of a given mineral makeup. Apparently, for a given mineral makeup the velocity-impedance is approximately (depending on rigidity and the bulk modulus) linear connecting the low velocity (high porosity) end member to the high velocity crystalline end member, e.g., calcite, basalt, chert (see Figure 57 for calcite relationship). This relationship in Figure 56 is coded for clastics, carbonate, chert, and basalt. A more

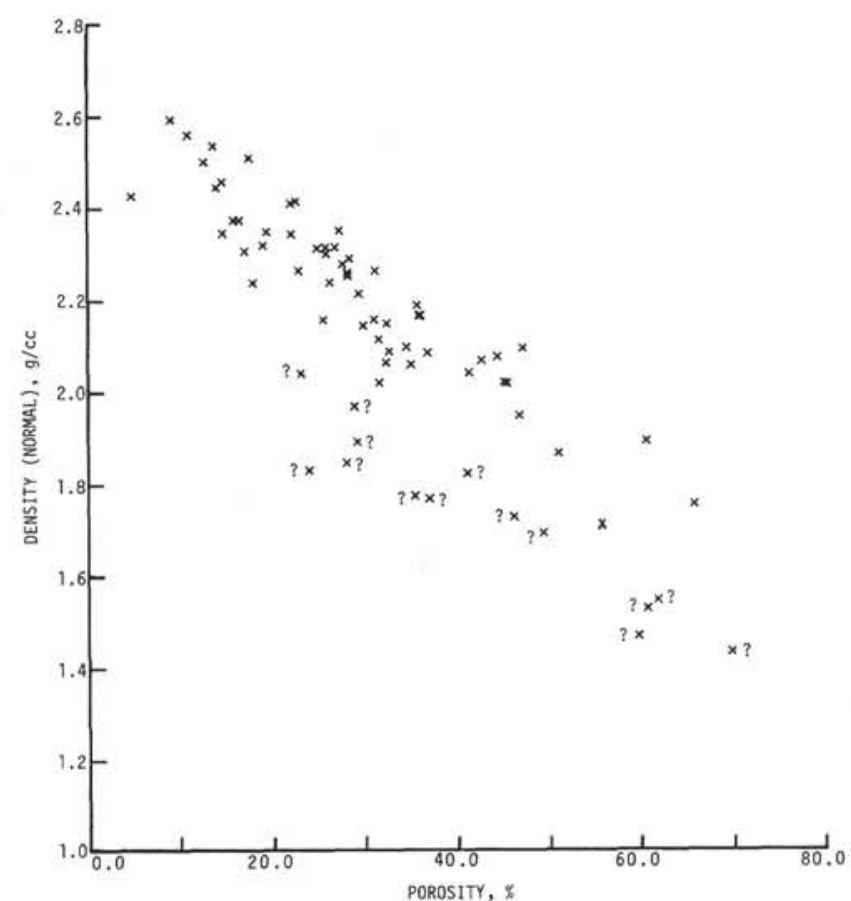

Figure 17. Wet-bulk density (normal) versus porosity for Site 315. The values which are question marked have a grain density solution which is questionable, therefore the wet water content and porosity values are probably too low.

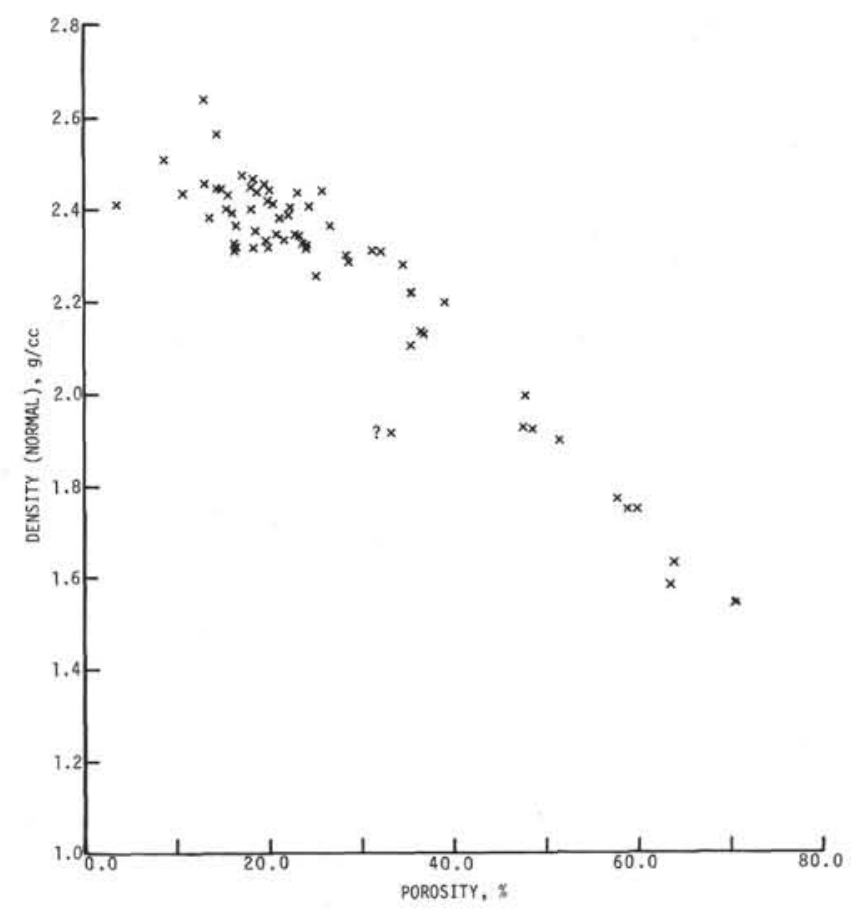

Figure 18. Wet-bulk density (normal) versus porosity for Site 316. The values which are question marked have a grain density solution which is questionable, therefore the wet water content and porosity values are probably too low. 


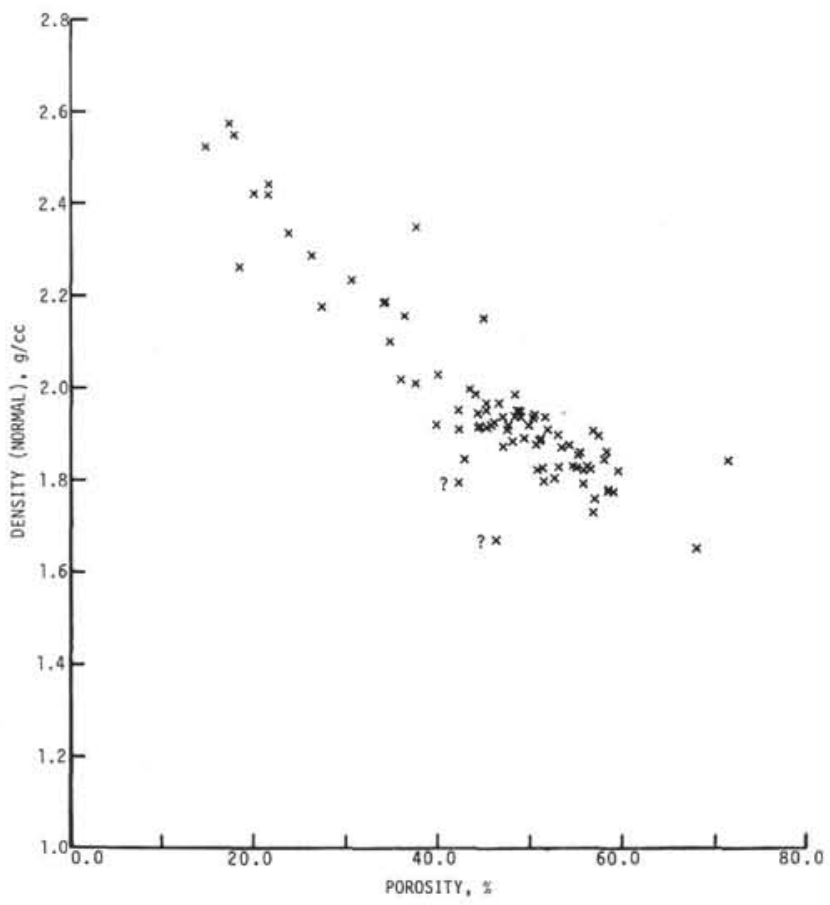

Figure 19. Wet-bulk density (normal) versus porosity for Site 317. The values which are question marked have a grain density solution which is questionable, therefore the wet water content and porosity values are probably too low.

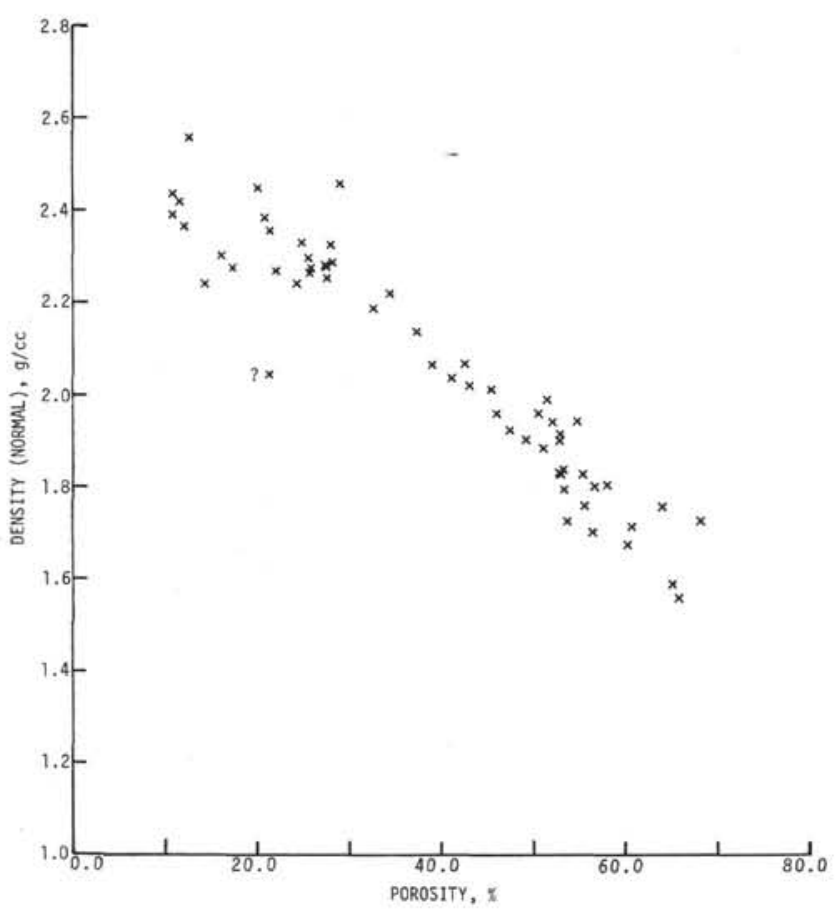

Figure 20. Wet-bulk density (normal) versus porosity for Site 318.

detailed breakdown based on lithology is not attempted here, because the percentage of the components was only estimated, and secondly the carbonate grouping in the sediment classification includes all pelagic samples with carbonate contents greater than $30 \%$; therefore, a

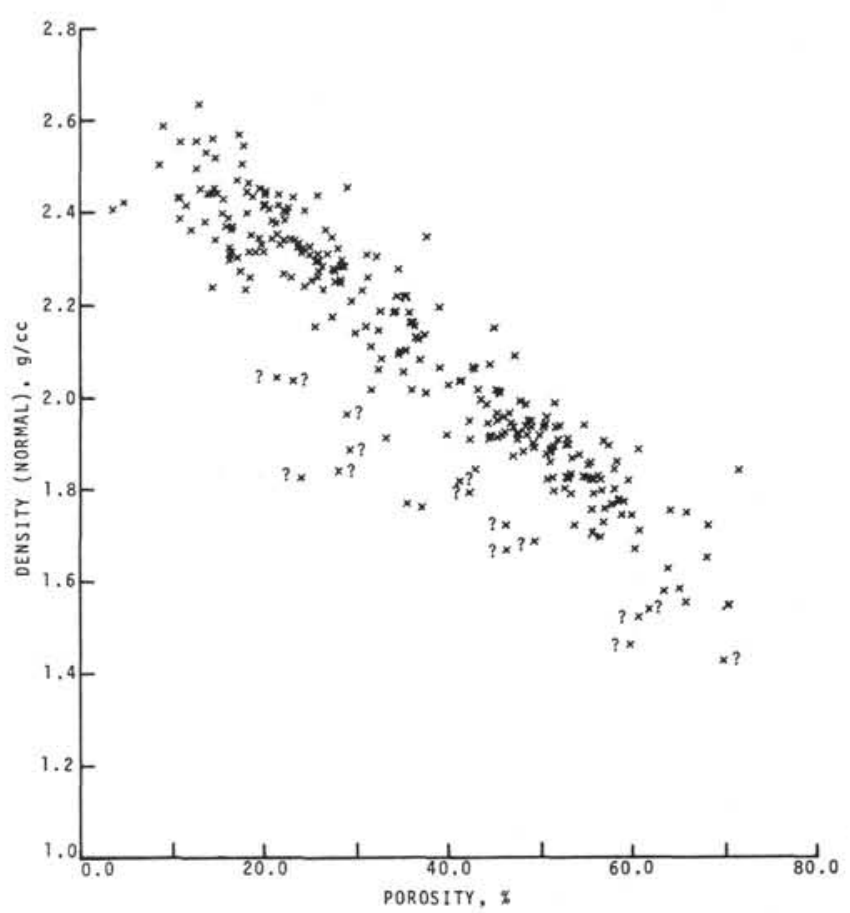

Figure 21. Wet-bulk density (normal) versus porosity for all sites. The values which are question marked have a grain density solution which is questionable, therefore, the wet water content and porosity values are probably too low.

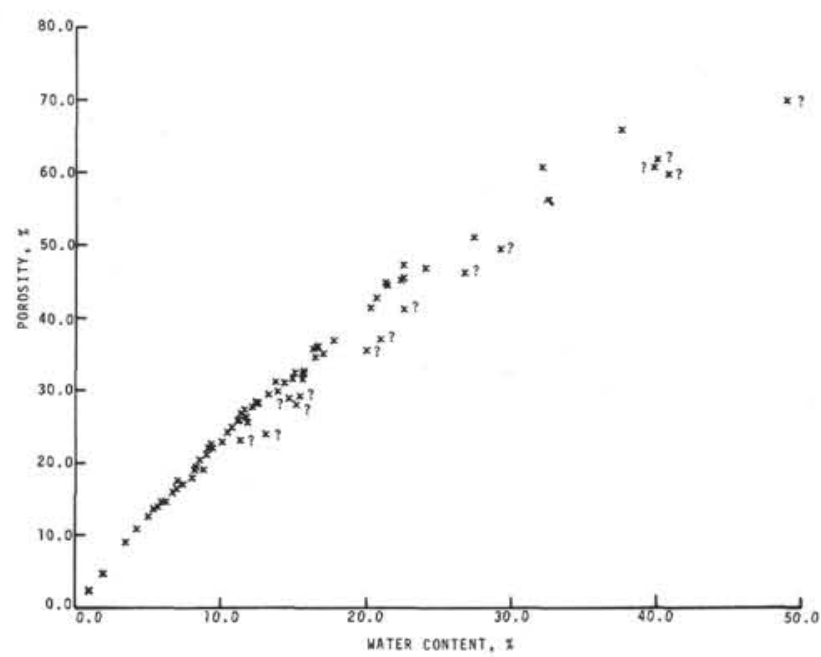

Figure 22. Porosity versus wet-water content for Site 315. The values which are question marked have a grain density solution which is questionable, therefore the wet water content and porosity values are probably too low.

refined sediment classification is needed before proceeding further with lithology identification.

The impedance-velocity relationship is essentially an empirical relationship and it is a coincidence that the geologic material makes it possible. For example, if the propagating media have a given elasticity $(L)$, then the velocity should be inversely proportional to the density $(\rho)$, and velocity versus impedance is an inverse relationship. When the media have differing elasticity $(L)$, 


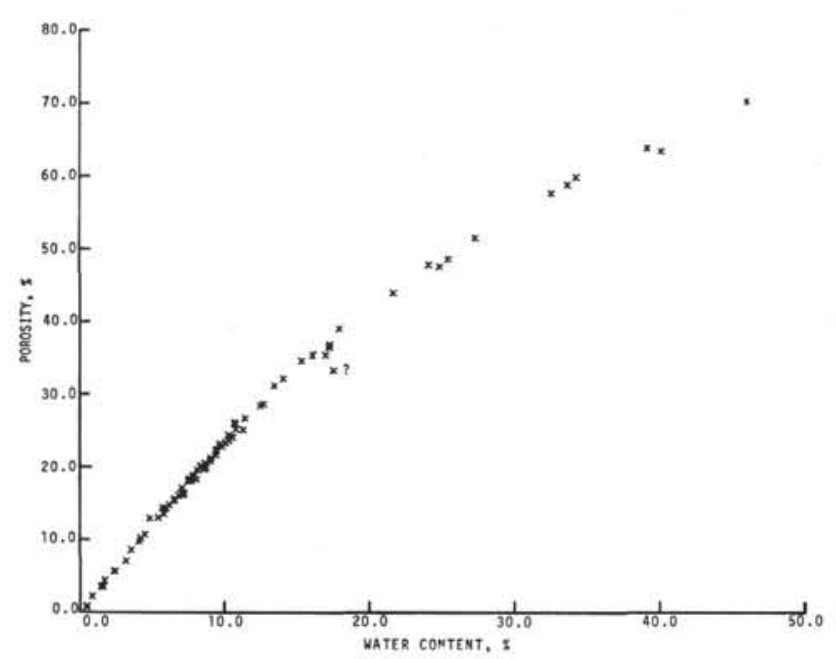

Figure 23. Porosity versus wet-water content for Site 316. The values which are question marked have a grain density solution which is questionable, therefore the wet water content and porosity values are probably too low.

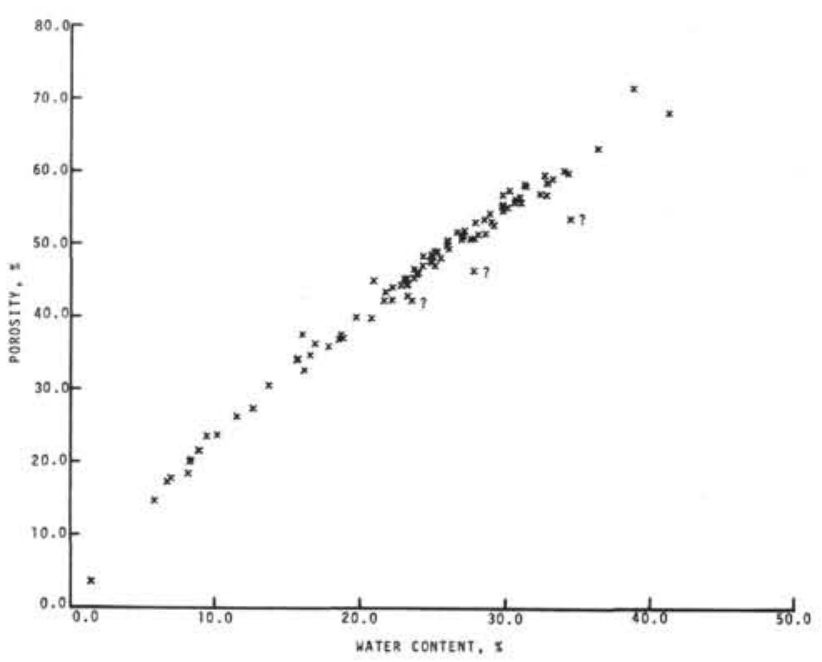

Figure 24. Porosity versus wet-water content for Site 317. The values which are question marked have a grain density solution which is questionable, therefore the wet water content and porosity values are probably too low.

but a constant density $(\rho)$, then the velocity is directly proportional to the elasticity $(L)$, and the velocity versus impedance is a direct relationship with slopes depending on the elasticity $(L)$. Of course if all combinations of the elasticity and density were available, then velocity versus density would be predominantly chaotic.

However, with Leg 33 geologic material and corresponding velocity-density data, not all combinations of elasticity and density are possible for every velocity value; for example, see Figure 58 for average velocity versus average elasticity $(L)$ for all sites and see Figures 59 and 60 for impedance versus density and porosity, and Figures 44 and 51 for velocity versus porosity and density, respectively. Leg 33 geologic material has water and solid grain end members, each with characteristic density and elasticity. Water has low density and

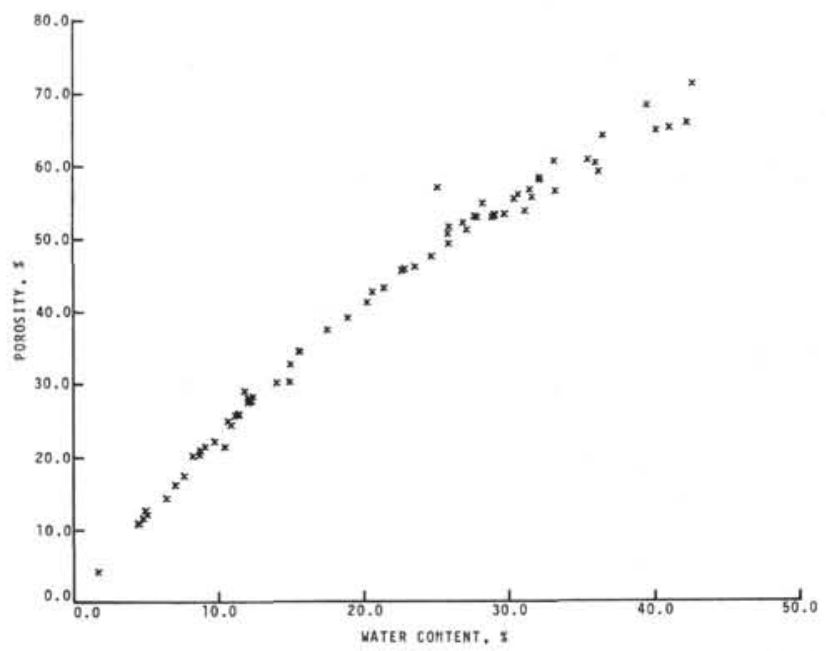

Figure 25. Porosity versus wet-water content for Site 318.

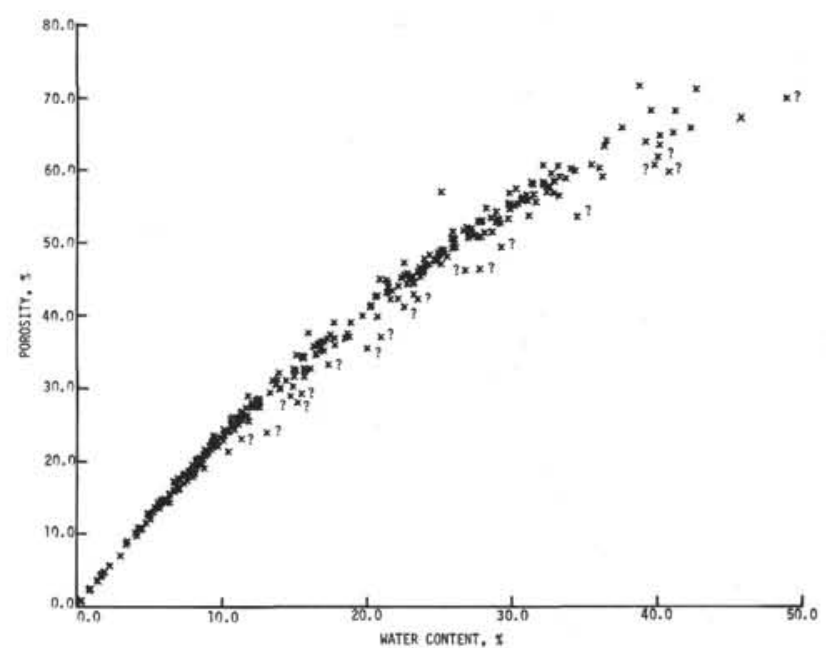

Figure 26. Porosity versus wet-water content for all sites. The values which are question marked have a grain density solution which is questionable, therefore the wet water content and porosity values are probably low.

elasticity, while most solid mineral end members have high characteristic density and elasticity combinations. Therefore, a continuous mixture of water with its solid mineral end member will provide a continuous variation of wet-bulk density and bulk elasticity, where both increase at the same time. Thus, velocity versus wet-bulk density or impedance will be a direct relationship, and, in addition, the solid end members, which have a given elasticity and density combination, will be aligned depending primarily on the amount of water in the rock, the degree of rigidity, and degree of anisotropy. This velocity-impedance alignment is not necessarily linear.

\section{Acoustic Anisotropy}

In general, the Pleistocene-Oligocene chalks have a typical acoustical anisotropy of 0 to $3 \%$ greater parallel to bedding planes (horizontal) than in a direction perpendicular to the bedding planes (vertical), while the Eocene and older sedimentary rock have acoustic 


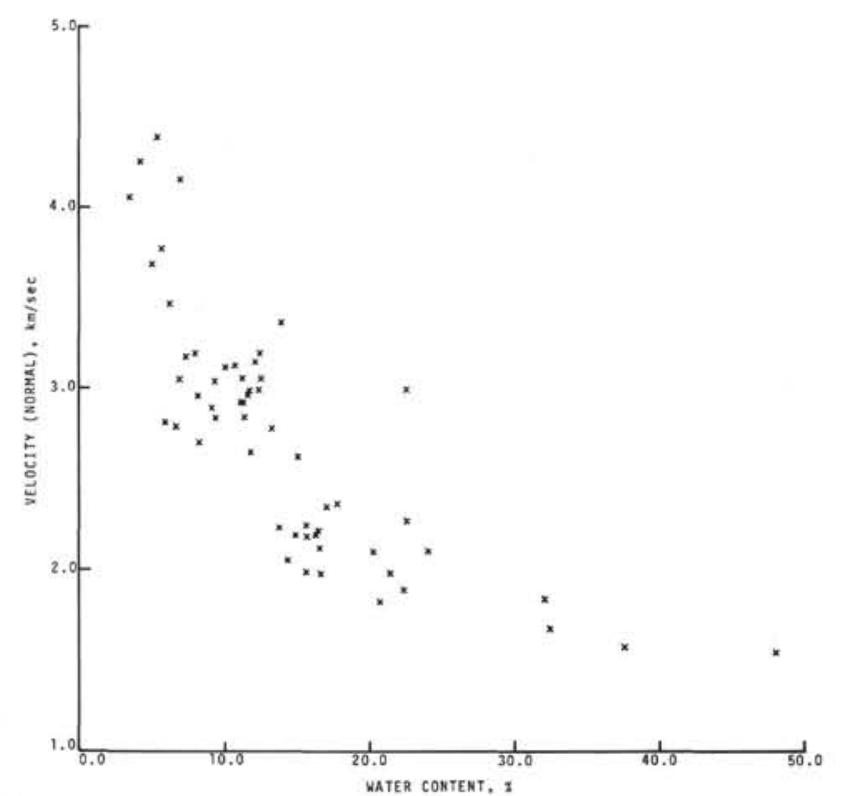

Figure 27. Velocity (normal) versus wet-water content for Site 315. The questioned water content values in Table 3 have been deleted.

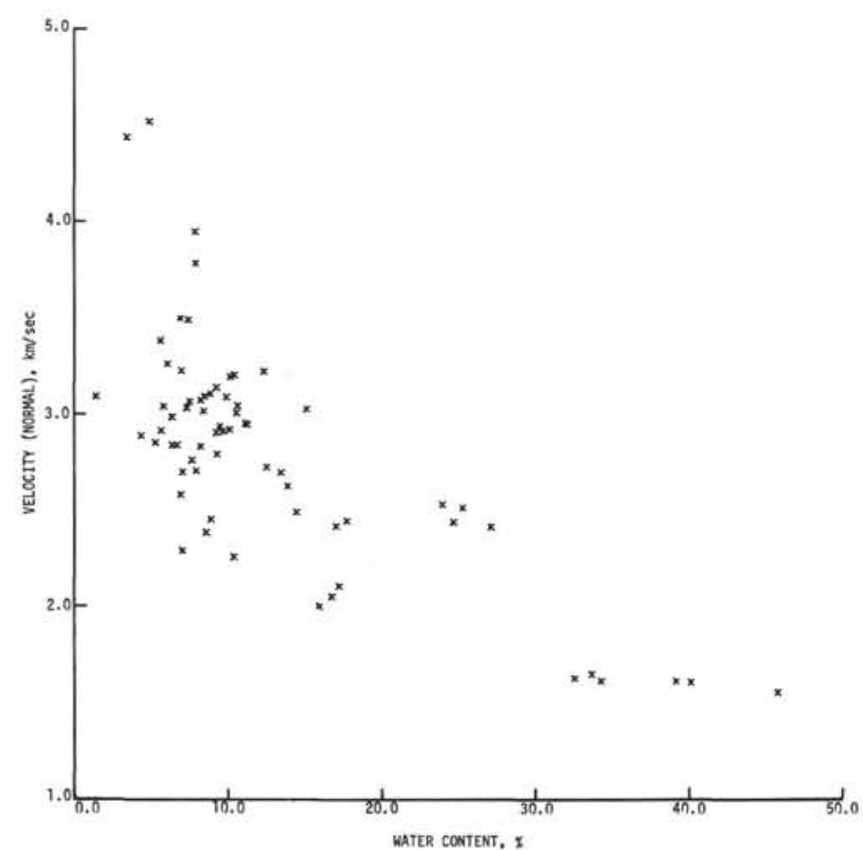

Figure 28. Velocity (normal) versus wet-water content for Site 316. The questioned water content values listed in Table 3 have been deleted.

anisotropies of typically 0 to $15 \%$ (see Figure 10 for a horizontal versus vertical velocity scatter diagram, and Figures 11 through 15 for an expanded velocity scale plotted versus depth showing anisotropy variations with depth and age). The anisotropy may have several causes, such as elongated grains being aligned with the bedding, with fewer spaces between the grains compared to the vertical direction, thus creating a faster sound path parallel to bedding or foliation. In addition, Christensen (1965) and Brace (1965) indicate that anisotropy exists in igneous and metamorphic rocks, and here is in part related in certain minerals which are anisotropic and, in

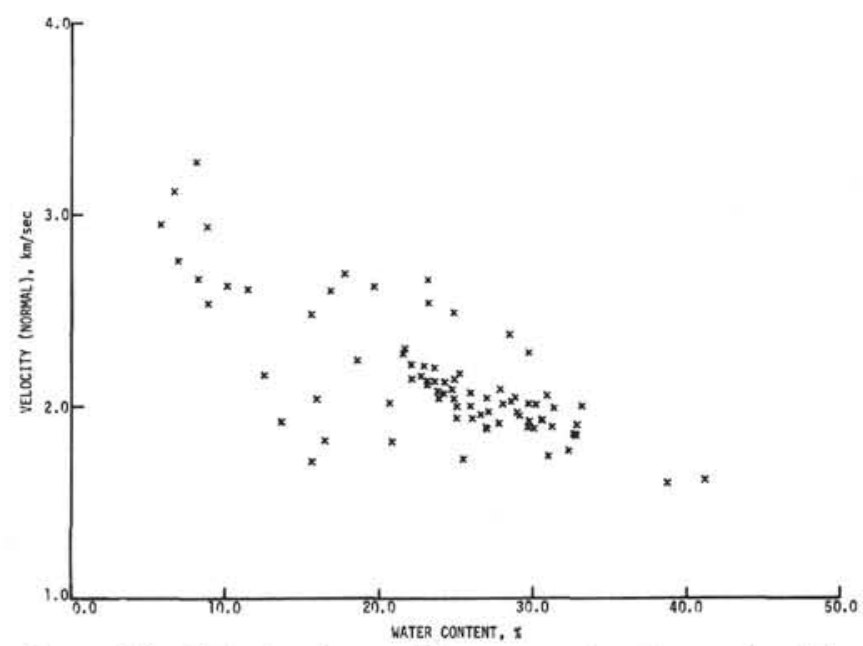

Figure 29. Velocity (normal) versus wet-water content for Site 317. The questioned water content values listed in Table 3 have been deleted.

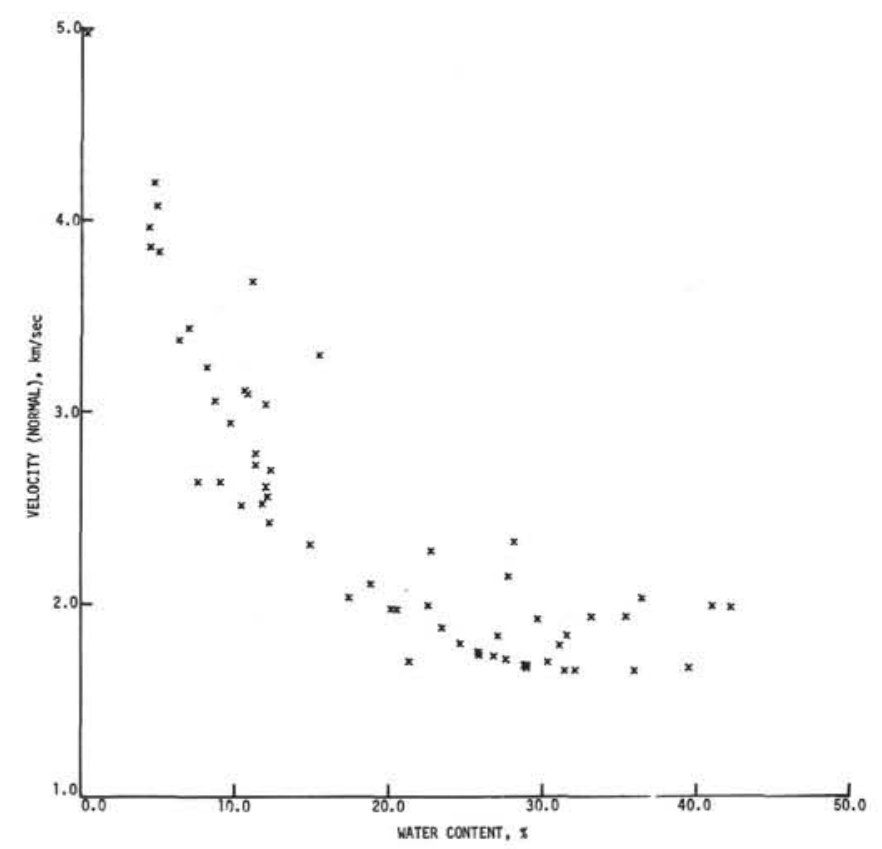

Figure 30. Velocity (normal) versus wet-water content for Site 318.

addition, they align themselves with the bedding or foliation planes. This mineral anisotropy can also contribute to the sedimentary anisotropy. In addition, the sedimentary rocks may have alternating soft and hard layers, plus layers caused by cementation or horizontal cracking. Thus the hard layers will tend to propagate sound faster horizontally than in a vertical direction.

There are a few instances where the anisotropy is negative. These may be areas which have nodules, burrows, or material of contrasting velocity. Some of these cannot be precluded from being errors.

Anisotropy is important when interpreting reflection data, wide-angle reflection or refraction data. On Leg 15 at Sites 146-149 there was a good correlation between the ties data because of sparse coring and sampling with depth at the drill sites. 


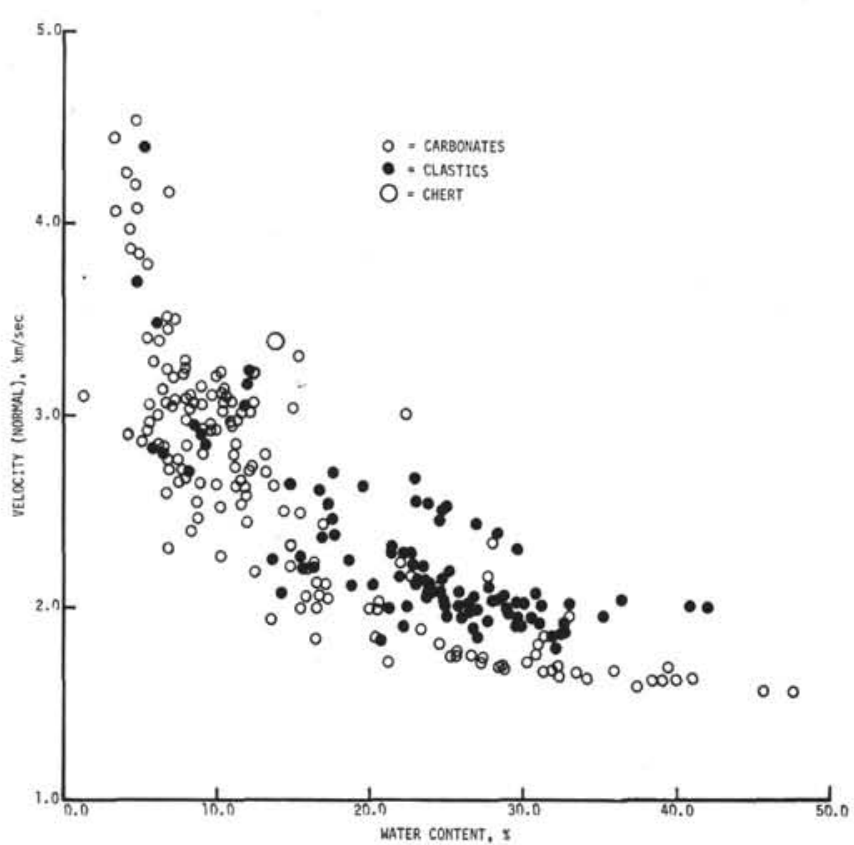

Figure 31. Velocity (normal) versus wet-water content for all sites. The questioned water content values listed in Table 3 have been deleted.

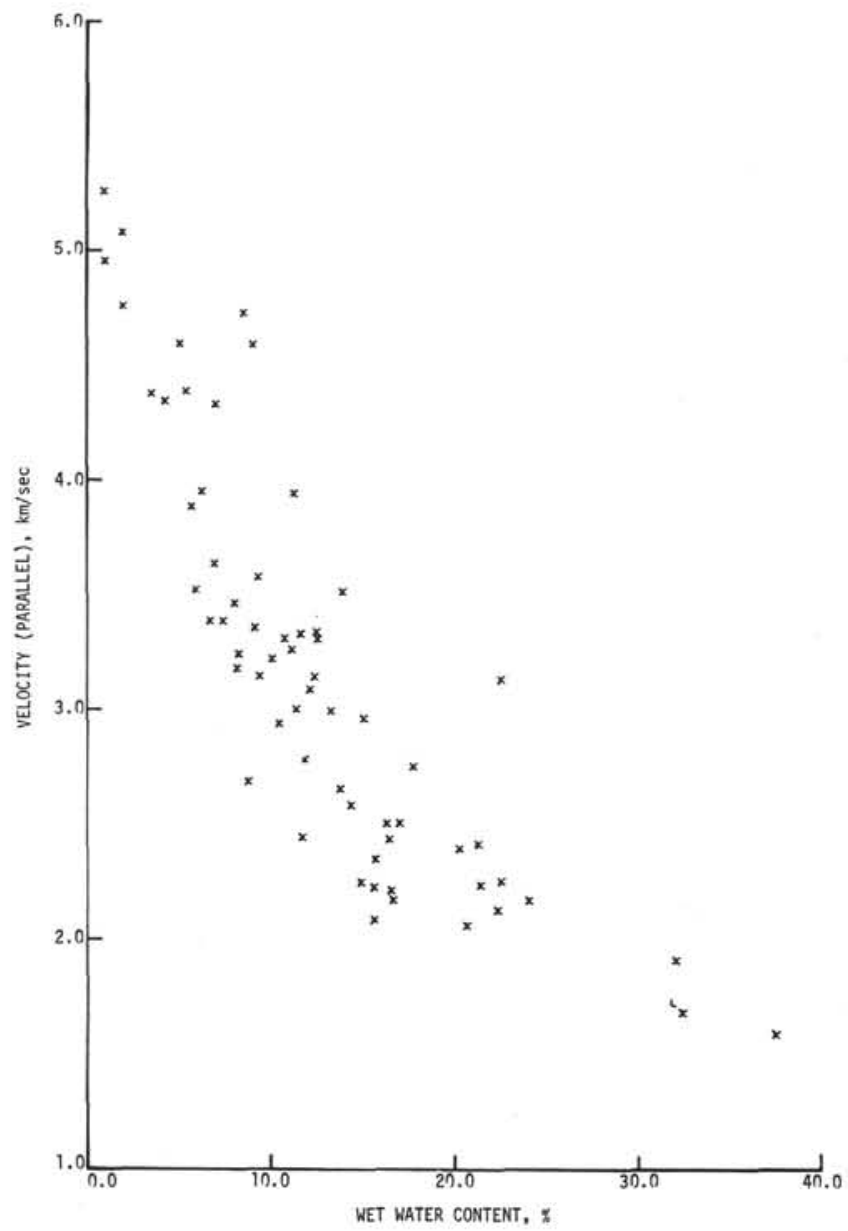

Figure 32. Velocity (parallel) versus wet-water content for Site 315. The questioned water content values listed in Table 3 have been deleted.

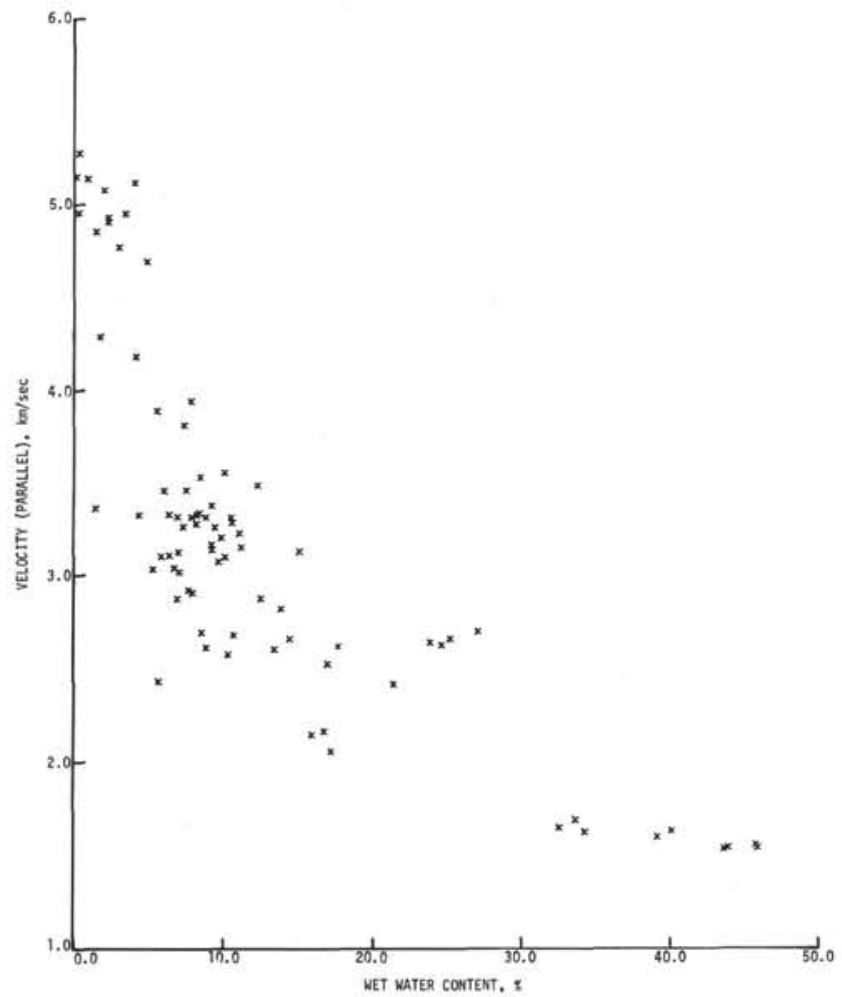

Figure 33. Velocity (parallel) versus wet-water content for Site 316. The questioned water content values listed in Table 3 have been deleted.

reflection profile velocity and the velocity from the laboratory. The reason the hard rock correlation was good, without pressure-temperature corrections, was that horizontal velocities were measured in the laboratory data, which were $5 \%-15 \%$ faster than the vertical velocity. This anisotropy was an approximate compensation (for these depths at Site 146/149) for the temperature-pressure corrections that would be necessary to correct the vertical laboratory velocities to in situ conditions.

\section{SEISMIC PROFILE CORRELATIONS}

Correlation of the stratigraphy to the seismic profile (Figures 2 through 5) is very subjective. To help resolve the subjectivity of these correlations two independent methods are used: (1) sonobuoy data and (2) by measuring the vertical sound velocity of cored samples. The seismic correlations are still subjective even though sonobuoy data are taken; therefore, the laboratorymeasured velocities are very important. But before the laboratory velocities can be used to calculate interval velocities, they must be corrected to in situ pressures and temperatures. Hamilton (1965), studying in situ velocity corrections for Mohole samples, states the following effects must be corrected for (1) temperature, (2) hydrostatic pressure, (3) porosity decrease with overburden pressure, and (4) increased rigidity due to overburden pressure. However, it is not simple and straightforward. Although a moderate number of studies have been done on end members of the rock types found, mainly the soft sediments and very hard rocks, only a 


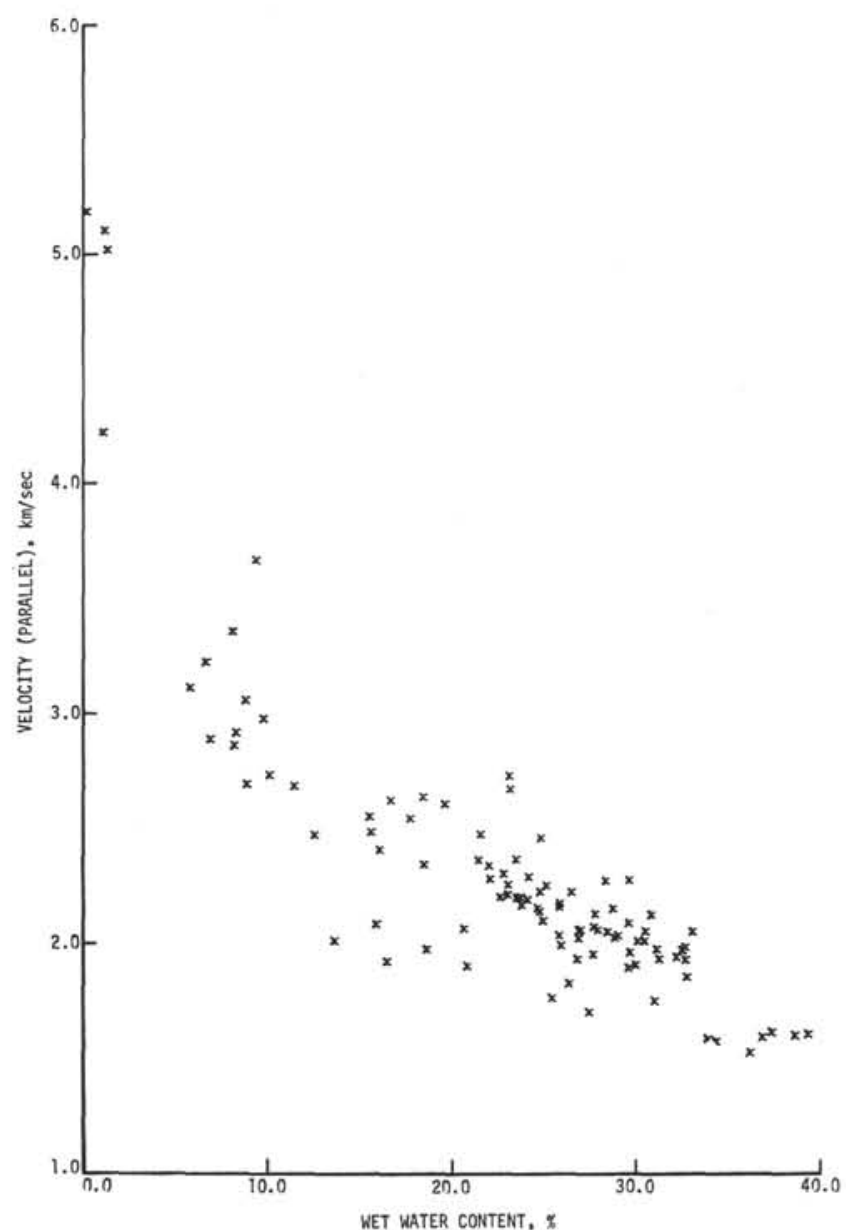

Figure 34. Velocity (parallel) versus wet-water content for Site 317. The questioned water content values listed in Table 3 have been deleted.

sparse amount of information is available for semilithified rocks with various porosities. The present interpretation of the vertical laboratory velocity and densityporosity data, the sonobuoy data, and the seismic profile and drill depth data, hopefully will give some indication as to the (1) quantitative nature of the in situ corrections necessary to apply to laboratory-measured interval velocities for a given stratigraphic interval of ooze, chalk, limestone, or volcaniclastics recovered on Leg $33,(2)$ how to determine and apply those corrections, and (3) what future systematic research is needed. These in situ corrections are important not only to interpret the drill site data, but are also necessary to correct laboratory velocities to in situ velocities when extrapolating the data away from the drill sites where there are different hydrostatic pressures, overburden pressures, and temperatures.

The following brief discussion of the different possible stratigraphic-seismic profile correlations will emphasize the Leg 33 problems and the need of seismicstratigraphic correlations using the proper in situ corrected sample velocities to help resolve these problems.

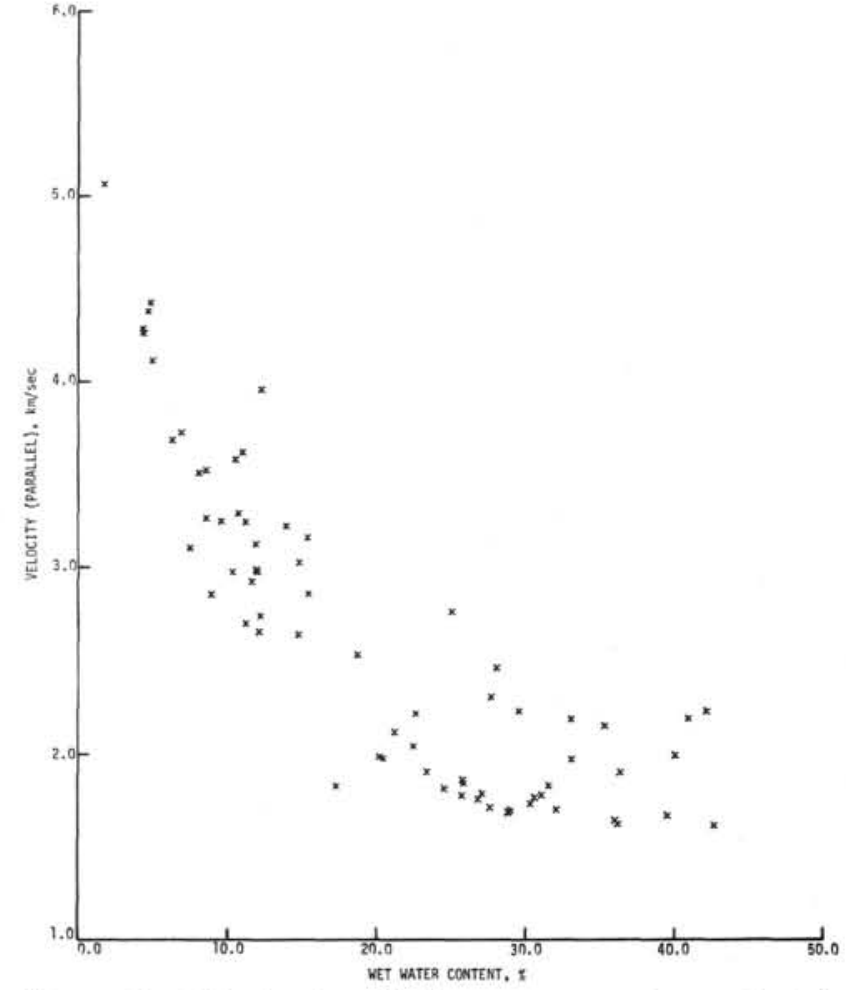

Figure 35. Velocity (parallel) versus wet-water content for Site 318

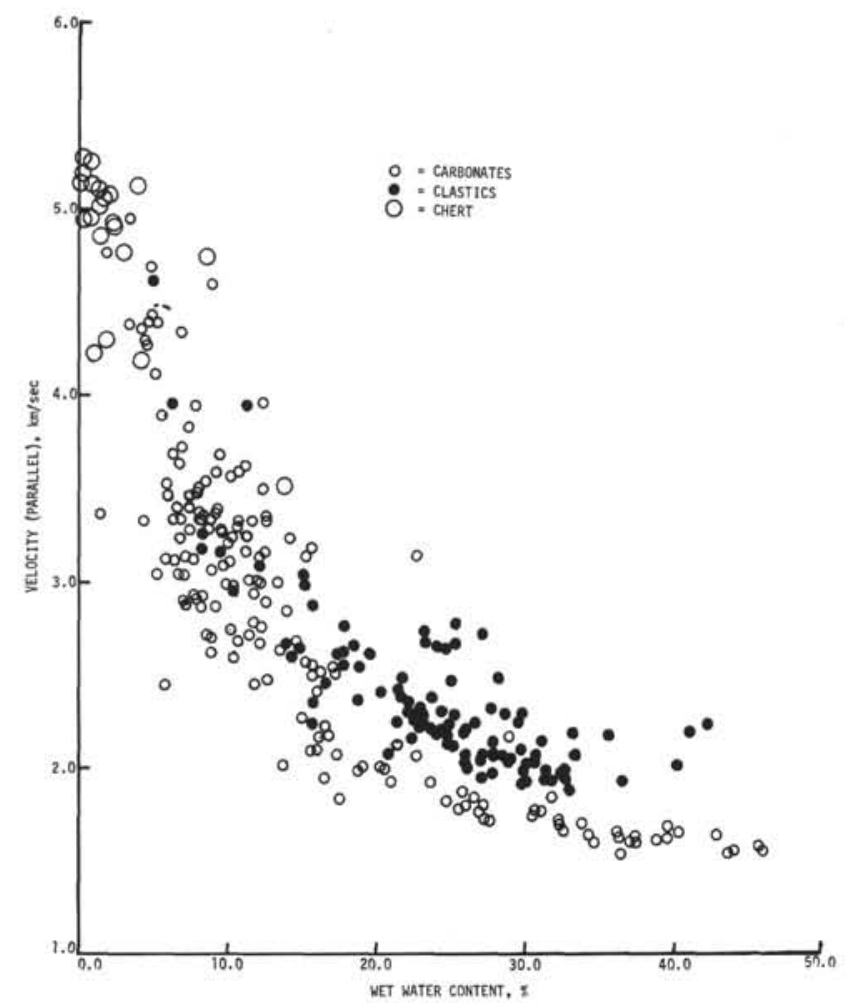

Figure 36. Velocity (parallel) versus wet-water content for all sites. The questioned water content values listed in Table 3 have been deleted. 


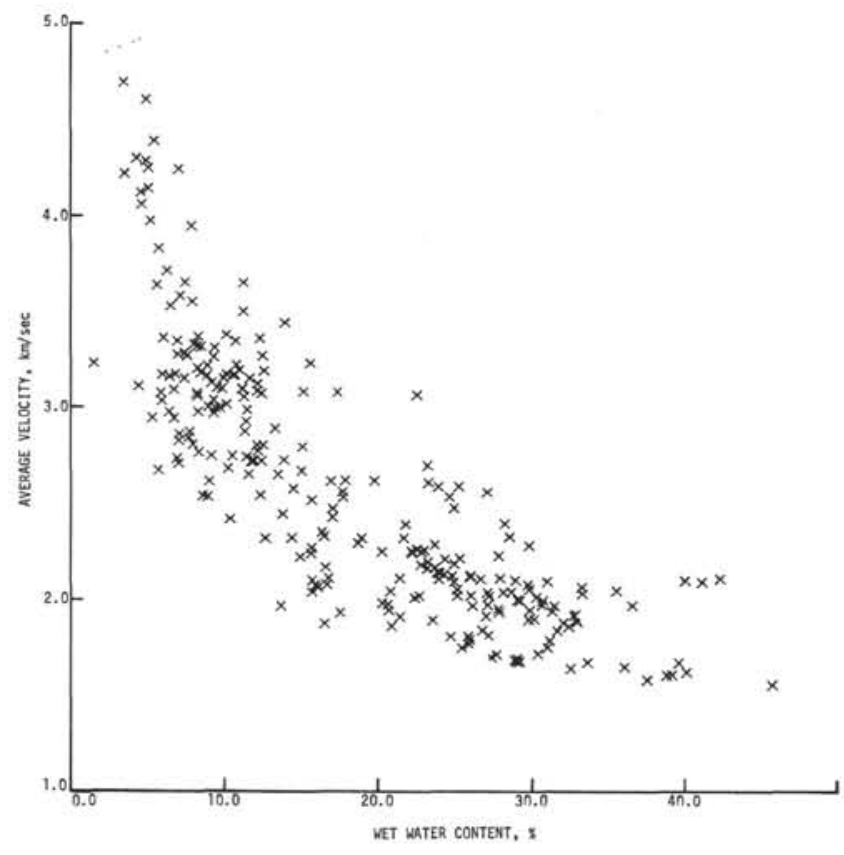

Figure 37. Average of vertical and horizontal velocity versus wet water content for all sites. The questioned water content values listed in Table 3 have been deleted.

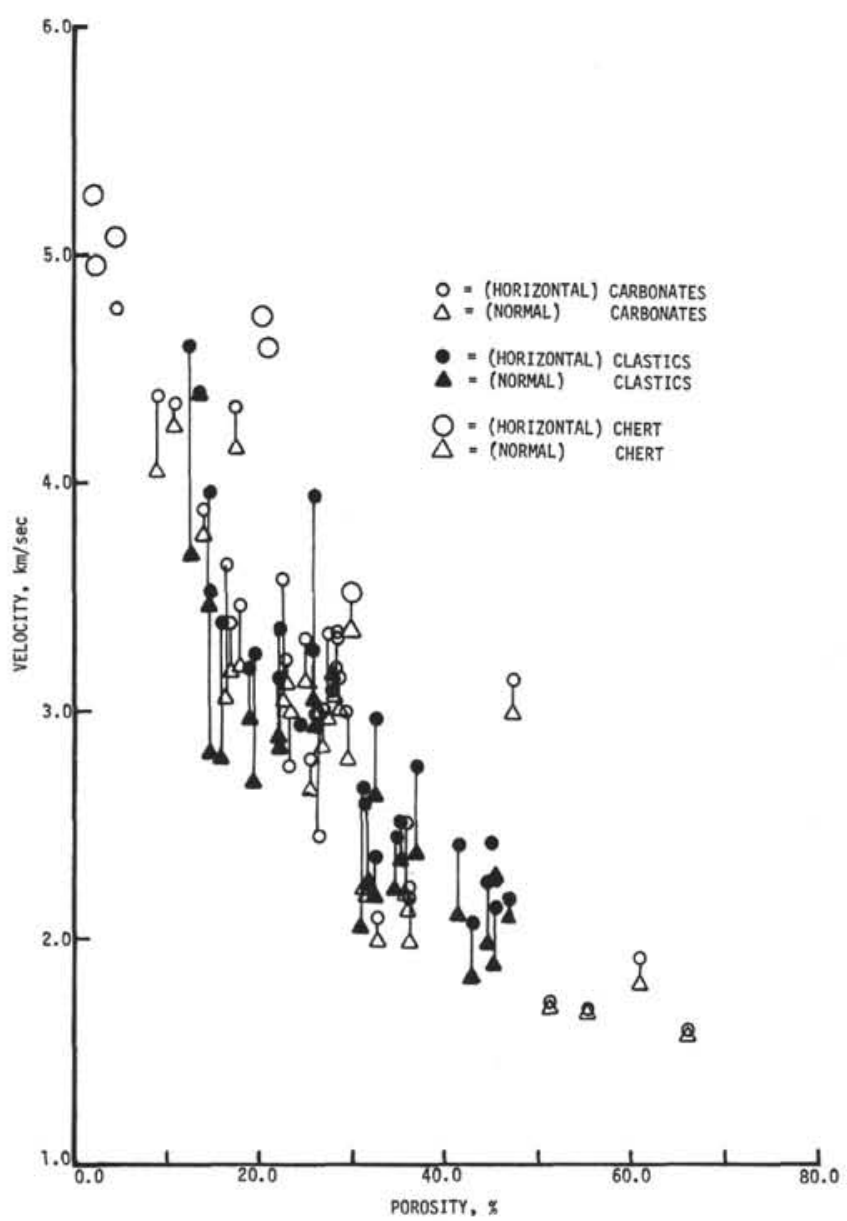

Figure 38. Velocity (normal and parallel) versus porosity for Site 315. Questionable porosity values listed in Table 3 have been deleted.

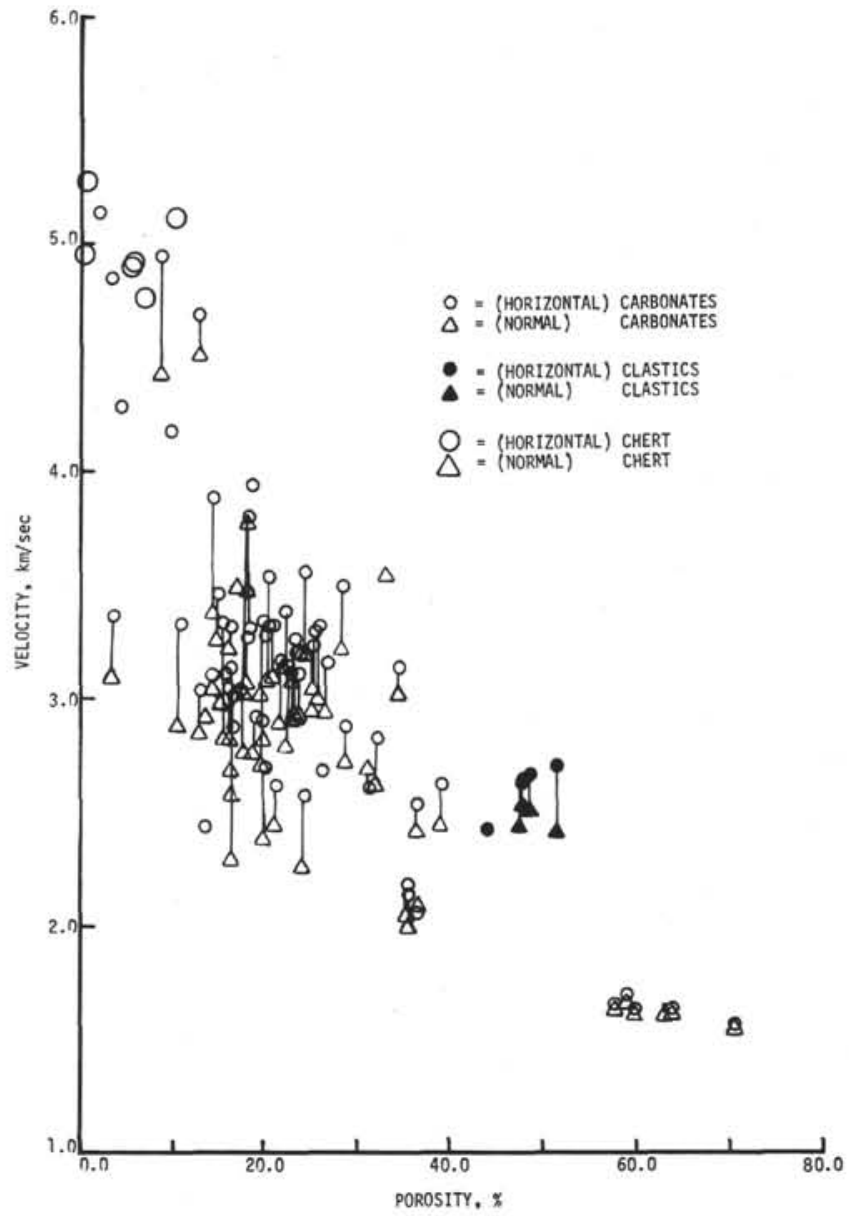

Figure 39. Velocity (normal and parallel) versus porosity for Site 316. Questionable porosity values listed in Table 3 have been deleted.

\section{Preliminary Possible Seismic Profile Correlations}

1) In general, if the sonobuoy correlations (from site chapters in this volume) are correct then average corrections are indicated for the interval laboratory data of $4 \%, 4 \%$, and $12 \%$ for the Cenozoic chalk at Sites 315 , 316 , and 317, respectively (see Figures 2 through 5 for sonobuoy and unadjusted laboratory velocity correlations to seismic profiles). This would allow corrections for the lower limestone volcanic sequence of about $13 \%$ as indicated in the Site 317 interpretation.

2) It is interesting to note that at Sites 315,316 , and 317 , if the major reflectors of $0.7,0.475$, and $0.6 \mathrm{sec}$, respectively, at each site, were correlated to where a major change occurs in the physical properties at 712,458 , and 580 meters at the bottom of the chalk interval, respectively, that the average velocity from the sea floor to the theoretical reflector horizons are 2.0, 1.94, and 1.9 $\mathrm{km} / \mathrm{sec}$, respectively, for the chalk. These velocities are in agreement with the refraction velocities summarized in Nafe and Drake (1963, in fig. 7 and 8). If the strong central reflectors are at the bottom of the chalk intervals, then the upper chalk laboratory velocities need average corrections of about $25 \%, 22 \%$, and $12 \%$, respectively, at Sites 315, 316, and 317. However, we cannot be certain of these correlations using the physical proper- 


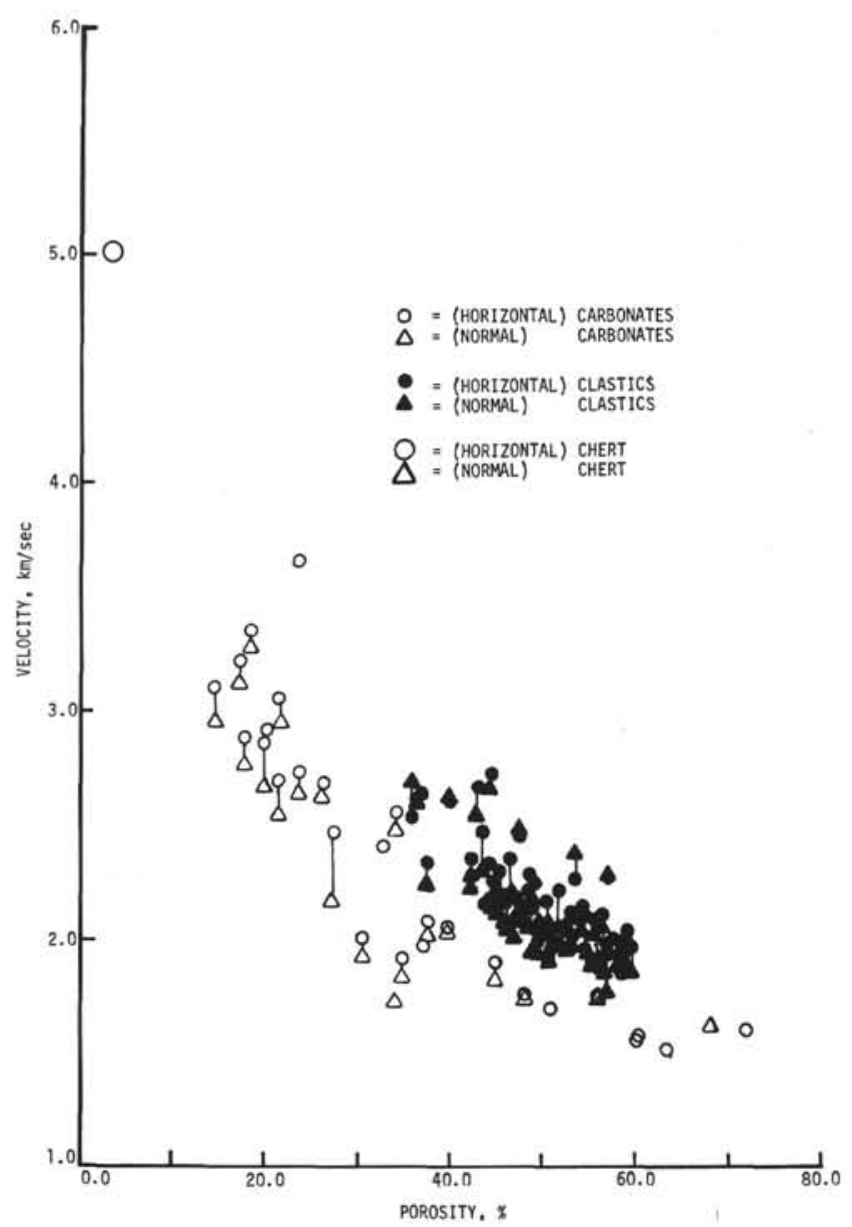

Figure 40. Velocity (normal and parallel) versus porosity for Site 317. Questionable porosity values listed in Table 3 have been deleted.

ties data because of sparse coring and sampling with depth at the drill sites.

3) It is interesting to note that at Sites 315 and 317, if the lowest reflector were assumed to be the basalt, then the average percentage increase necessary to apply to the overall average interval laboratory velocities for pressure-temperature corrections would be $15 \%$ at both sites. With the present unadjusted laboratory velocity data, it is not possible to be certain the lowest reflectors actually correlate with the basalt recovered at those sites. It seems unusual that the lowest reflector, if basalt, is so parallel to the sedimentary rocks. It might be expected to provide a more irregular surface. If these lowest reflectors are sedimentary rock, then the unadjusted laboratory values are fairly good.

4) The Schlanger and Douglas (1974) suggestion that the upper reflectors are related to the unconformities in the Cenozoic section cannot be proved or disproved with the sparse physical property data in these areas.

In a general summary of the seismic profile data, the sonobuoy correlations are probably the best estimate, as these correlations are based on all data available; however, it is apparent that seismic profile correlations can be very subjective. What is needed to help redefine or verify the sonobuoy correlations are some estimates

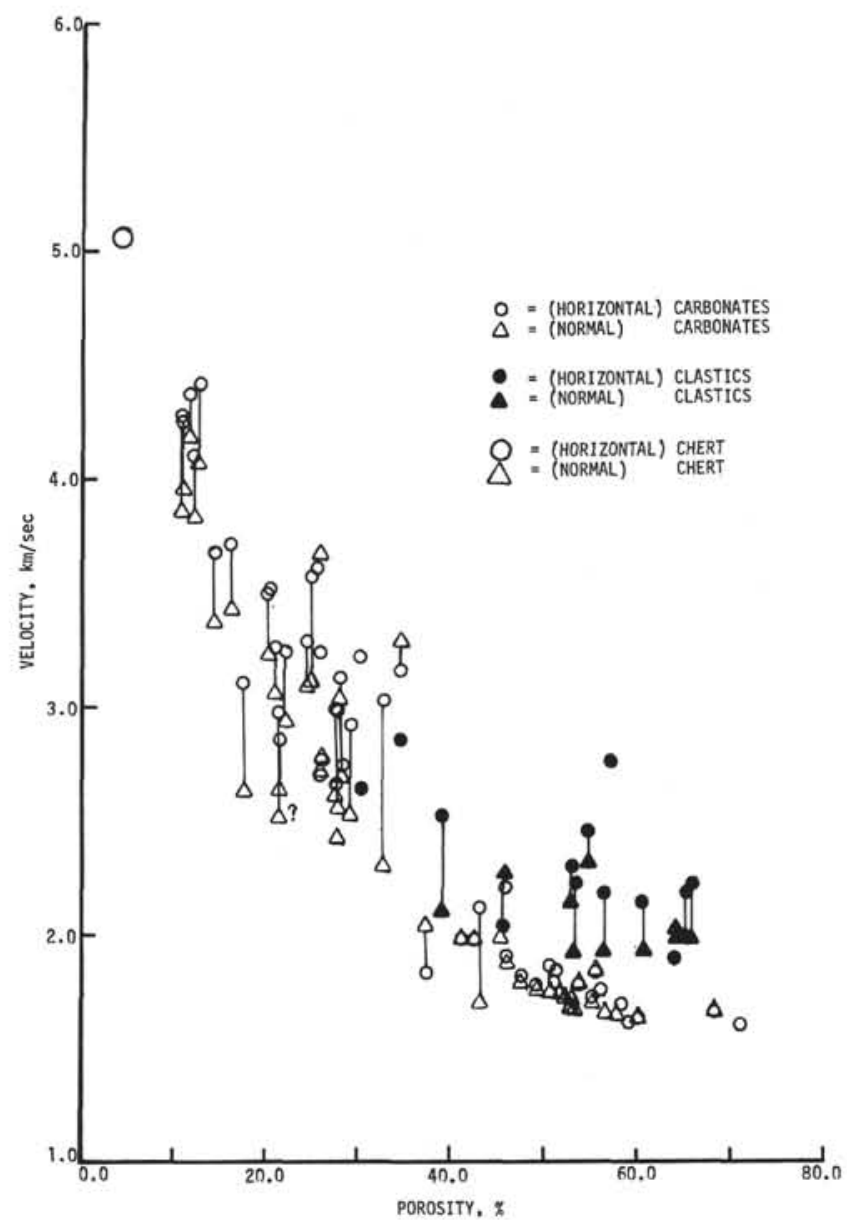

Figure 41. Velocity (normal and parallel) versus porosity for Site 318.

of the in situ interval velocities, which can be obtained by studying and applying the adjustments necessary to apply to the laboratory velocities in order to correct them to in situ velocities. This will provide another independent correlation of the Leg 33 stratigraphy to the seismic profiles.

\section{Seismic-Stratigraphic Correlation With Adjusted Laboratory Velocities}

An attempt will be made here to correlate the seismic profile to the stratigraphic column, using the laboratory-measured sound velocities. These correlations cannot be very accurate because of the sparsity of samples in parts of the section, plus the lack of the appropriate data to carefully correct laboratory (1 atmosphere pressure and room temperatures) sound velocity to in situ velocity for a large range of lithologies. Therefore, this study is not to be considered as a definitive correlation, but a study of what theoretical corrections are needed, and point out what research needs to be done before a definitive correlation, based on laboratory velocity samples, can be properly done.

During Leg 33, sound velocity was measured both parallel and perpendicular to the bedding of the samples at laboratory (1 atmosphere) pressure and temperatures. The vertical velocities will be used to correlate the 


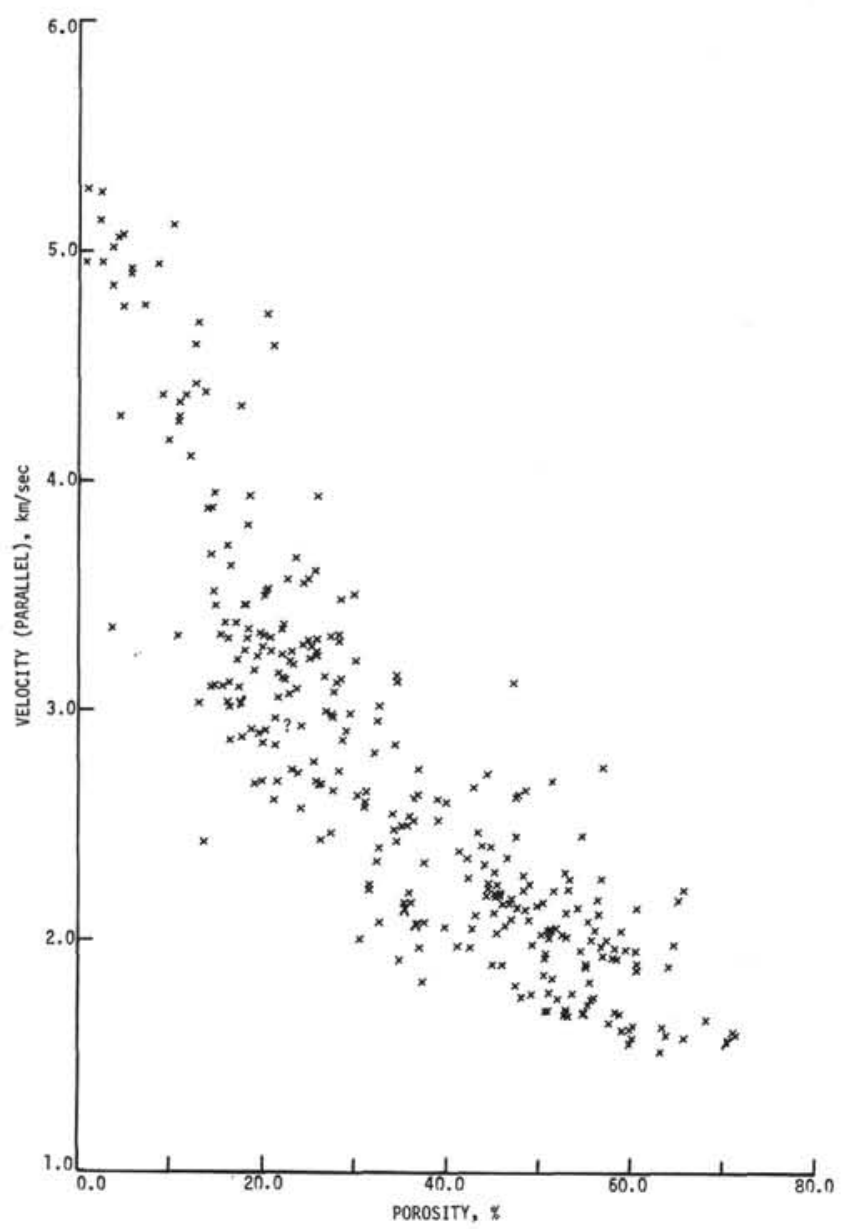

Figure 42. Velocity (parallel) versus porosity for all sites. Questionable porosity values listed in Table 3 have been deleted.

seismic profile to the stratigraphic column. Problems arise as we must first make an estimate of in situ temperatures and pressures, and then study how to apply any adjustments to the laboratory velocities in order to estimate in situ interval velocities.

These vertical velocities were measured on samples at laboratory pressures (1 atmosphere) and temperatures after $(4+\mathrm{hr})$ being removed from a deep drill hole; therefore, the velocities measured must be adjusted for the following (Hamilton, 1964): (1) porosity rebound as the overburden pressure (the accumulative weight of the mineral grains, in sea water, for the geologic section above any given sample) is released as the sample is removed from the hole to the laboratory; (2) a rigidity decrease in the grain to grain structures as the overburden pressure is released; (3) hydrostatic pressure (pore pressure); and (4) temperature effects on the interstitial water and solid grain portions of the sediment or rock samples.

According to Hamilton $(1964,1965)$, porosity rebound can be measured in consolidation tests by observing the porosity increase of a sample after the pressure is released (as an example, see the consolidation tests on the Mohole samples by Hamilton, 1964).

These soil mechanics consolidation tests by Hamilton (1964) were on essentially uncemented red clay. For clay

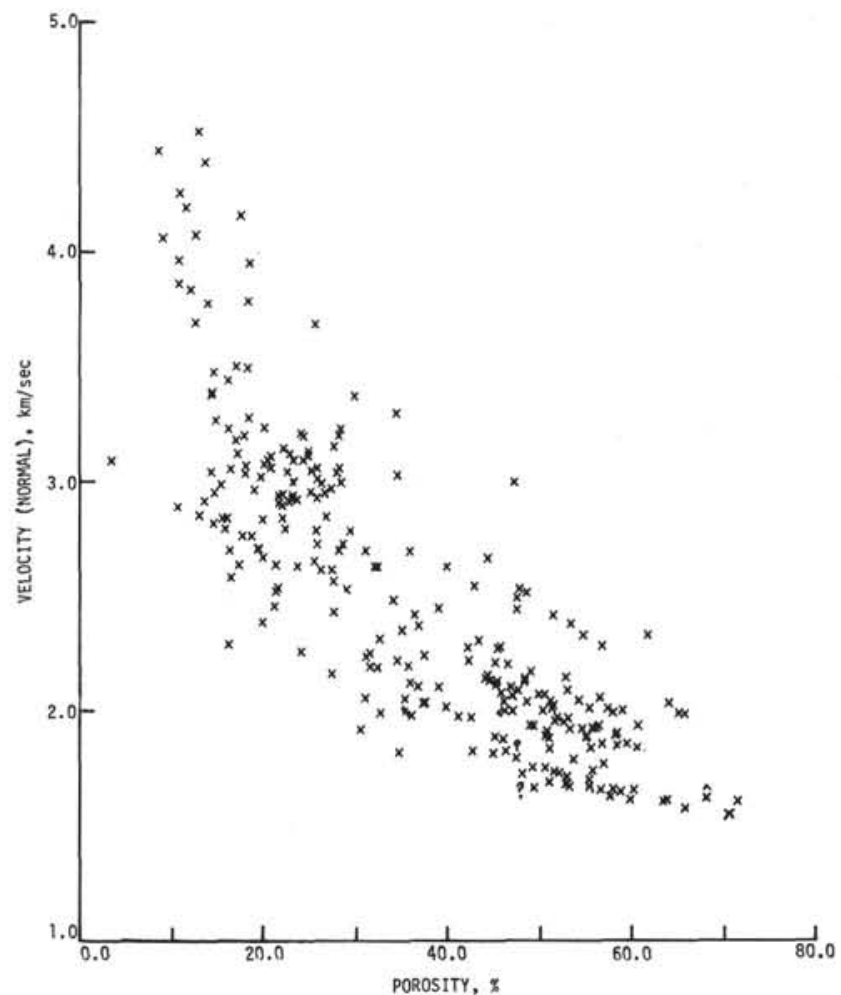

Figure 43. Velocity (normal) versus porosity for all sites. Questionable porosity values listed in Table 3 have been deleted.

samples with porosities between $45 \%$ and $60 \%$ and after a pressure of less than $100 \mathrm{~kg} / \mathrm{cm}^{2}$ had been applied and released, a typical porosity rebound of $5 \%$ (absolute) was observed. However, clays with porosities greater than $60 \%$ had smaller rebounds with a theoretical zero rebound for sediments on the sea-floor surface.

Trabant (1972) measured velocity and consolidation simultaneously, but did not report the velocity rebound after the pressures were released. Trabant's sediments were from Leg 10 of the Deep Sea Drilling Project in the Gulf of Mexico and were silty clay and silty sand. The velocity increase with pressure, compared to the 1 atmosphere laboratory velocity for these $(43 \%$ to $57 \%$ porosity) unlithified sediments, appears to be essentially the result of the porosity decrease and does not appear to have a significant grain-to-grain rigidity factor related to overburden pressure. The samples' porosity rebound after the pressures $\left(128 \mathrm{~kg} / \mathrm{cm}^{2}\right)$ were released were also about $5 \%$ to $6 \%$ (absolute).

Laughton (1957) simultaneously measured the consolidation and velocity of a foraminifer ooze ( $54 \%$ carbonate). This sample was consolidated until it reached $28 \%$ porosity from which it rebounded after the pressure was released $\left(1025 \mathrm{~kg} / \mathrm{cm}^{2}\right)$ to $33 \%$, which is also a $5 \%$ porosity rebound. His velocities, however, rebounded from 3.05 to $1.96 \mathrm{~km} / \mathrm{sec}$ mainly as a result of grain to grain rigidity, as the further compaction probably would not have been possible without mechanical destruction of mineral grains because of the low porosity.

An important point is that the samples of Laughton (1957), Hamilton (1964), and Trabant (1972) had significant amounts of clay, and were uncemented, while the 


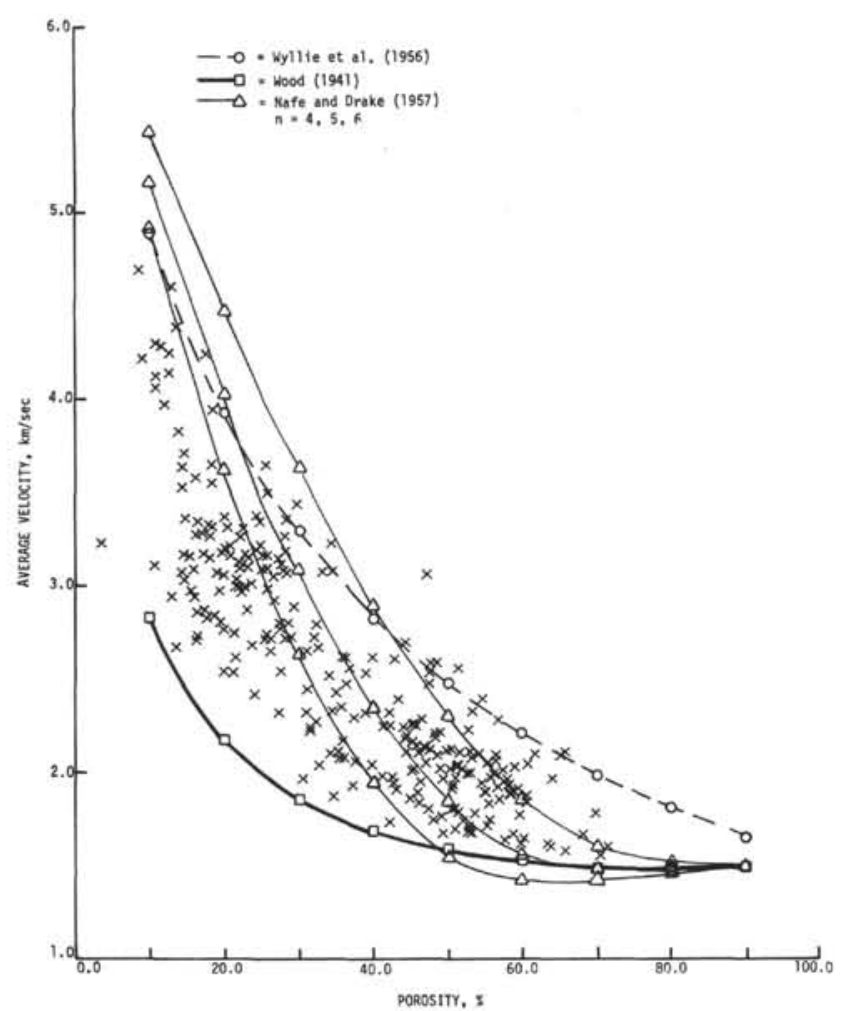

Figure 44. Average of the vertical and horizontal velocity for all sites versus porosity. This does not include data where only one velocity was measured. The Wood (1941) Equation \#7, Wyllie et al. (1956) Equation \#8, and Nafe and Drake (1957) Equation \#9, are drawn in using calcite $12.72 \mathrm{~g} / \mathrm{cc}, 6.45 \mathrm{~km} / \mathrm{sec}$ and sea water $(1.53 \mathrm{~km} / \mathrm{sec}$, $1.025 \mathrm{~g} / \mathrm{cc}$ ) as end member constituents. Questionable porosity data listed in Table 3 have been deleted.

Leg 33 data have some samples without significant amounts of clay and in addition all the samples have various degrees of cementation. Therefore, the porosity rebound upon release of pressure may or may not be precisely applicable to Leg 33 samples.

For the Leg 33 data a $5 \%$ porosity rebound on removal of the uncemented sample from the hole to the laboratory is probably closer to reality than not; therefore, as a very rough estimate, a porosity rebound of $5 \%$ will be used for sediment between $30 \%$ and $60 \%$ porosity, and for lithologies with porosities between $20 \%$ and $30 \%$ only a $2.5 \%$ porosity rebound will be assumed, and below $20 \%$ porosity rebound will be considered very small. Of course, near the sediment surface the overburden rebound becomes smaller until it is zero at the sea floor, but fortunately, velocity variations with porosity in these high porosity sediments are also very small (Hamilton, 1959; Nafe and Drake, 1963; Sutton et al., 1957; Shumway, 1960); therefore, it is not a major problem for Leg 33 data (Figure 44).

Future research should test porosity and velocity rebound characteristics of different types of sediments and rocks and with different degrees of cementation and porosity so that proper corrections can be applied to 1 atmosphere pressure velocity measurements. These measurements should allow some evaluation of the rigidity caused by the overburden pressure on the grain to grain contacts.

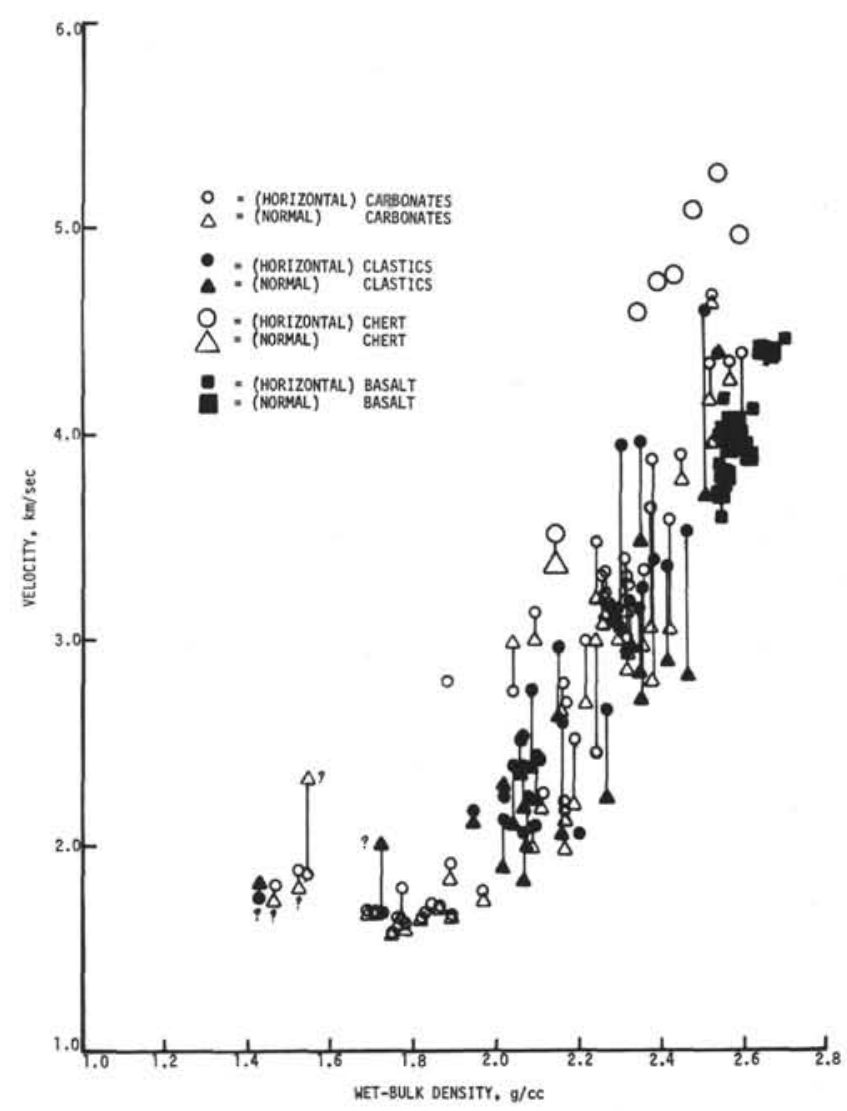

Figure 45. Velocity (normal and parallel) versus wet-bulk density for Site 315.

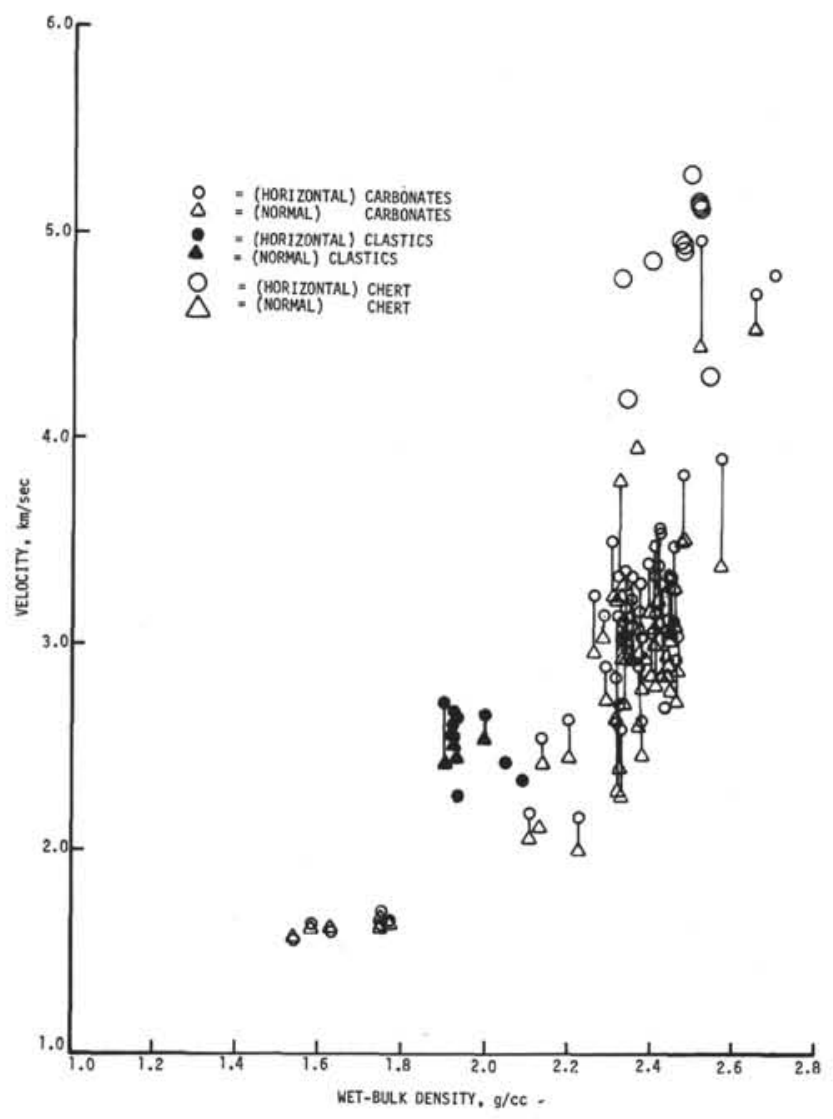

Figure 46. Velocity (normal and parallel) versus wet-bulk density for Site 316. 


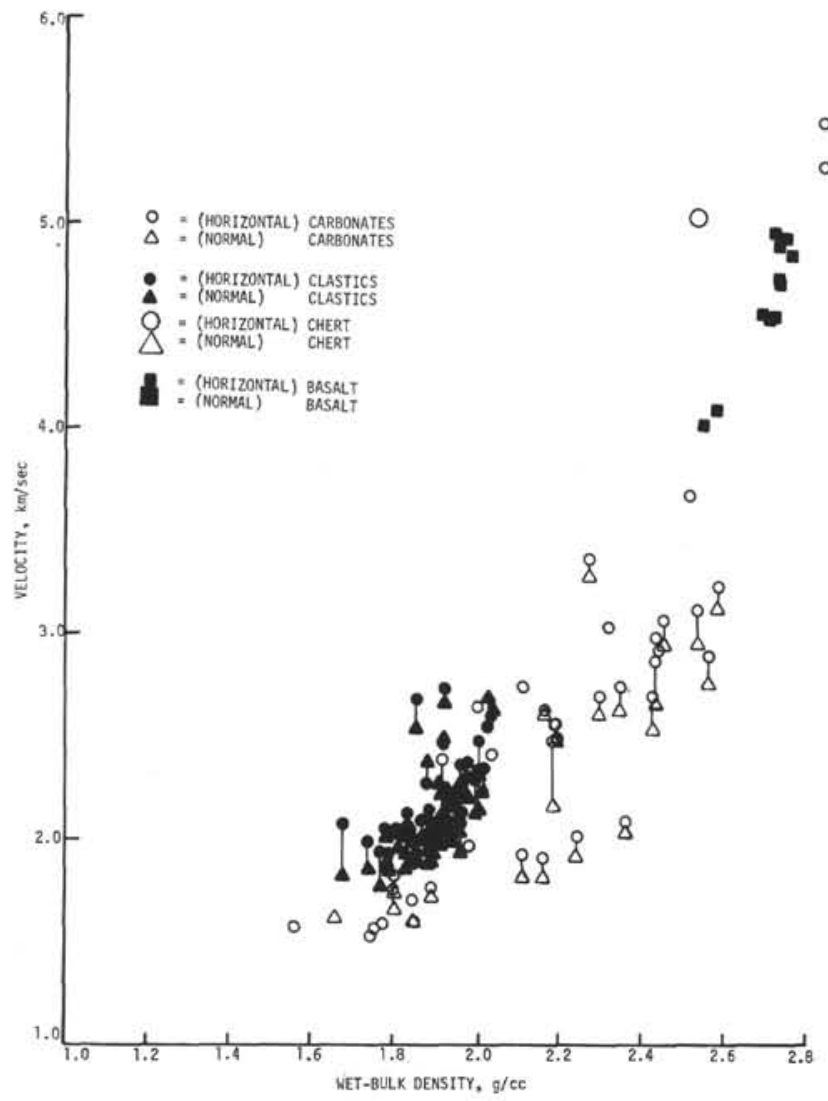

Figure 47. Velocity (normal and parallel) versus wet-bulk density for Site 317.

Hamilton (1965) suggests that with uncemented high porosity sediments the overburden pressure primarily consolidates the sample with the rigidity effect on the grain structure probably being very small. However, these rigidity effects should increase with samples that are more consolidated or cemented.

Laughton's (1957) data show that a foraminifer ooze that has been consolidated to $28 \%$ porosity is very sensitive to overburden pressure. This sample was consolidated to $28 \%$ porosity with $1024 \mathrm{~kg} / \mathrm{cm}^{2}$ overburden pressure, and when the pressure was released the sample's velocity changed from 3.05 to $1.96 \mathrm{~km} / \mathrm{sec}$ with only a $5 \%$ porosity rebound; thus, most of this change represents rigidity of the grain structure. Laughton's sample was compressed as far as consolidation without grain deformation (?) and destruction can go; therefore, relatively large velocity decreases probably can be expected around $30 \%$ porosity in uncemented samples, or when porosity consolidation becomes difficult. In addition, rigidity may also have various degrees of significance in the 60 to $20($ ?)\% porosity range in semicemented to cemented samples. Another possibility is that the high velocity rebound could be characteristic of the foraminiferal sediments as the "spherical" tests which could provide more elasticity when they are compressed (assuming that the Globigerina tests had not already been crushed); however, this is not probable.

Increased rigidity caused by the overburden pressure on the grain structure for semicemented or cemented

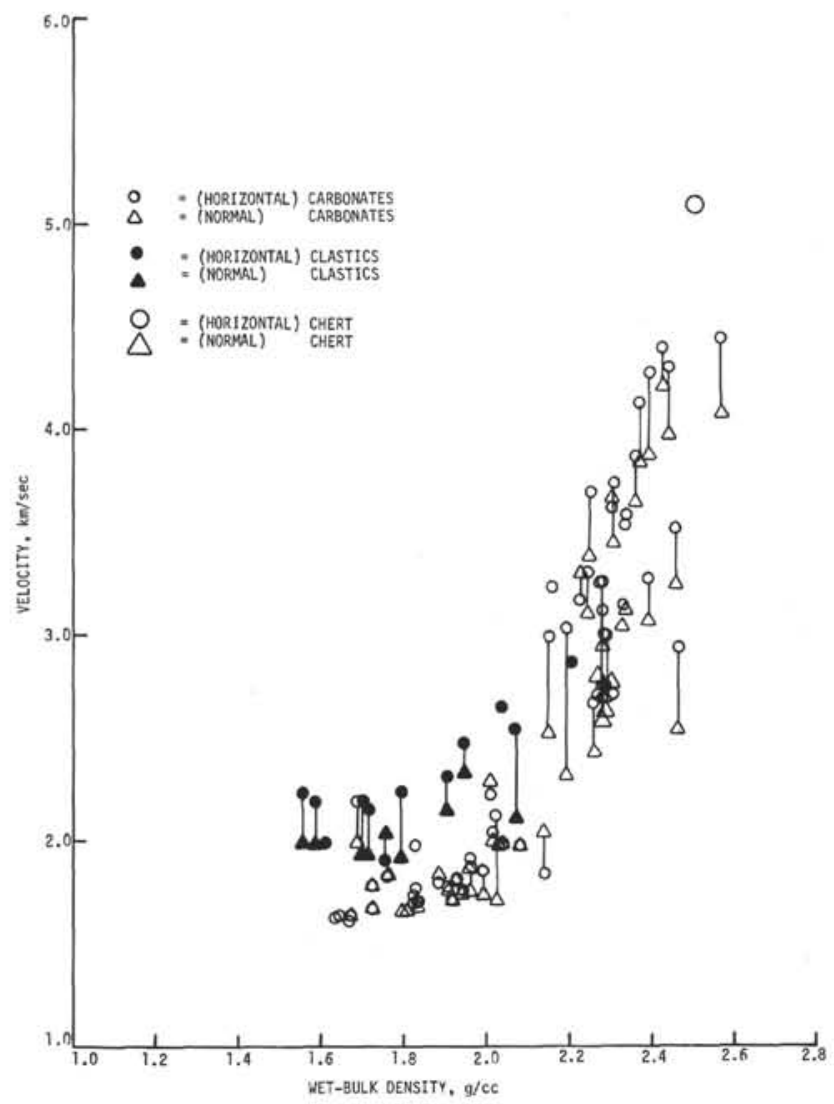

Figure 48. Velocity (normal and parallel) versus wet-bulk density for Site 318.

sediments and rocks, with highly variable porosity, cannot be presently compensated for Leg 33 data as there is too little systematic knowledge on velocity variations when various consolidation pressures are released for different sediment types, degrees of cementation, and various porosities. Therefore, Leg 33 laboratory velocity corrections will not include a rigidity factor due to the release of the overburden pressure; thus, these final corrections will be minimal.

The next set of corrections are for the in situ hydrostatic pressures (pore pressure) and temperatures. Sea-floor temperatures were assumed to be $1.5^{\circ}$ and $2.0^{\circ} \mathrm{C}$ depending on the depth at the drill sites (Hamilton, 1971b). Temperature variations below the sea floor were assumed, for simplicity, to be a linear gradient of $50^{\circ} \mathrm{C} / \mathrm{km}$ below the sea floor, as precise heat flow measurements are not available at this area. In the calculations of the hydrostatic pressure another simplification was used in regard to the density of sea water. Sea-water densities vary from $1.025 \mathrm{~g} / \mathrm{cc}$ to $1.05(?) \mathrm{g} / \mathrm{cc}$; therefore, as a simplification, a single sea-water density of $1.035 \mathrm{~g} / \mathrm{cc}$ was used for pore pressure calculations $\left(\mathrm{kg} / \mathrm{cm}^{2}\right)$ :

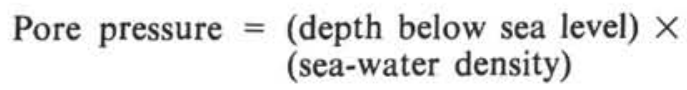

Temperature and hydrostatic pressure affects the interstitial water and solid grain portions of the sediment 


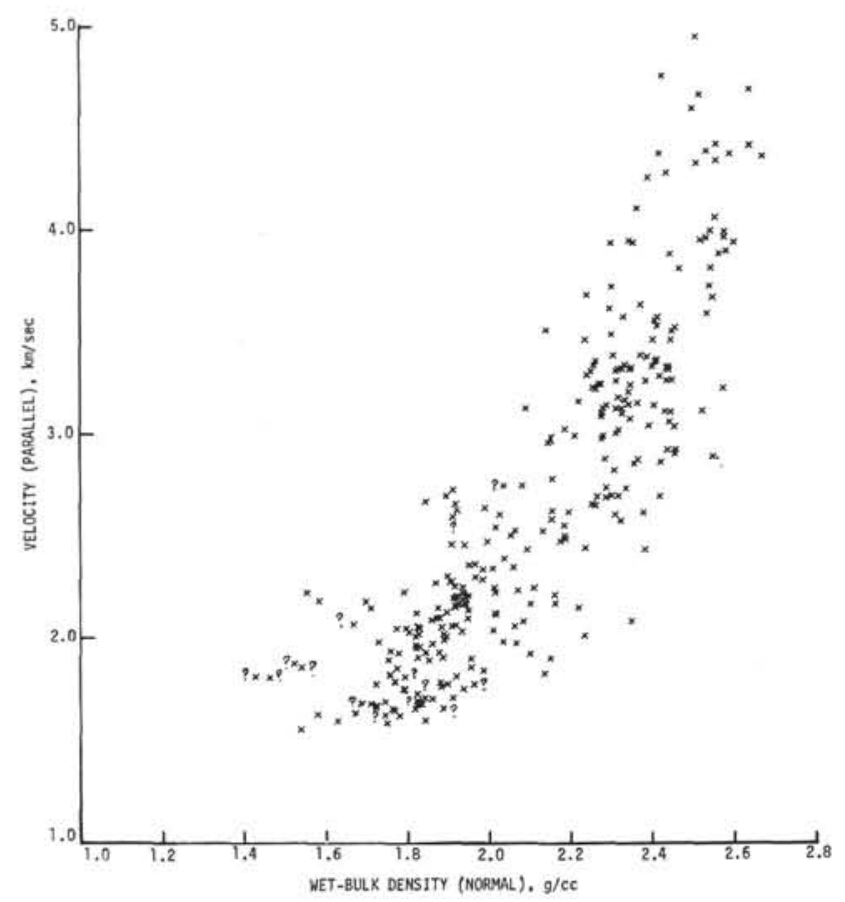

Figure 49. Velocity (parallel) versus wet-bulk density for all sites.

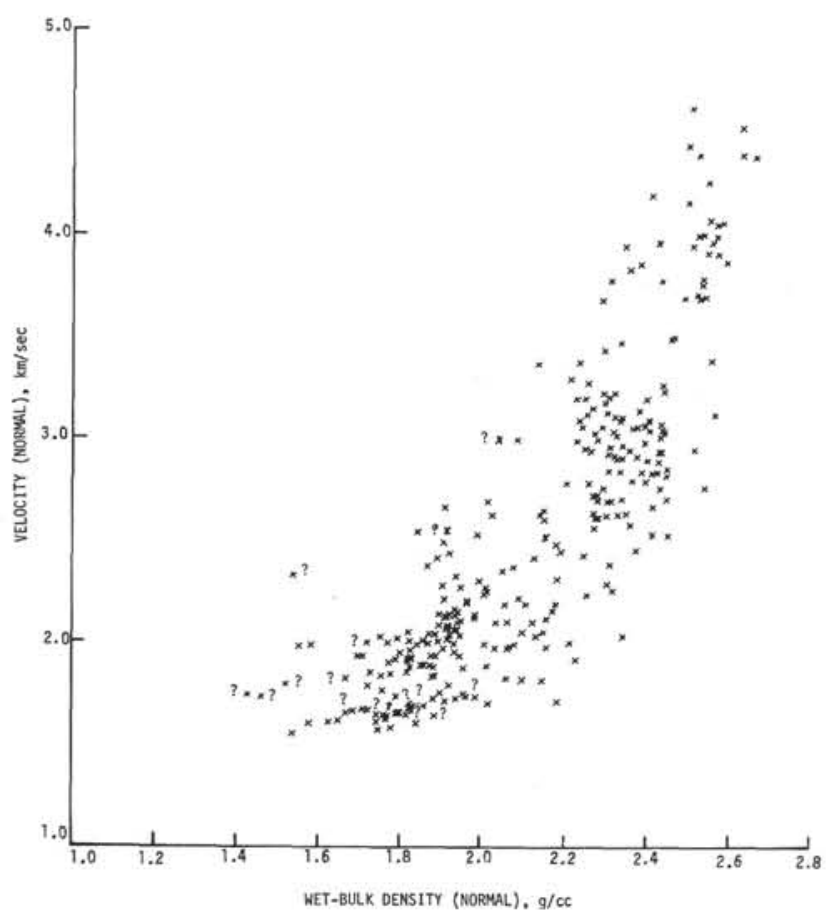

Figure 50. Velocity (normal) versus wet-bulk density for all sites.

or rock differently. Sea-water velocity increases with both increasing pressure and temperature, while the solid mineral grain velocity increases with increasing pressure and decreases with increasing temperatures (Hughes and Cross, 1951; Press, 1966).

Since the wet-saturated sediment or rock has the combined velocity of the essentially a two-phase system-(1)

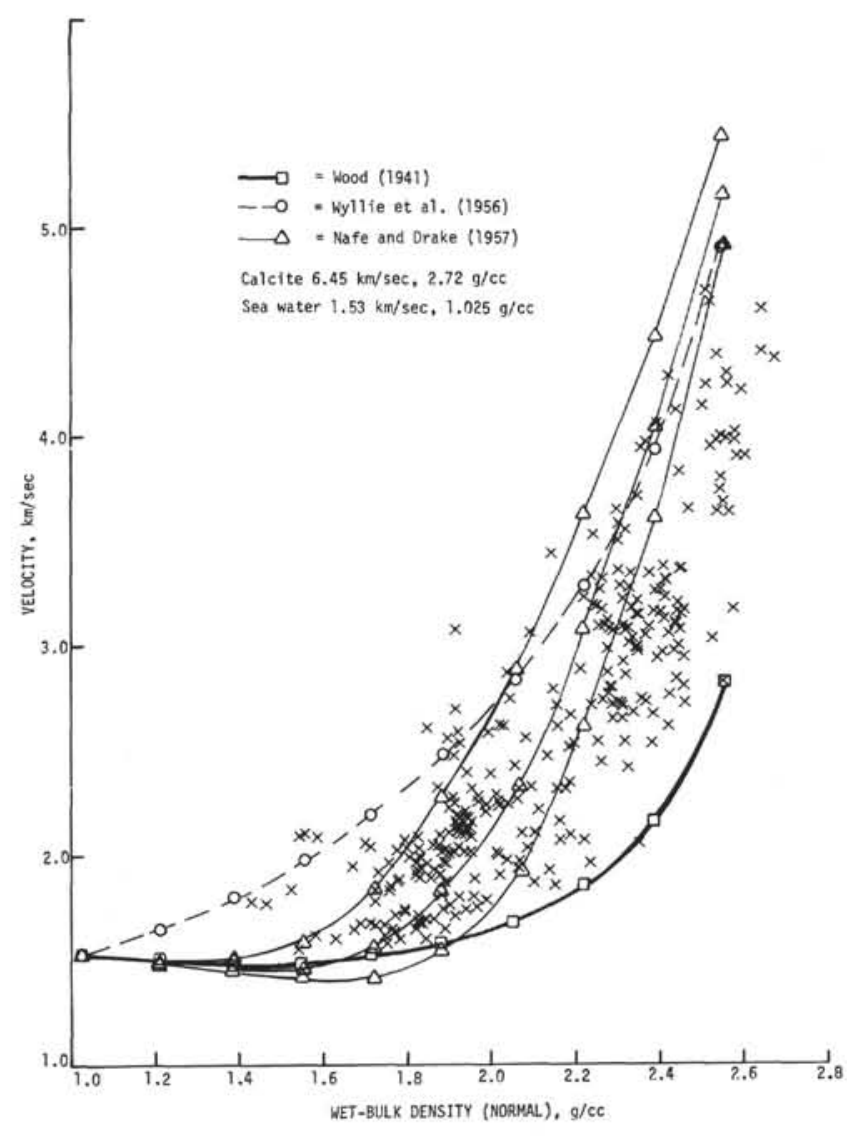

Figure 51. Average of the vertical and horizontal velocity from all sites versus vertical density. This does not include points where only one velocity was measured in where vertical density was not measured. The Wood (1941) Equation \#7, Wyllie et al. (1956) Equation \#8, and Nafe and Drake (1957 Equation \#9 for $n=4,5,6$, and for calcite sea water mixtures (calcite $=2.72 \mathrm{~g} / \mathrm{cc}, 6$. $6.45 \mathrm{~km} / \mathrm{sec}:$ sea water $=1.025 \mathrm{~g} / \mathrm{cc}, 1.53 \mathrm{~km} / \mathrm{sec})$. These plots were reproduced on the density graph because the density values measured are probably more accurate than the porosity values measured.

a sea-water low velocity phase and (2) a solid grain high velocity phase-then the resulting in situ velocities are a function of the in situ velocities of the two end-member phases. The low velocity sea-water variations with hydrostatic pressure and temperature are well documented (Table of Sound Speed in Sea Water, U.S. Naval Oceanographic Office, Special Publication 58; Press, 1966). Velocities of the high porosity sediments (with velocities near that of sea water) have been empirically shown to have a similar percentage velocity change as that of sea water with temperature and pressure variations (Laughton, 1957; Shumway, 1960). Wet and dry limestone, and sandstone (5\% porosity) velocity variations with temperature and pressure have been measured by Hughes and Cross (1951), which suggests that a pure mineral end member such as calcite may not have a velocity variance of more than $1 \%$ for the hydrostatic pressure and temperature estimated at Leg 33 sites. 


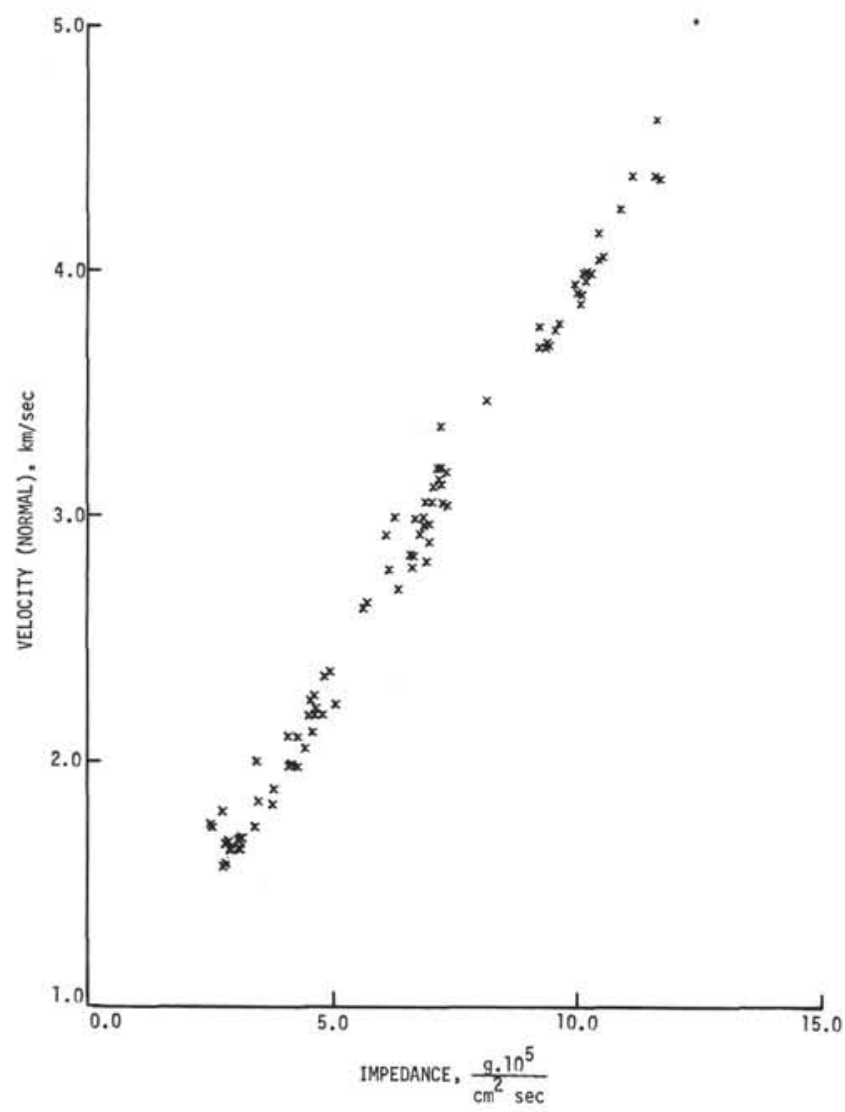

Figure 52. Velocity (normal) versus impedance at Site 315.

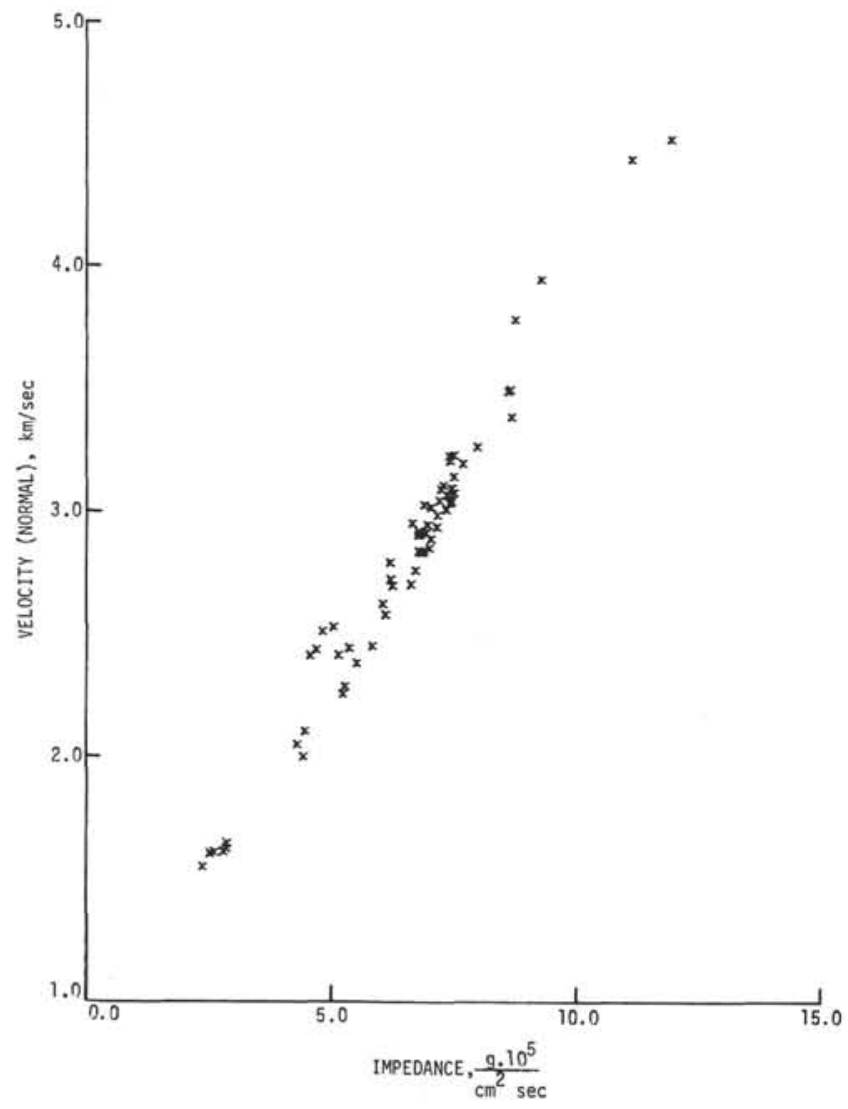

Figure 53. Velocity (normal) versus impedance at Site 316.

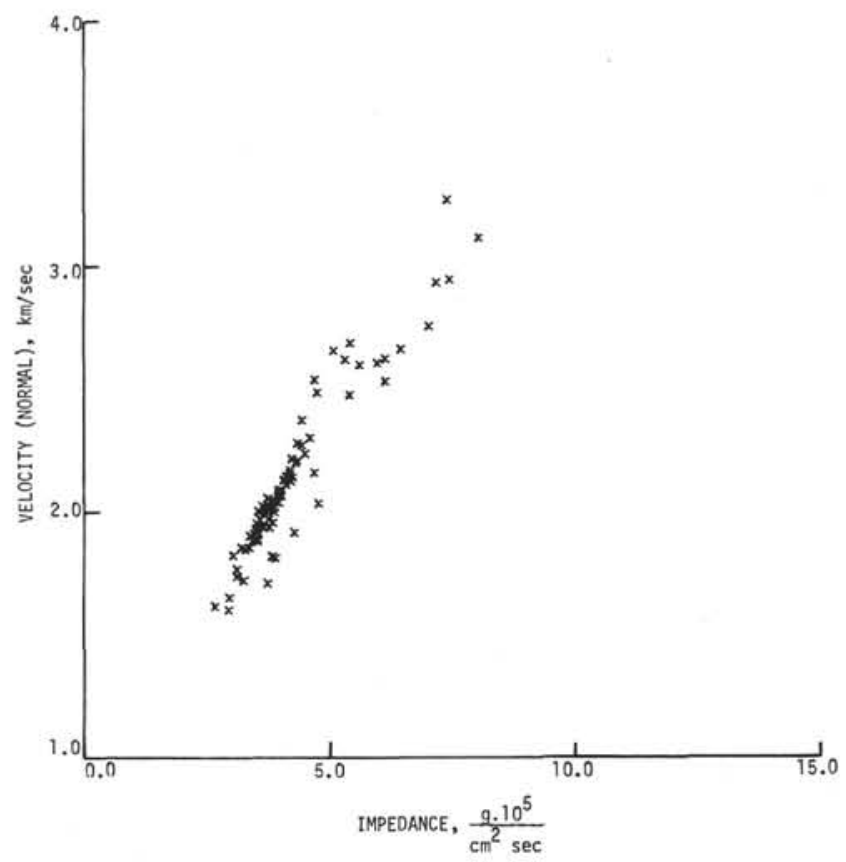

Figure 54. Velocity (normal) versus impedance at Site 317.

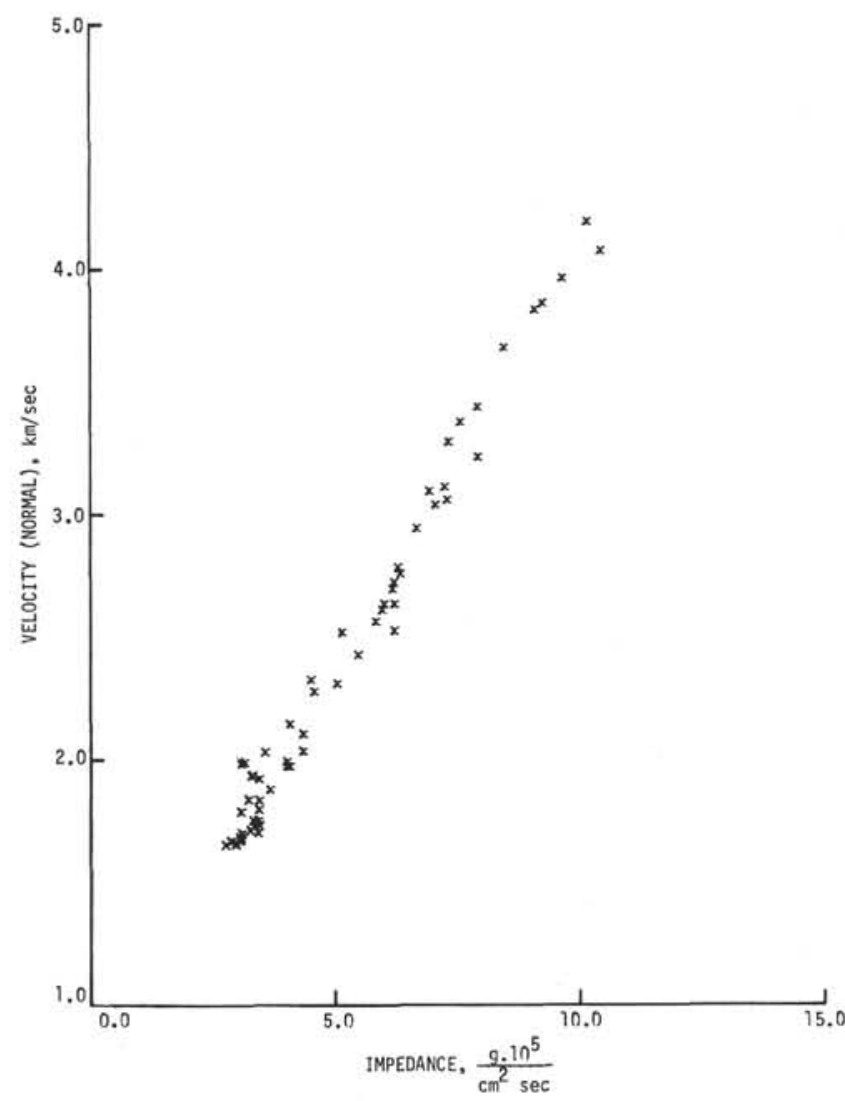

Figure 55. Velocity (normal) versus impedance at Site 318.

The greatest change in the calcite velocity would be just at the sea floor as the pressure increase and the temperature decrease at the sea floor causes the velocity of calcite to be about $1 \%$ higher than laboratory conditions, but deeper in the hole the temperature and hydrostatic pressure effects tend to cancel each other. 


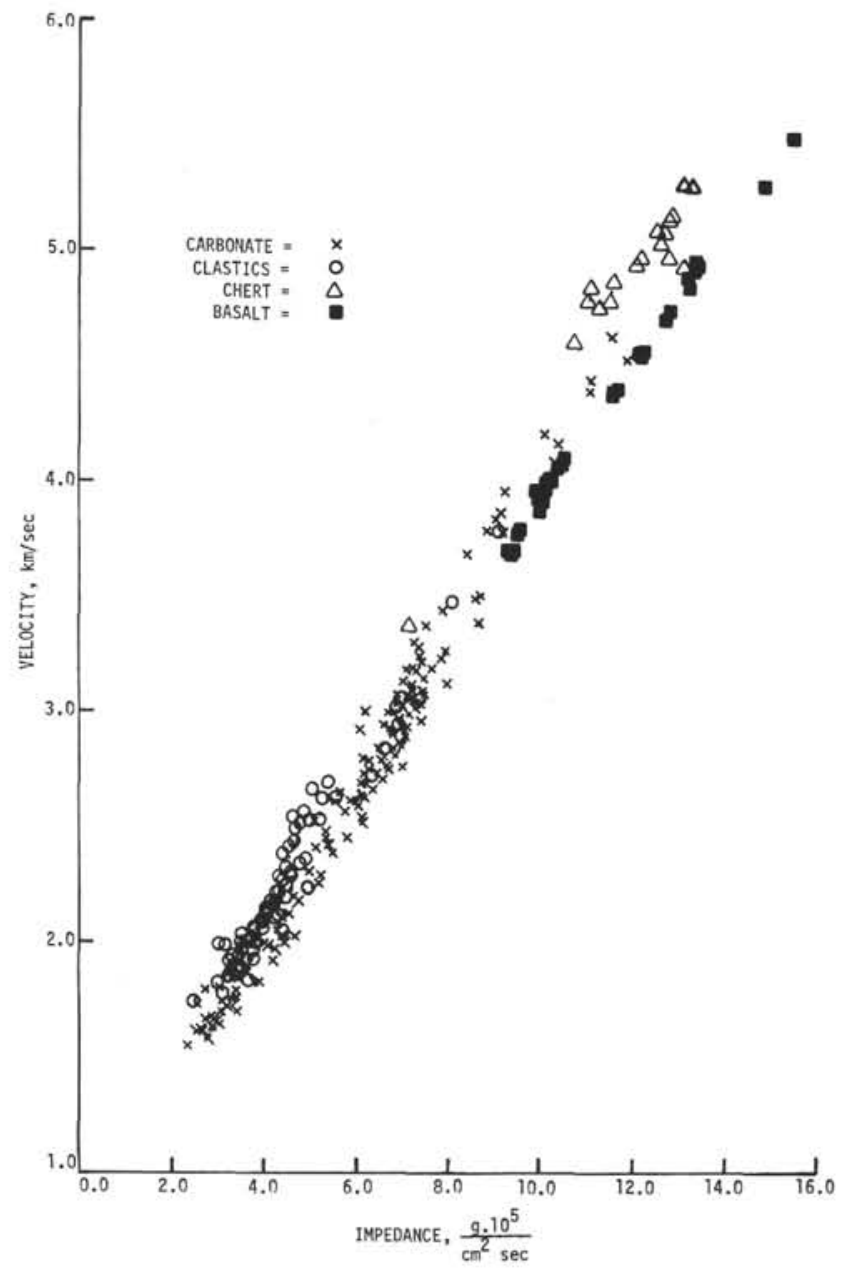

Figure 56. Velocity (normal) versus impedance at all sites. Predominantly normal velocities, but horizontal velocities used to fill in where needed for lithologic representation.

Therefore, if low porosity rocks are at the sea floor or if the stratigraphy extends below 1000-meter depths, then the variations of the solid end member may be significant.

For Leg 33 data a constant velocity for calcite (for all the pressures and temperatures encountered at the Leg 33 sites) will be assumed for the solid grain velocity phase of all the sediments and rocks (including volcaniclastic rocks), for purposes of simplicity and because of the sparsity of more precise studies of both temperature and pressure velocity variation for different minerals. A Voigt-Reuss velocity average of $6.45 \mathrm{~km} / \mathrm{sec}$ for calcite (Christensen, 1965) will be used for the solid grain end member for all Leg 33 data.

From Figures 44, 51, and 56, which show velocity relationships versus porosity, wet-bulk density, or impedance, and from the various equations which relate porosity to velocity, such as Wyllie et al. (1956) Equation 8, Nafe and Drake (1957) Equation 9, and Wood (1941) Equation 7, the following relationship can be derived. For a given solid mineral grain makeup and sea-water mixture, if the velocity versus porosity, density, or impedance scatter diagrams are true for labora-

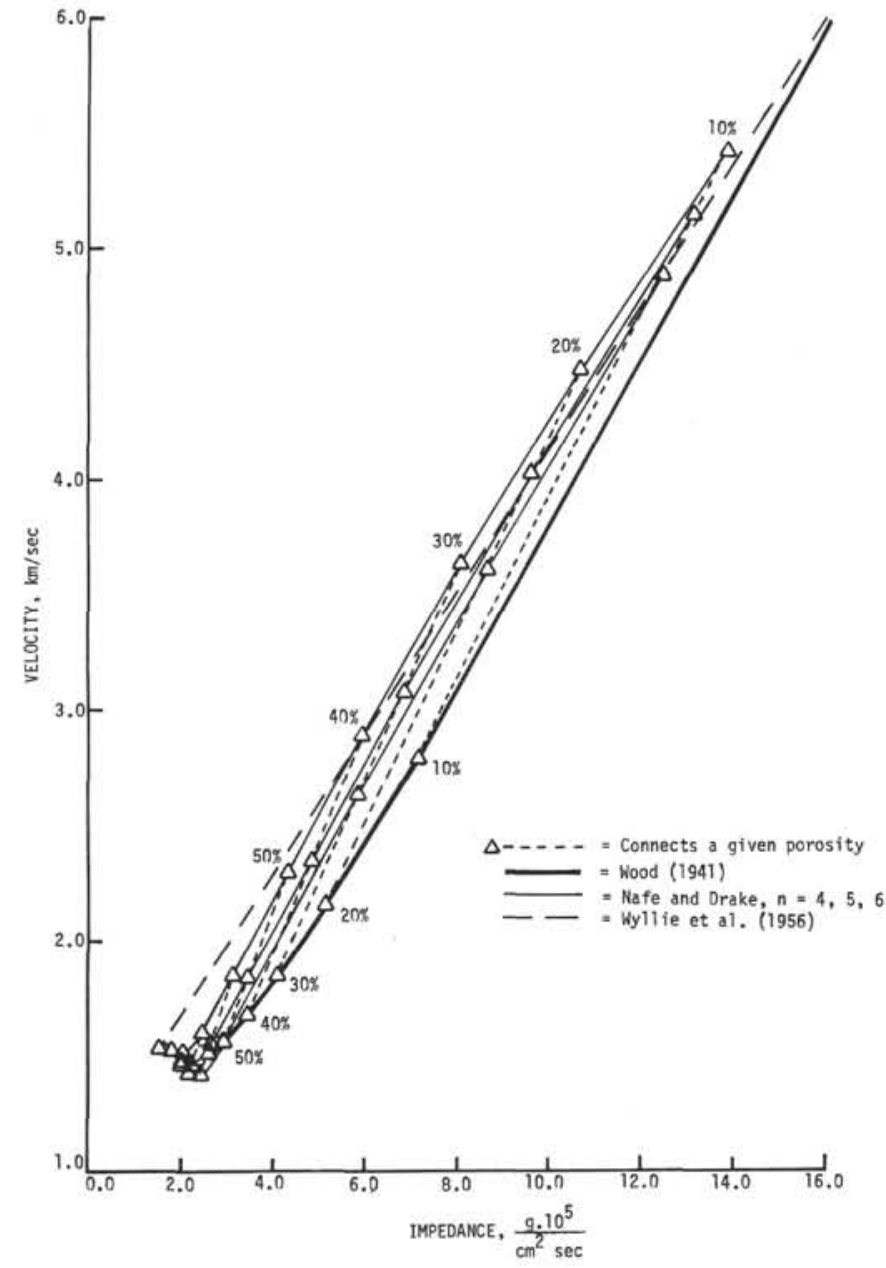

Figure 57. Velocity versus impedance diagram with the Wood (1941) Equation \#8, and Nafe and Drake (1957) Equation \#9, are drawn in using calcite $(2.72 \mathrm{~g} / \mathrm{cc}, 6.45$ $\mathrm{km} / \mathrm{sec})$ and sea water $(1.025 \mathrm{~g} / \mathrm{cc}, 1.53 \mathrm{~km} / \mathrm{sec})$ as end member constituents.

tory pressures and temperatures, and the Nafe and Drake (1957) equation, Wood (1941) equation, and the Wyllie et al. (1956) equation are also true using laboratory temperature and pressure sea water and calcite velocities as end-member relationships, then they should also be valid for in situ temperature and hydrostatic pressure conditions but only using different in situ endmember velocities, as follows (for a given mineralogy such as calcite):

$V_{1}=$ velocity of sea water at laboratory conditions

$V_{2}=$ velocity of calcite at laboratory conditions

$V_{3}=$ velocity of sample at laboratory conditions

$V_{1}=$ velocity of sea water at in situ temperature and hydrostatic pressure

$\mathrm{V}_{\mathrm{II}}=$ velocity of calcite at in situ temperature and hydrostatic pressure

$\mathrm{V}_{\mathrm{III}}=$ velocity of sample at in situ temperature and hydrostatic pressure

$$
\frac{\mathrm{V}_{3}-\mathrm{V}_{2}}{\mathrm{~V}_{1}-\mathrm{V}_{2}}=\frac{\mathrm{V}_{\text {III }}-\mathrm{V}_{\text {II }}}{\mathrm{V}_{\mathrm{I}}-\mathrm{V}_{\mathrm{II}}}
$$




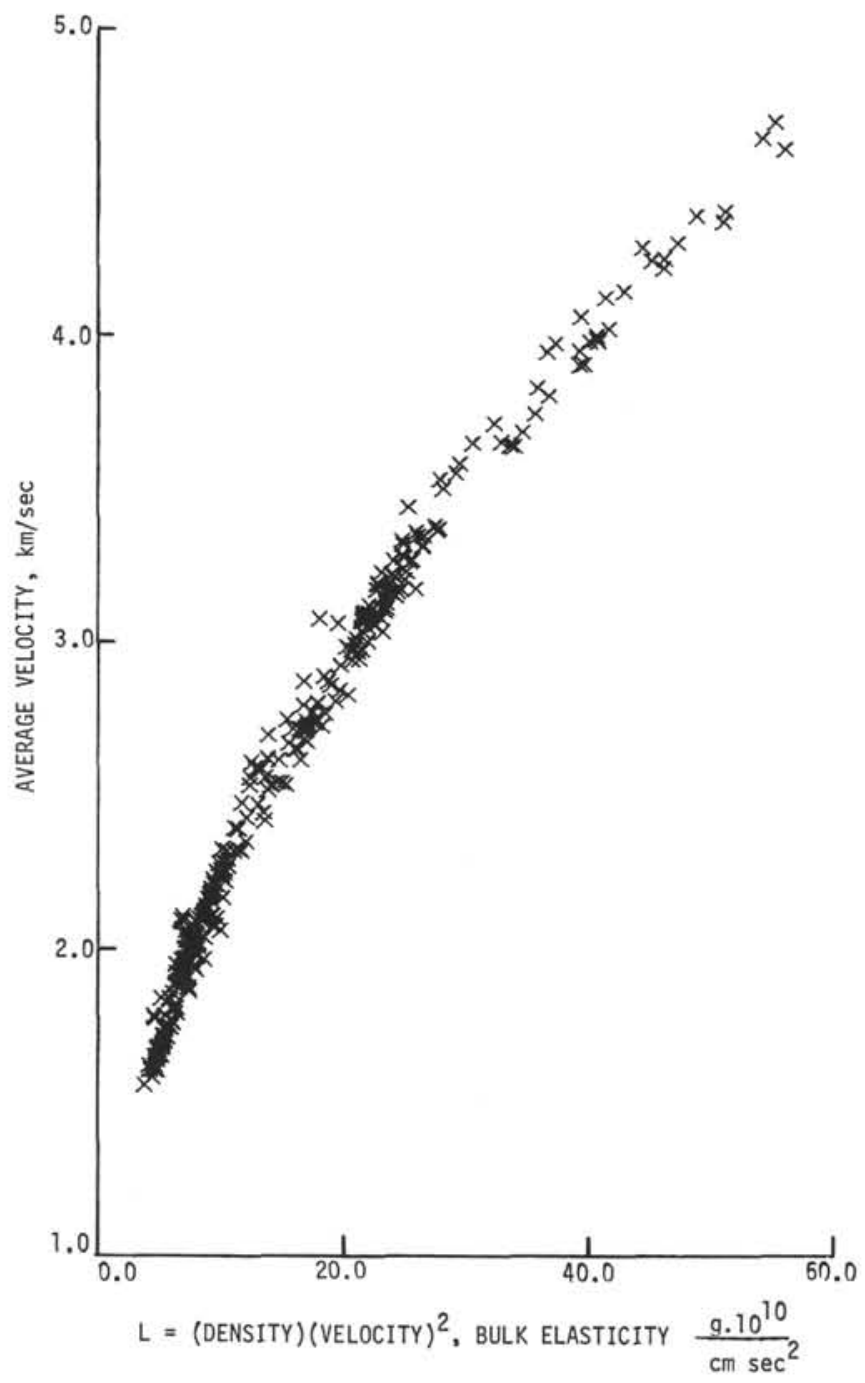

Figure 58. Average of the horizontal and vertical velocity for all sites versus the bulk elasticity (L) of the rock.

This relationship should be approximately true for small velocity changes with in situ temperature and hydrostatic pressure.

$$
\mathrm{V}_{\mathrm{III}}=\left[\frac{\left(\mathrm{V}_{3}-\mathrm{V}_{2}\right)\left(\mathrm{V}_{\mathrm{I}}-\mathrm{V}_{\mathrm{II}}\right)}{\left(\mathrm{V}_{1}-\mathrm{V}_{2}\right)}\right]+\mathrm{V}_{\mathrm{II}}
$$

For Leg 33 data an approximate in situ velocity was estimated by first correcting laboratory velocities for a porosity rebound and then adjusting those new values to in situ temperatures and hydrostatic pressures by Equation 11 (see Tables 3 through 6). The porosity correction is applied to the raw laboratory velocity by first studying the velocity-porosity trend for a given sediment with a given mineral makeup in the velocity-porosity scatter diagram for that particular drill site. By finding the laboratory velocity-porosity intersection, and then migrating along the velocity-porosity trend for a 5\% (absolute) (5\% for samples greater than $30 \%$ porosity, $2.5 \%$ for samples with porosities within $20 \%$ to $30 \%$ porosity) decrease, then the corresponding velocity at the new porosity is the porosity-corrected velocity.

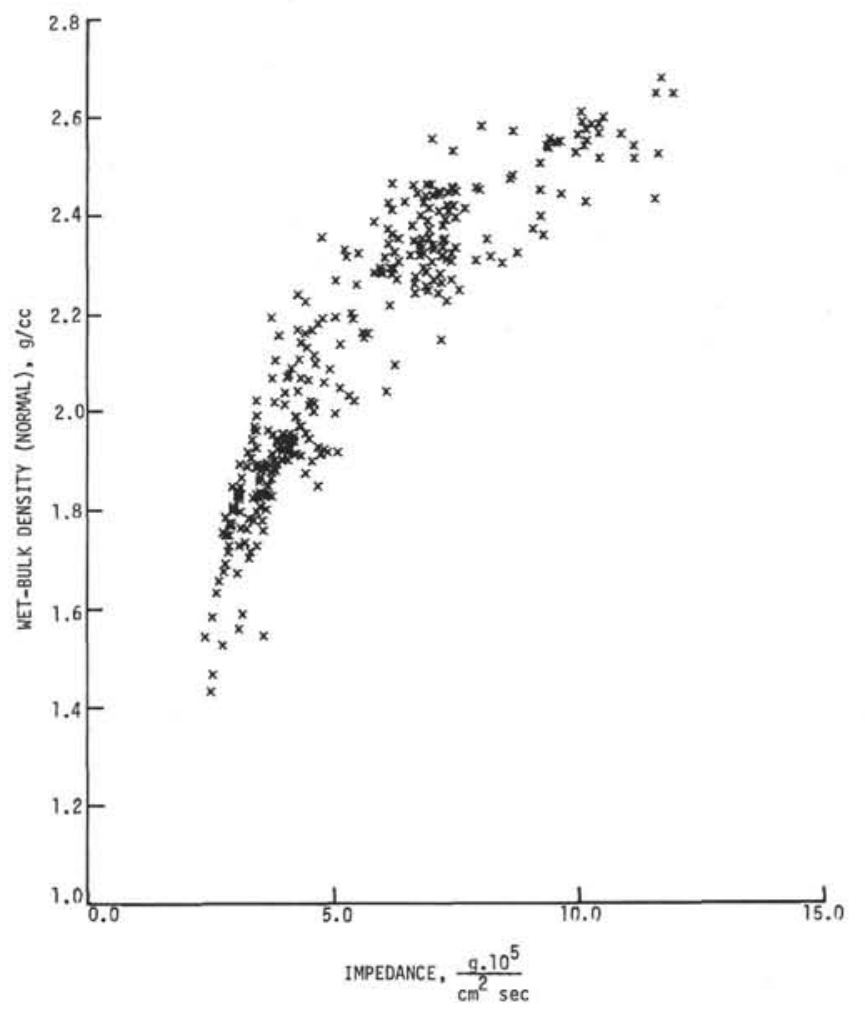

Figure 59. Wet-bulk density (normal) versus impedance for all sites.

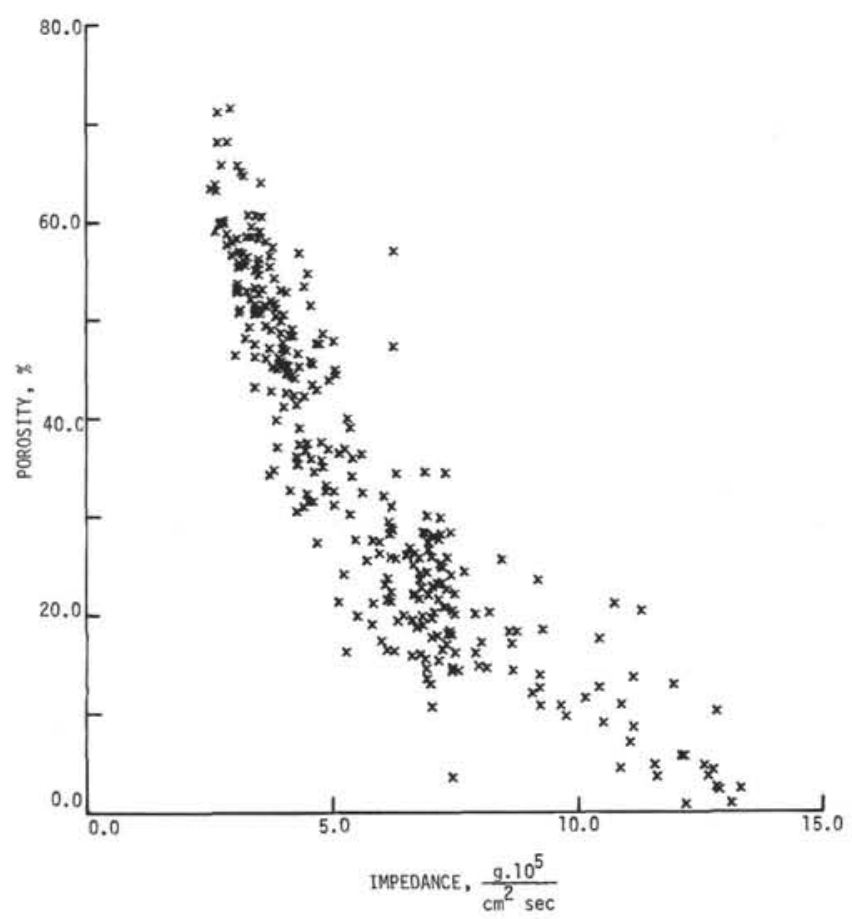

Figure 60. Porosity versus impedance for all sites.

This porosity-corrected velocity was then corrected for in situ temperature and hydrostatic pressure (pore pressure) by Equation 11. However, this final velocity does not have a rigidity factor for the grain structure resulting from overburden pressure, which is small for uncemented high porosity sediments and hard rock but 
TABLE 3

Listing of Samples With a Suspicious Value for Either the Wet-Water Content, Wet-Bulk Density,

or Porosity, as Noted as a Low Grain Density Solution in the Wet-Bulk Density Versus Porosity Scatter Diagrams

\begin{tabular}{|c|c|c|c|c|c|c|c|c|c|c|c|c|}
\hline \multirow[b]{3}{*}{$\begin{array}{c}\text { Sample } \\
\text { (Interval in } \mathrm{cm} \text { ) }\end{array}$} & \multirow{3}{*}{$\begin{array}{c}\text { Depth in } \\
\text { Hole } \\
\text { (m) }\end{array}$} & \multicolumn{5}{|c|}{ Compressional Sound Velocity } & \multirow{2}{*}{\multicolumn{2}{|c|}{$\begin{array}{c}\text { "Special" } \\
\text { Wet-Bulk } \\
\text { Densitya } \\
\text { 2-minute } \\
\text { count } \\
\text { (g/cc) }\end{array}$}} & \multirow{3}{*}{$\begin{array}{l}\text { Wet- } \\
\text { Water } \\
\text { Content } \\
\text { Salt } \\
\text { Cor. } \\
(\%)\end{array}$} & \multirow[b]{3}{*}{$\begin{array}{c}\text { Porosity } \mathrm{b} \\
(\%)\end{array}$} & \multirow{3}{*}{$\begin{array}{c}\text { Acoustic } \\
\text { Impedance } \\
\frac{\mathrm{g} 10^{5}}{\mathrm{~cm}^{2} \mathrm{sec}}\end{array}$} & \multirow[b]{3}{*}{ Lithology } \\
\hline & & \multirow{2}{*}{$\begin{array}{c}\| \\
\text { Beds } \\
(\mathrm{km} / \mathrm{sec})\end{array}$} & \multirow{2}{*}{$\begin{array}{c}\perp \\
\text { Beds } \\
(\mathrm{km} / \mathrm{sec})\end{array}$} & \multicolumn{2}{|c|}{ Anisotropy } & \multirow[b]{2}{*}{$\begin{array}{c}\text { Temp. } \\
\left({ }^{\circ} \mathrm{C}\right)\end{array}$} & & & & & & \\
\hline & & & & $\begin{array}{c}\|-1 \\
(\mathrm{~km} / \mathrm{sec})\end{array}$ & $\begin{array}{c}(\|-1) \div 1 \\
(\%)\end{array}$ & & $\begin{array}{c}\| \\
\text { Beds }\end{array}$ & $\stackrel{1}{\stackrel{1}{\text { Beds }}}$ & & & & \\
\hline $315 \mathrm{~A}-6-1,101-103$ & 466.01 & 1.792 & 1.639 & +0.153 & +9.33 & 21.0 & & 1.773 & 20.02 & 35.50 & 2.91 & Rad-rich foram nanno chalk \\
\hline $315 \mathrm{~A}-6-2,116-118$ & 467.66 & 1.684 & 1.665 & +0.019 & +1.14 & 21.0 & & 1.690 & $29.25^{\mathrm{c}}$ & 49.43 & 2.81 & Rad nanno chalk \\
\hline $315 \mathrm{~A}-6-3,12-14$ & 468.12 & 1.655 & 1.646 & +0.009 & +0.55 & 21.0 & & 1.767 & 20.99 & 37.09 & 2.91 & Rad nanno chalk \\
\hline $315 \mathrm{~A}-7-1,44-46$ & 512.94 & 1.711 & 1.690 & +0.021 & +1.24 & 21.0 & & 1.846 & 15.19 & 28.04 & 3.12 & Rad-rich foram nanno chalk \\
\hline $315 \mathrm{~A}-7-2,30-32$ & 514.30 & 1.678 & 1.679 & -0.001 & +0.06 & 21.0 & & 1.830 & 13.09 & 23.95 & 3.07 & Foram-rich rad nanno chalk \\
\hline $315 \mathrm{~A}-8-7,21-22$ & 588.71 & 1.658 & 1.641 & +0.017 & +1.04 & 21.0 & & 1.892 & 15.46 & 29.25 & 3.11 & Foram-rich rad nanno chalk \\
\hline $315 \mathrm{~A}-8-2,141-145$ & 591.41 & 1.654 & 1.646 & +0.008 & +0.49 & 21.0 & & 1.822 & 22.61 & 41.20 & 3.00 & Foram-rich rad nanno chalk \\
\hline $315 A-8-3,131-133$ & 592.81 & 1.778 & 1.734 & +0.044 & +2.54 & 20.0 & & 1.968 & 14.69 & 28.91 & 3.41 & Foram-rich rad nanno chalk \\
\hline $315 \mathrm{~A}-10-4,122-125$ & 736.52 & 1.881 & 1.796 & +0.085 & +4.73 & 21.0 & & 1.525 & 39.81 & 60.71 & 2.74 & Clay-rich rad nanno chalk \\
\hline $315 \mathrm{~A}-10-5,54-57$ & 737.34 & 1.863 & 2.326 ? & -0.463 ? & -19.91 ? & 19.0 & & 1.544 & 40.04 & 61.82 & 3.59 & Rad nanno chalk \\
\hline $315 \mathrm{~A}-10-5,129-131$ & 738.09 & 1.817 & 1.745 & +0.072 & +4.13 & 19.0 & & 1.430 & 48.93 & 69.97 & 2.50 & Nanno rad claystone \\
\hline $315 \mathrm{~A}-10-6,118-120$ & 739.48 & 1.812 & 1.732 & +0.080 & +4.62 & 19.0 & & 1.465 & 40.81 & 59.79 & 2.54 & Spic. clay-rich rad nanno chlak \\
\hline $315 \mathrm{~A}-15-1,122-124$ & 779.22 & 1.672 & 2.001 & -0.329 & -16.44 & 19.0 & & 1.726 & 26.80 & 46.26 & 3.45 & Rad claystone \\
\hline $315 \mathrm{~A}-23-3,39-41$ & 857.39 & 2.750 & 2.992 & -0.242 & -8.09 & 20.0 & & 2.040 & 11.33 & 23.11 & 6.10 & Clay-rich micritic limestone \\
\hline $316-28-1,72-74$ & 771.22 & 2.596 & 2.556 & +0.040 & +1.56 & 23.0 & 1.930 & 1.916 & 17.35 & 33.24 & 4.90 & Volcanic breccia \\
\hline $317 \mathrm{~A}-6-2,85-87$ & 584.85 & 1.815 & 1.654 & +0.161 & +9.73 & 26.0 & 1.791 & 1.797 & 23.53 & 42.28 & 2.97 & Claystone \\
\hline $317 \mathrm{~A}-14-1,121-123$ & 659.71 & 2.072 & 1.825 & +0.247 & +13.53 & 23.0 & & 1.671 & 27.77 & 46.41 & 3.05 & Volcanic nanno sandstone \\
\hline $317 \mathrm{~B}-24-4,140-143$ & 221.40 & 1.576 & & & & 22.0 & 1.553 & & 34.49 & 53.56 & $2.45^{\mathrm{d}}$ & Foram nanno firm ooze, disturbed lump \\
\hline
\end{tabular}

Note: These data in the porosity or wet-water content diagrams are either indicated with a question mark or deleted.

${ }^{\mathrm{a}} \rho_{\mathrm{g}}$ and $\rho_{\mathrm{gc}}=2.70$ for sed. rocks, 2.65 for cherts, and 2.86 for basalt.

${ }^{b}$ Porosity $=$ (salt corrected wet-water content $) \times$ (wet-bulk density).

${ }^{\mathrm{c}}$ Large sample.

$\mathrm{d}_{\text {Horizontal. }}$ 
TABLE 4

Site 315 Theoretical Reflection Times From Laboratory Velocity Measurements

\begin{tabular}{|c|c|c|c|c|c|c|c|c|c|c|c|}
\hline $\begin{array}{l}\text { Depth } \\
\text { Interval } \\
\text { (m) }\end{array}$ & $\begin{array}{c}\text { In Situ } \\
\text { Hydrostatic } \\
\text { Pressure } \\
\left(\mathrm{kg} / \mathrm{cm}^{2}\right)\end{array}$ & $\begin{array}{c}\text { Estimated } \\
\text { In Situ } \\
\text { Temperature } \\
\left.\text { ( }{ }^{\circ} \mathrm{C}\right)\end{array}$ & $\begin{array}{c}\text { In Situ } \\
\text { Velocity of } \\
\text { Sea Waterc } \\
(\mathrm{km} / \mathrm{sec})\end{array}$ & $\begin{array}{c}\text { Specific } \\
\text { Interval } \\
\text { Velocity } \\
\text { of } \\
\text { Sea Water } \\
(\mathrm{km} / \mathrm{sec})\end{array}$ & $\begin{array}{l}\text { Specific } \\
\text { Interval } \\
\text { Velocity } \\
\text { of } \\
\text { Formation } \\
\text { at Lab } \\
\text { Conditions } \\
(\mathrm{km} / \mathrm{sec})\end{array}$ & $\begin{array}{c}\text { Estimated } \\
\text { Porosity } \\
\text { Rebound } \\
\text { as Sample } \\
\text { Removed } \\
\text { From } \\
\text { In Situ } \\
(\%)\end{array}$ & $\begin{array}{l}\text { Porosity } \\
\text { Corrected } \\
\text { Lab } \\
\text { Velocity } \\
(\mathrm{km} / \mathrm{sec})\end{array}$ & $\begin{array}{c}\text { Porosity } \\
\text { Corrected } \\
\text { Lab } \\
\text { Velocities } \\
\text { Adjusted for } \\
\text { Hydrostatic } \\
\text { Temp. } \\
\text { Pressure and } \\
\text { (km/sec) }\end{array}$ & $\begin{array}{c}\text { Specific } \\
\text { Interval } \\
\text { Distance } \\
\text { (m) }\end{array}$ & $\begin{array}{c}\text { Reflection } \\
\text { Time Using } \\
\text { Unadjusted } \\
\text { Lab } \\
\text { Velocities } \\
\text { (sec) }\end{array}$ & $\begin{array}{c}\text { Reflection } \\
\text { Time Using } \\
\text { Lab } \\
\text { Velocities } \\
\text { Adjusted } \\
\text { for Porosity } \\
\text { Hydrostatic } \\
\text { Pressure and } \\
\text { Temp. } \\
\text { (sec) }\end{array}$ \\
\hline 0 & 431 & 1.5 & 1.53 & & & & & & & 0.000 & 0.000 \\
\hline 250 & 457 & 15 & 1.58 & 1.555 & 1.54 & 5.0 & 1.55 & 1.58 & 250 & 0.325 & 0.316 \\
\hline 480 & 481 & 26 & 1.62 & 1.60 & 1.60 & 5.0 & 1.68 & 1.75 & 230 & 0.613 & 0.579 \\
\hline 712 & 505 & 37 & 1.64 & 1.63 & 1.61 & 5.0 & 1.80 & 1.89 & 232 & 0.891 & 0.825 \\
\hline 790 & 513 & 42 & 1.65 & 1.645 & 2.00 & 5.0 & 2.30 & 2.40 & 78 & 0.969 & 0.890 \\
\hline 902 & 524 & 47 & 1.66 & 1.665 & 2.20 & 5.0 & 2.42 & 2.53 & 94 & 1.044 & 0.958 \\
\hline 996 & 534 & 52 & 1.67 & & & & & & & 1.129 & 1.032 \\
\hline
\end{tabular}

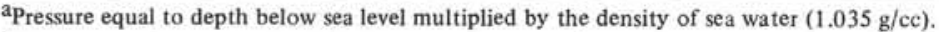

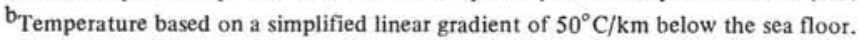

c Sea-water velocities assume a salinity of $35 \%$ with a velocity of $1.53 \mathrm{~km} / \mathrm{sec}$ at room temperatures and pressure. In situ velocities from "Tables of Sound Speed in Sea Water: U.S. Naval Oceanographic Office, Special Publication 58; and Press (1966).

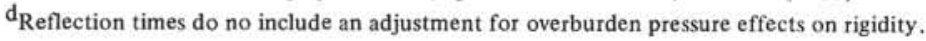

TABLE 5

Site 316 Theoretical Reflection Times From Laboratory Velocity Measurements

\begin{tabular}{|c|c|c|c|c|c|c|c|c|c|c|c|}
\hline $\begin{array}{l}\text { Depth } \\
\text { Interval } \\
\text { (m) }\end{array}$ & $\begin{array}{c}\text { In Situ } \\
\text { Hydrostatic } \\
\text { Pressure } \\
\left(\mathrm{kg} / \mathrm{cm}^{2}\right)\end{array}$ & $\begin{array}{c}\text { Estimated } \\
\text { In Situ } \\
\text { Temperature } b \\
\left.{ }^{\circ} \mathrm{C}\right)\end{array}$ & $\begin{array}{c}\text { In Situ } \\
\text { Velocity of } \\
\text { Sea Waterc } \\
(\mathrm{km} / \mathrm{sec})\end{array}$ & $\begin{array}{l}\text { Specific } \\
\text { Interval } \\
\text { Velocity } \\
\text { of } \\
\text { Sea Water } \\
(\mathrm{km} / \mathrm{sec})\end{array}$ & $\begin{array}{l}\text { Specific } \\
\text { Interval } \\
\text { Velocity } \\
\text { of } \\
\text { Formation } \\
\text { at Lab } \\
\text { Conditions } \\
(\mathrm{km} / \mathrm{sec})\end{array}$ & $\begin{array}{c}\text { Estimated } \\
\text { Porosity } \\
\text { Rebound } \\
\text { as Sample } \\
\text { Removed } \\
\text { From } \\
\text { In Situ } \\
(\%)\end{array}$ & $\begin{array}{c}\text { Porosity } \\
\text { Corrected } \\
\text { Lab } \\
\text { Velocity } \\
\text { (km/sec) }\end{array}$ & $\begin{array}{c}\text { Porosity } \\
\text { Corrected } \\
\text { Lab } \\
\text { Velocities } \\
\text { Adjusted for } \\
\text { Hydrostatic } \\
\text { Temp. } \\
\text { Pressure and } \\
\text { (km/sec) }\end{array}$ & $\begin{array}{c}\text { Specific } \\
\text { Interval } \\
\text { Distance } \\
\text { (m) }\end{array}$ & $\begin{array}{c}\text { Reflection } \\
\text { Time Using } \\
\text { Unadjusted } \\
\text { Lab } \\
\text { Velocities } \\
\text { (sec) }\end{array}$ & $\begin{array}{c}\text { Reflection } \\
\text { Time Using } \\
\text { Lab } \\
\text { Velocities } \\
\text { Adjusted } \\
\text { for Porosity } \\
\text { Hydrostatic } \\
\text { Pressure and } \\
\text { Temp.d } \\
\text { (sec) }\end{array}$ \\
\hline 0 & 462 & 1.5 & 1.53 & & & & & & & 0.000 & 0.000 \\
\hline 269 & 490 & 16 & 1.58 & 1.555 & 1.54 & 5.0 & 1.55 & 1.58 & 269 & 0.349 & 0.341 \\
\hline 457 & 509 & 25 & 1.62 & 1.600 & 1.63 & 5.0 & 1.69 & 1.76 & 188 & 0.580 & 0.555 \\
\hline 580 & 522 & 31 & 1.64 & 1.64 & 3.00 & 2.5 & 3.15 & 3.22 & 172 & 0.683 & 0.649 \\
\hline 752 & 540 & 40 & 1.65 & 1.66 & 2.50 & 5.0 & 2.70 & 2.80 & 85 & 0.798 & 0.756 \\
\hline 837 & 549 & 44 & 1.67 & & & & & & & 0.866 & 0.817 \\
\hline
\end{tabular}

aPressure equal to depth below sea level multiplied by the density of sea water $(1.035 \mathrm{~g} / \mathrm{cc})$.

b Temperature based on a simplified linear gradient of $50^{\circ} \mathrm{C} / \mathrm{km}$ below sea floor.

cSea-water velocities assume a salinity of $35 \%$ with a velocity of $1.53 \mathrm{~km} / \mathrm{sec}$ at room temperature and pressure. In situ velocities from "Tables of Sound Speed in Sea $\mathrm{H}_{2} \mathrm{O}$ : U.S. Naval Oceanographic Office, Special Publication 58; and Press (1966).

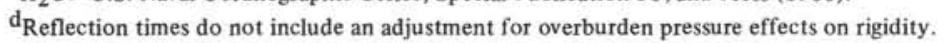

should be significant for semilithified rock samples. Therefore, these adjusted in situ velocities will be minimal, but will be used to correlate the stratigraphic column to the seismic profiles. For the calculations, interval velocities, and reflection times see Tables 4 through 7 , and for visual stratigraphic-seismic profile correlations see Figures 2 through 5 . Shown in these figures are the correlations with the sonobuoy data (from site reports in this volume), the unadjusted laboratory data, and the adjusted laboratory velocity correlation.

For simplicity, the laboratory data had corrections applied to the interval velocities and not to individual samples. Also chert was not included in the interval velocity averages as it was not known how thick the chert beds actually were, but as an example at Site 315 , if it is assumed that $10 \%$ of the limestone section is chert, then the total reflection time would be decreased by 
TABLE 6

Site 317 Theoretical Reflection Times From Laboratory Velocity Measurements

\begin{tabular}{|c|c|c|c|c|c|c|c|c|c|c|c|}
\hline $\begin{array}{l}\text { Depth } \\
\text { Interval } \\
(\mathrm{m})\end{array}$ & $\begin{array}{c}\text { In Situ } \\
\text { Hydrostatic } \\
\text { Pressure } \\
\left(\mathrm{kg} / \mathrm{cm}^{2}\right)\end{array}$ & $\begin{array}{c}\text { Estimated } \\
\text { In Situ } \\
\text { Temperature b } \\
\left({ }^{\circ} \mathrm{C}\right)\end{array}$ & $\begin{array}{c}\text { In Situ } \\
\text { Velocity of } \\
\text { Sea Waterc } \\
(\mathrm{km} / \mathrm{sec})\end{array}$ & $\begin{array}{l}\text { Specific } \\
\text { Interval } \\
\text { Velocity } \\
\text { of } \\
\text { Sea Water } \\
(\mathrm{km} / \mathrm{sec})\end{array}$ & $\begin{array}{l}\text { Specific } \\
\text { Interval } \\
\text { Velocity } \\
\text { of } \\
\text { Formation } \\
\text { at Lab } \\
\text { Conditions } \\
(\mathrm{km} / \mathrm{sec})\end{array}$ & $\begin{array}{c}\text { Estimated } \\
\text { Porosity } \\
\text { Rebound } \\
\text { as Sample } \\
\text { Removed } \\
\text { From } \\
\text { In Situ } \\
(\%)\end{array}$ & $\begin{array}{c}\text { Porosity } \\
\text { Corrected } \\
\text { Lab } \\
\text { Velocity } \\
(\mathrm{km} / \mathrm{sec})\end{array}$ & $\begin{array}{c}\text { Porosity } \\
\text { Corrected } \\
\text { Lab } \\
\text { Velocities } \\
\text { Adjusted for } \\
\text { Hydrostatic } \\
\text { Temp. } \\
\text { Pressure and } \\
\text { (km/sec) }\end{array}$ & $\begin{array}{c}\text { Specific } \\
\text { Interval } \\
\text { Distance } \\
\text { (m) }\end{array}$ & $\begin{array}{c}\text { Reflection } \\
\text { Time Using } \\
\text { Unadjusted } \\
\text { Lab } \\
\text { Velocities } \\
\text { (sec) }\end{array}$ & $\begin{array}{c}\text { Reflection } \\
\text { Time Using } \\
\text { Lab } \\
\text { Velocities } \\
\text { Adjusted } \\
\text { for Porosity } \\
\text { Hydrostatic } \\
\text { Pressure and } \\
\text { Temp.d } \\
\text { (sec) }\end{array}$ \\
\hline 0 & 271 & 2 & 1.50 & & & & & & & 0.000 & 0.000 \\
\hline 150 & 287 & 10 & 1.54 & & & 3.0 & & 1.54 & & 0.195 & 0.195 \\
\hline 377 & 310 & 21 & 1.575 & 1.56 & 1.61 & 5.0 & 1.68 & 1.71 & 227 & 0.477 & 0.460 \\
\hline 602 & 334 & 32 & 1.61 & 1.59 & 1.81 & 5.0 & 2.00 & 2.05 & 43 & 0.725 & 0.680 \\
\hline 645 & 338 & 34 & 1.61 & & .00 & & 5.20 & 3.25 & & 0.754 & 0.706 \\
\hline 680 & 342 & 36 & 1.62 & & & & & & & 0.781 & 0.730 \\
\hline 900 & 365 & 47 & 1.63 & & & 5.0 & 2.25 & 2.34 & 226 & 1.001 & 0.923 \\
\hline
\end{tabular}

apressure equal to depth below sea level multiplied by the density of sea water $(1.035 \mathrm{~g} / \mathrm{cc})$.

${ }^{\mathrm{b}} \mathrm{Temperature} \mathrm{based} \mathrm{on} \mathrm{a} \mathrm{simplified} \mathrm{linear} \mathrm{gradient} \mathrm{of} 50^{\circ} \mathrm{C} / \mathrm{km}$ below the sea floor.

cSea-water velocities assume a salinity of $35 \%$ with a velocity of $1.53 \mathrm{~km} / \mathrm{sec}$ at room temperatures and pressure. In situ velocities from Tables of Sound Speed in Sea Water: U.S. Naval Oceanographic Office, Special Publication 58; and Press (1966).

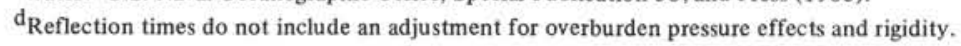

$0.010 \mathrm{sec}$. This approach should allow individual investigators to manipulate the data.

\section{DISCUSSION OF THE SEISMIC PROFILE CORRELATIONS}

At Site 315 the adjusted velocity correlations were slightly higher in the seismic profile than the sonobuoy correlation (see Table 4 for the interval velocities and reflection times, and Figure 2 for the visual correlations). The major median reflector is correlated to the approximate location of the high-density $(4 \mathrm{~g} / \mathrm{cc})$ celestite layer, which is just below the sonobuoy correlation. It is interesting to note that the major median reflector did not correlate to the major change in the physical properties lower in the section. The last reflector may be the basalt, as the adjusted laboratory velocity correlation of the basalt was just below the last reflector, and perhaps, if rigidity of the overburden pressure had been added as a factor, then the basalt may correlate with the last reflector. The sonobuoy and raw unadjusted laboratory correlations of the basalt were significantly lower than the last reflector.

At Site 316, the adjusted laboratory correlation agreed fairly well with the sonobuoy data (see Table 5 for the interval velocities and reflection times and Figure 3 for the visual correlations). The dark median reflector correlated with a drill break where physical properties data are meager.

At Site 317 the adjusted velocity correlation did not systematically disagree or agree with the sonobuoy correlations (see Table 6 for the interval velocities and reflection times and Figure 4 for the visual correlation). The 0.6-sec reflector was correlated higher in the stratigraphic section than the sonobuoy correlations, slightly above where a significant drill break occurred.
The sonobuoy correlation was slightly below the drill break. Chances are that this reflector should correlate with the drill break. The last reflector is correlated by the sonobuoy data to the basalt, but the adjusted laboratory velocity correlation of the basalt is just below the last reflector, but it is possible if rigidity factors had been included that the basalt would correlate with the last reflector.

At Site 318 , sonobuoy correlations to which to compare the laboratory data do not exist. The adjusted laboratory data were significantly higher in the seismic section than the unadjusted laboratory velocities (see Table 7 for the interval velocities and reflection times and Figure 5 for visual correlations).

\section{SUMMARY AND CONCLUSIONS}

1. Laboratory pressure and temperature, compressional sound velocity, wet-bulk density, wet-water content, acoustic impedance, and acoustic anisotropy were determined for Quaternary through Cretaceous sediment and rock from the Line Islands chain, Manihiki Plateau, and Tuamotu Ridge.

2. The drilling rate, sedimentation rate, and other physical properties correlated regionally with the Line Islands chain, Manihiki Plateau, and Tuamotu Ridge based on lithology and age. Basically, the characteristic sequences are the Pleistocene-Oligocene low density and velocity ooze and chalk, the Eocene-Paleocene chalklimestone transition, the Cretaceous high velocity and density limestone and its transition to low velocity and density volcaniclastics, which in turn overlie higher velocity and higher density basalt. At Tuamotu Ridge, drilling was not continued long enough to recover the Cretaceous limestone, volcaniclastics, or basalt, which are characteristic correlation markers. 
TABLE 7

Site 318 Theoretical Reflection Times From Laboratory Velocity Measurements

\begin{tabular}{|c|c|c|c|c|c|c|c|c|c|c|c|}
\hline $\begin{array}{l}\text { Depth } \\
\text { Interval } \\
(\mathrm{m})\end{array}$ & $\begin{array}{c}\text { In Situ } \\
\text { Hydrostatic } \\
\text { Pressure } \\
\left(\mathrm{kg} / \mathrm{cm}^{2}\right)\end{array}$ & $\begin{array}{c}\text { Estimated } \\
\text { In Situ } \\
\text { Temperature }^{\mathrm{b}} \\
\left.{ }^{\circ} \mathrm{C}\right)\end{array}$ & $\begin{array}{c}\text { In Situ } \\
\text { Velocity of } \\
\text { Sea Waterc } \\
(\mathrm{km} / \mathrm{sec})\end{array}$ & $\begin{array}{c}\text { Specific } \\
\text { Interval } \\
\text { Velocity } \\
\text { of } \\
\text { Sea Water } \\
(\mathrm{km} / \mathrm{sec})\end{array}$ & $\begin{array}{l}\text { Specific } \\
\text { Interval } \\
\text { Velocity } \\
\quad \text { of } \\
\text { Formation } \\
\text { at Lab } \\
\text { Conditions } \\
(\mathrm{km} / \mathrm{sec})\end{array}$ & $\begin{array}{c}\text { Estimated } \\
\text { Porosity } \\
\text { Rebound } \\
\text { as Sample } \\
\text { Removed } \\
\text { From } \\
\text { In Situ } \\
(\%)\end{array}$ & $\begin{array}{c}\text { Porosity } \\
\text { Corrected } \\
\text { Lab } \\
\text { Velocity } \\
(\mathrm{km} / \mathrm{sec})\end{array}$ & $\begin{array}{c}\text { Porosity } \\
\text { Corrected } \\
\text { Lab } \\
\text { Velocities } \\
\text { Adjusted for } \\
\text { Hydrostatic } \\
\text { Temp. } \\
\text { Pressure and } \\
\text { (km/sec) }\end{array}$ & $\begin{array}{c}\text { Specific } \\
\text { Interval } \\
\text { Distance } \\
\text { (m) }\end{array}$ & $\begin{array}{c}\text { Reflection } \\
\text { Time Using } \\
\text { Unadjusted } \\
\text { Lab } \\
\text { Velocities } \\
\text { (sec) }\end{array}$ & $\begin{array}{c}\text { Reflection } \\
\text { Time Using } \\
\text { Lab } \\
\text { Velocities } \\
\text { Adjusted } \\
\text { for Porosity } \\
\text { Hydrostatic } \\
\text { Pressure and } \\
\text { Temp. d } \\
\text { (sec) }\end{array}$ \\
\hline 0.0 & 273 & 2 & 1.50 & & & & & & & 0.000 & 0.000 \\
\hline 265.5 & 301 & 16 & 1.56 & 1.53 & 1.66 & 5.0 & 1.67 & 1.67 & 265.5 & 0.320 & 0.318 \\
\hline 408 & 316 & 22 & 1.58 & 1.57 & 1.72 & & 1.85 & 1.89 & 142.5 & 0.486 & 0.469 \\
\hline 494 & 324 & 27 & 1.59 & 1505 & 1.80 & & 1.98 & 2.03 & 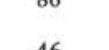 & 0.582 & 0.554 \\
\hline 540 & 329 & 29 & 1.60 & 1605 & 3.50 & 2.3 & 3.08 & & & 0.608 & 0.579 \\
\hline 581.5 & 333 & 31 & 1.61 & 1615 & 300 & 25 & 3.18 & 324 & 1635 & 0.651 & 0.616 \\
\hline 745 & 350 & 39 & 1.62 & & & & & & & 0.760 & 0.717 \\
\hline
\end{tabular}

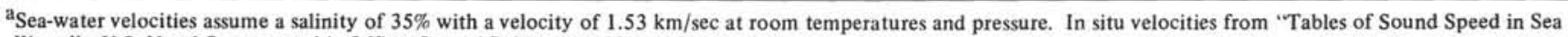
Water": U.S. Naval Oceanographic Office, Special Publication 58; and Press (1966).

${ }^{\mathrm{b}}$ Temperature is based on a simplified linear gradient of $50^{\circ} \mathrm{C} / \mathrm{km}$ below the sea floor.

${ }^{c_{R}}$ Rfection times do not include an adjustment for overburden pressure effects on rigidity.

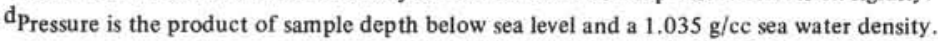

3. Drill rates and age versus depth appear to correlate well with the physical properties variations versus depth. The relative drill rates in general correlate well with certain chronologic and lithologic horizons.

4. The Cretaceous volcaniclastic sequence is a relatively high porosity and low velocity layer beneath a high velocity, low porosity limestone layer, which is of interest to any seismic refraction survey interpretations which assume increasing velocity layers with depth.

5. The empirical interrelationships between porosity (and wet-bulk density) versus velocity now includes some semilithified material as empirical data which was previously sparse. In addition, acoustic anisotropy is now systematically introduced as a factor in these relationships. The equations of Wood (1941) and Wyllie et al. (1956), which relate velocity to porosity, tend to bracket most of the data in the velocity-porosity scatter diagram. Perhaps an average of these two equations will provide a very general overall fit for all types of sediments and rocks combined (assuming same mineral makeup). The Nafe and Drake (1957) equation can be made to fit the data for values of $n$ from 4 to 9 , but of course no single value of $n$ characterizes all the data points.

6. The acoustic anisotropy is typically faster parallel to the bedding. Anisotropy is about 0 to $3 \%$ in the Pleistocene-Oligocene chalks and typically $2 \%$ to $15 \%$ in the Eocene and older chalks, limestone, and volcaniclastics. The basalts do not have an anisotropy within the precision of the velocimeter. The anisotropy, in general, is probably related to the preferred orientation of elongated grains (horizontal), which provides a faster path in the direction of elongation. The anisotropy contributions may also be from alternating soft and hard layers, alignment of minerals which have an acoustic anisotropy, and a larger number of horizontal cracks or foliation.
7. The scatter diagrams of velocity versus its corresponding impedance, for a given mineral makeup, is an approximately linear empirical relationship.

8. Equation 11 should allow in situ hydrostatic pressure and temperature velocities to be calculated from laboratory temperature and pressure velocity measurements. This does not include the rigidity caused by overburden pressure, or the porosity rebound caused by the release of the overburden pressure (as these corrections should be made prior to using Equation 11).

9. Comparison of the unadjusted laboratory interval velocities to the sonobuoy data indicates pressuretemperature corrections as much as $15 \%$ should be applied to the laboratory interval velocities (this will be lesser and greater for individual samples). With an estimated adjustment applied to the laboratory interval velocities (not including rigidity due to overburden pressure), there is a better agreement with the sonobuoy data at Sites 316 and 317 , with only minor discrepancies. However, at Site 315 the interval velocities of the sonobuoy data are slightly low relative to in situ velocities estimated from the adjusted laboratory data. Using the adjusted laboratory interval velocities at Sites 315 and 317 the basalt layers do not precisely correlate to the last reflector, and approximately an $8 \%$ increase to the adjusted interval velocity is needed to make the basalt correlate with the last reflector. This $8 \%$ discrepancy is probably in part related to the rigidity caused by overburden pressure on semilithified samples. The rigidity will be much less than $8 \%$ for very soft and very hard samples, and probably much greater than $8 \%$ for semilithified samples or uncemented samples with low porosity $(30 \%)$.

10. Future research should test porosity and velocity rebound (upon release of overburden pressure) characteristics of different types of sediments and rocks with different degrees of cementation so that proper correc- 
tions can be applied to 1 atmospheric pressure velocity measurements. The velocity measurements should allow some evaluation of the rigidity (after porosity effects are subtracted) caused by the overburden pressure on the grain to grain structure of semilithified sediment and rock where the relative rigidity effects should be the greatest. The hard rocks and high porosity soft sediments should have smaller (relative) overburden pressure rigidity-velocity effects.

11. Additional temperature variation studies should also be made of rock and minerals.

\section{REFERENCES}

Archie, G.E., 1942. The electrical resistivity log as an aid in determining some reservoir characteristics: AIME Trans., v. 146 , p. 54 .

Birch, F., 1960. The velocity of compressional waves in rocks to 10 kilobars, Part 1: J. Geophys. Res., v. 65, p. 1083. 1961. The velocity of compressional waves in rocks to 10 kilobars, Part 2: J. Geophys. Res., v. 66, p. 2199.

Boyce, R.E.. 1968. Electrical resistivity of modern marine sediments from the Bering Sea: J. Geophys. Res., v. 73, p. 4759.

Boyce, R.E., 1973a. Appendix I. Physical propertiesmethods. In Edgar, N.T., Saunders, J.B., et al., Initial Reports of the Deep Sea Drilling Project, Volume 15: Washington (U.S. Government Printing Office), p. 1115. 1973b. Summary of physical properties. In Edgar, N.T., Saunders, J.B., et al., Initial Reports of the Deep Sea Drilling Project, Volume 15: Washington (U.S. Government Printing Office), p. 1067.

Brace, W.F., 1965. Relation of elastic properties of rocks to fabric: J. Geophys. Res., v. 70, p. 5657.

Bullard, E.C., Maxwell, A.E., and Revelle, R., 1956. Advances in Geophysics: New York (Academic Press), v. 3, p. 153-181.

Bullen, K.E., 1947. Introduction to the theory of seismology: London (Cambridge University Press).

Christensen, N.I., 1965. Compressional wave velocities in metamorphic rocks at pressures to 10 kilobars: J. Geophys. Res., v. 70, p. 6147.

Evans, H.B., 1965. GRAPE-A device for continuous determination of material density and porosity: SPWIA Logging Symp., 6th Annual, Dallas, Texas, Trans., v. 2, p. B1.

Greene, E.S., 1962. Principles of physics: Englewood Cliffs, New Jersey (Prentice Hall Inc.).

Hamilton, E.L., 1959. Thickness and consolidation of deep sea sediments: Geol. Soc. Am. Bull., v. 70, p. 1399.

1964. Consolidation characteristics and related properties of sediments from experimental Mohole (Guadalupe site): Geophys. Res., v. 69, p. 4257.

1965. Sound speed and related physical properties of sediments from experimental Mohole (Guadalupe site): Geophysics, v. 30, p. 257.
1970. Reflection coefficients and bottom losses at normal incidence computed from Pacific sediment properties: Geophysics, v. 35 , p. 995 .

, 1971a. Elastic properties of marine sediments: J. Geophys. Res., v. 76, p. 579.

1971b. Prediction of in situ acoustic and elastic properties of marine sediments: J. Geophys., v. 36, p. 266.

Hughes, D.S. and Cross, J.H., 1951. Elastic wave velocity in rocks at high pressures and temperatures: Geophysics, v. 16 , p. 577 .

Laughton, A.S., 1957. Sound propagation in compacted ocean sediments: Geophysics, v. 22, p. 233.

Nafe, J.E. and Drake, C.L., 1957. Variation with depth in shallow and deep water marine sediments of porosity density and the velocities of compressional and shear waves: Geophysics, v. 22, p. 523.

, 1963. Physical properties of marine sediments. In Hill, M.N. (Ed.), The Sea: New York (Interscience), v. 3, p. 749.

Parasonis, D.S., 1960. The compaction of sediments and its bearing on some geophysical problems: Geophys. J., v. 3, p. 1 .

Press, F., 1966. Seismic velocities. In Clark, S.P., Jr. (Ed.), Handbook of physical constants: GSA Mem. 97, p. 195218.

Ratcliff, E.H., 1960. The thermal conductivities of ocean sediments: J. Geophys. Res., v. 65, p. 153.

Richards, A.F. and Hamilton, E.L., 1967. Investigations of deep sea sediment cores, III. consolidation. In Richards, A.F. (Ed.), Marine geotechnique: Urbana (University of Illinois Press), p. 93-117.

Schlanger, S.O. and Douglas, R.G., 1974. The pelagic oozechalk-limestone transition and its implications for marine stratigraphy. In Hsu, K.J. and Jenkyns, H.C. (Eds.), Pelagic Sediments on land and under the sea: Int. Assoc. Sedimentol., Spec. Publ. No. 1, p. 117-148.

Shumway, G., 1960. Sound speed and absorption studies of marine sediments by a resonance method, part 1: Geophysics, v. 25 , p. $451-467$.

Sutton, G.H., Berckheimer, H., and Nafe, J.E., 1957. Physical analysis of deep sea sediments: Geophysics, v. 22, p. 779 812.

Trabant, P.K., 1972. Consolidation characteristics and related geotechnical properties of sediments retrieved by the Glomar Challenger from the Gulf of Mexico: M.S. Thesis at Graduate College, Texas A\&M University, unpublished.

Winsauer, W.O., Shearin, H.M., Jr., Masson, P.H., and Williams, M., 1952. Resistivity of brine-saturated sands in relation to pore geometry: Am. Assoc. Petrol. Geol. Bull., v. 36 , p. $253-277$.

Wood, A.B., 1941. A textbook of sound: New York (Mac Millan).

Worzel, J.L. and Harrison, J.C., 1963. Gravity at sea. In Hill, M.N. (Ed.), The sea: New York (Interscience), v. 3, p. 134.

Wyllie, M.R.J., Gregory, H.R., and Gardner, L.W., 1956. Elastic waves in heterogeneous and porous media: Geophysics, v. 21 , p. 41 . 